\author{
Universidade de Brasília \\ Faculdade de Ciências da Saúde \\ Programa de Pós-Graduação em Enfermagem
}

JACKELINE NERES BELLUCCI

ESTUDO COMPARATIVO DA EFICÁCIA DE AÇÕES DE ENSINO A DISTÂNCIA DE TÓPICOS DE NANOCIÊNCIA E NANOTECNOLOGIA, APLICADAS ÀS CIÊNCIAS DA SAÚDE E ENFERMAGEM

BRASÍLIA 


\author{
UNIVERSIDADE DE BRASÍLIA \\ FACULDADE DE CIÊNCIAS DA SAÚDE \\ PROGRAMA DE PÓS-GRADUAÇÃO EM ENFERMAGEM
}

JACKELINE NERES BELLUCCI

\title{
ESTUDO COMPARATIVO DA EFICÁCIA DE AÇÕES DE ENSINO A DISTÂNCIA DE TÓPICOS DE NANOCIÊNCIA E NANOTECNOLOGIA APLICADAS, ÀS CIÊNCIAS DA SAÚDE E ENFERMAGEM
}

\begin{abstract}
Dissertação apresentada como requisito parcial para a obtenção do título de Mestre em Enfermagem, pelo Programa de Pós-Graduação em Enfermagem, da Universidade de Brasília.

Área de Concentração: Cuidado, Gestão e Tecnologia em Saúde e Enfermagem.

Linha de Pesquisa: Gestão dos Sistemas e de Serviços em Saúde e Enfermagem.
\end{abstract}

Orientador: Professor Doutor Gilberto Lacerda Santos

BRASÍLIA 
Ficha catalográfica elaborada automaticamente, com os dados fornecidos pelo(a) autor(a)

Estudo Comparativo da Eficácia de Ações de Ensino a Distância de Tópicos de Nanociência e Nanotecnologia, Aplicadas às Ciências da Saúde e Enfermagem / Jackeline Neres Bellucci; orientador Gilberto Lacerda Santos. -- Brasília, 2016. $124 \mathrm{p}$.

Dissertação (Mestrado - Mestrado em Enfermagem) -Universidade de Brasilia, 2016.

1. Educação a Distância. 2. Eficácia de Ações de Ensino. 3. Ensino da Nanociência. 4. Ensino da Nanotecnologia. 5. Aplicações em Ciências da Saúde e Enfermagem. I. Santos, Gilberto Lacerda, orient. II. Título. 


\title{
ESTUDO COMPARATIVO DA EFICÁCIA DE AÇÕES DE ENSINO A DISTÂNCIA DE TÓPICOS DE NANOCIÊNCIA E NANOTECNOLOGIA, APLICADAS ÀS CIÊNCIAS DA SAÚDE E ENFERMAGEM
}

\begin{abstract}
Dissertação apresentada como requisito parcial para a obtenção do título de Mestre em Enfermagem, pelo Programa de PósGraduação em Enfermagem, da Universidade de Brasília.
\end{abstract}

Aprovado em 11/11/2016

BANCA EXAMINADORA

Professor Doutor Gilberto Lacerda Santos - Presidente da Banca Universidade de Brasília

Professor Doutor Lucio França Teles - Membro Efetivo, Externo ao Programa Universidade de Brasília

Professora Doutora Maria Cristina Soares Rodrigues - Membro Efetivo Universidade de Brasília 
Dedico este trabalho ao meu esposo Felipe, aos meus pais Djair e Rosimeire, ao meu irmão Douglas e aos meus avós João, Jacira e Ilda, que sempre foram meus pilares de sustentação, amor e moral. 


\section{AGRADECIMENTOS}

Meus mais sinceros agradecimentos:

- A Deus, pela dádiva da saúde e amparo proporcionados a mim e a todas as pessoas envolvidas na realização deste trabalho.

- Aos meus orientadores, Prof. Emérito Dr. Elioenai Dornelles Alves (in memoriam), do $2^{\circ}$ semestre/2014 ao $1^{\circ}$ semestre/2015, e Prof. Dr. Gilberto Lacerda Santos, do $2^{\circ}$ semestre/2015 até a defesa, pela forma extremamente profissional e amiga que conduziram os trabalhos, pela credibilidade, confiança e apoio incondicional que me proporcionaram tranquilidade nos bons e menos bons momentos, além das frutíferas discussões científicas em torno dos resultados.

- Aos integrantes e amigos do Programa de Pós-Graduação em Enfermagem da UnB. O apoio de todos, não só profissionalmente como também no âmbito da amizade, somou de forma significativa para a conclusão deste trabalho.

- Ao grupo de orientandos do meu orientador, por toda a ajuda, confiança e apoio em mim depositados. Este grupo me recebeu de braços abertos no final do $2^{\circ}$ semestre/2015.

- Aos professores: Dr. Lucio França Teles, Dr. ${ }^{a}$ Maria Cristina Soares Rodrigues e Dr. Pedro Sadi Monteiro, por participarem da minha "Defesa Pública de Mestrado" com significativas discussões e sugestões para o aprimoramento desta dissertação.

- Aos parentes e amigos dos estados do Mato Grosso do Sul, Rondônia e outras regiões, que sempre me apoiaram nessa jornada.

- À Coordenação de Aperfeiçoamento de Pessoal em Nível Superior (CAPES), pela concessão da bolsa do Programa de Demanda Social (DS), que foi decisiva para a obtenção da titulação de mestre.

- Ao CNPq, que colaborou financeiramente na participação da pesquisadora em Congressos e Missões de trabalho realizados na Universidade de Brasília, por meio do Projeto de Chamada Universal - MCTI/CNPq nº 14/2014. 
"A Enfermagem é uma arte; e para realizá-la como arte, requer uma devoção tão exclusiva, um preparo tão rigoroso, como a obra de qualquer pintor ou escultor;

Pois o que é o tratar da tela morta ou do frio mármore comparado ao tratar do corpo vivo, o templo do espírito de Deus. É uma das artes; poderse-ia dizer, a mais bela das artes." (Florence Nightingale) 
BELLUCCI, J. N. Estudo comparativo da eficácia de ações de ensino a distância de tópicos de Nanociência e Nanotecnologia, aplicadas às Ciências da Saúde e Enfermagem. 2016. 124f. Dissertação (Mestrado em Enfermagem) - Departamento de Enfermagem, Faculdade de Ciências da Saúde, Universidade de Brasília, Brasília, 2016.

\section{RESUMO}

Ações de ensino na modalidade parcial ou totalmente a distância têm crescido vigorosamente nos últimos anos, e as ferramentas associadas a essa modalidade de ensino têm sido desenvolvidas, possibilitando a abordagem de temas mais complexos, tais como Nanociência e Nanotecnologia (N\&N), Engenharias e Tópicos específicos de Saúde. Contudo, estudos que analisam ações de ensino na modalidade de educação a distância na temática de "Nanociência e Nanotecnologia Aplicadas às Ciências da Saúde e Enfermagem" e propõem comparações entre elas, ainda demandam inúmeras reflexões. O objetivo deste trabalho foi propor três ações de ensino baseadas em diferentes estratégias didáticas, na temática do trabalho na modalidade totalmente a distância, e identificar a mais eficaz entre elas para a difusão e promoção do tema proposto. Foram desenvolvidas, por meio de abordagens qualitativas e quantitativas, três ações de ensino na modalidade totalmente $\mathrm{EaD}$, fundamentadas com base na utilização de conhecimento na forma de conteúdos escritos (Turma A), recursos multimídias e vídeos (Turma B) e aulas expositivas (Turma C). Dentre os principais resultados obtidos no trabalho, destacam-se: (i) a metodologia $\mathrm{EaD}$ se mostrou eficiente no ensino da N\&N; (ii) o parâmetro "Índice de Sucesso ou Aprovados" foi melhor avaliado para Turma A (39,6\%), enquanto a Turma C exibiu o menor valor (12,5\%) e, consequentemente, a Turma A apresentou o menor valor de "Insucesso ou Não Aprovados", e para o índice de “Evasão" a Turma C obteve o maior valor (29,7\%); e (iii) o parâmetro "Média da Avaliação de Retenção do Conhecimento" por ação de ensino exibiu valores percentuais altos, porém decrescentes, sendo iguais a $88 \%$ para a Turma A, $85 \%$ para a Turma B e $76 \%$ para a Turma C. Os resultados apontam para a possibilidade de utilização de ações de ensino na modalidade totalmente a distância, para a transmissão e difusão do conhecimento associados à Nanociência e Nanotecnologia Aplicadas às Ciências da Saúde e Enfermagem. A temática atraiu o interesse de cursistas de diversas áreas do conhecimento, sendo que a estratégia de ensino associada à utilização de conteúdos escritos (Turma A) se mostrou mais eficaz e exibiu, de maneira geral, melhor avaliação e maior aproveitamento por parte dos cursistas.

Palavras-chave: Educação a Distância; Eficácia de Ações de Ensino; Ensino da Nanociência; Ensino da Nanotecnologia; Aplicações em Ciências da Saúde e Enfermagem. 
BELLUCCI, J. N. Comparative effectiveness of distance educational methods for nanoscience and nanotechnology topics, applied to the study of health sciences and nursing. 2016. 124p. Dissertation (Master Degree in Nursing) - Department of Nursing, Faculty of Health Sciences, University of Brasília, Brasília, 2016.

\begin{abstract}
Both part-time and distance education have become increasingly more widespread in the last few years, and consequently the tools related to these kinds of education have also developed, enabling an approach to more complex issues such as Nanoscience and Nanotechnology $(\mathrm{N} \& N)$, Engineering and Health related topics. However, studies and comparisons related to distance education in the field of "Nanoscience and Nanotechnology Applied to Health Sciences and Nursing" still require reflection. The aim of this study is to propose three teaching methods based on different teaching strategies for distance education and to identify the most effective of them for the dissemination and promotion of the theme. By means of the use of qualitative and quantitative approaches, three teaching methods have been developed for distance learning based on the use of knowledge in the written form (Class A), multimedia features and videos (Class B) and lectures (Class C). The main results of the work show: (i) the distance education methodology was efficient in the teaching of $\mathrm{N} \& \mathrm{~N}$; (ii) the parameter "Success Index or Approved" was more highly rated for Class A (39.6\%), while Class C showed the lowest value (12.5\%) and, consequently, Class A showed the lowest value "Failure or not Approved", and the index "Evasion" Class C had the highest value (29.7\%); and (iii) the parameter "Average Knowledge Retention Assessment" showed high percentages, but decreasing to $88 \%$ for Class A, $85 \%$ for the Class B and $76 \%$ for Class C. The results appear to indicate the possibility of using educational methods for distance learning for the transmission and dissemination of knowledge related to Nanoscience and Nanotechnology applied to Health Sciences and Nursing. The theme attracted the interest of course participants possessing different areas of knowledge and the teaching strategy associated with the use of the written form (Class A) was more effective, exhibiting better evaluation and a higher rate of use by the course participants in general.
\end{abstract}

Keywords: Distance Education; Education Action Effectiveness; Education of Nanoscience; Nanotechnology Education; Applications in Health Sciences and Nursing. 
BELLUCCI, J. N. Efectividad comparativa de las acciones de educación a distancia en temas relacionados a nanociencia y nanotecnología, aplicada a ciencias de la salud $\mathbf{y}$ enfermería. 2016. 124f. Disertación (Master en Enfermería) - Departamento de Enfermería, Facultad de Ciencias da la Salud, Universidad de Brasília, Brasília, 2016.

\section{RESUMEN}

Acciones de enseñanza de manera parcial o totalmente a distancia han crecido rápidamente en los últimos años y el desarrollo de herramientas asociadas a este tipo de educación crecen de manera gradual, lo que permite el enfoque de cuestiones más complejas como la nanociencia y la nanotecnología $(\mathrm{N}+\mathrm{N})$, la ingeniería y temas específicos como es el caso de la Salud. Sin embargo, los estudios dedicados a las acciones educativas en la modalidad de educación a distancia sobre temas relacionados a "la nanociencia y la nanotecnología aplicada a la Ciencia de la Salud y Enfermería" y propone comparaciones entre ellos aún requieren muchas reflexiones. El objetivo de este estudio fue proponer tres acciones de enseñanza mediante diferentes estrategias didácticas, basada en la modalidad de trabajo totalmente a distancia e identificar la más eficaz entre ellos para la difusión y promoción del tema propuesto. Fueron desarrollados, mediante métodos cualitativos y cuantitativos, tres acciones de enseñanza en la modalidad de educación totalmente a distancia, basadas en el uso del conocimiento en la forma de contenido escrito (Clase A), características y videos (Clase B) y conferencias multimedia (Clase C). Los principales resultados obtenidos en este trabajo son: (i) la metodología de educación a distancia fue eficiente en la enseñanza $\mathrm{N}+\mathrm{N}$; y (ii) el parámetro "Índice de éxito o Aprobado" obtuvo mejor puntuación para la Clase A (39,6\%), mientras que la Clase C presentó el valor más bajo (12,5\%) y, como consecuencia, la Clase A presentó el valor más bajo del parámetro "Sin éxito o no aprobados". Con respecto al índice de "evasión", la Clase C obtuvo el valor más elevado (29,7\%). Los resultados permiten considerar la posibilidad del uso de las acciones educativas en la modalidad completamente a distancia para la transmisión y difusión de los conocimientos relacionados a nanociencia y nanotecnología aplicada a las ciencias de la salud y enfermería. El tema atrajo interés de alumnos de distintas áreas del conocimiento, además la estrategia docente asociado al uso de contenido escrito (Clase A) fue la más eficaz y presento, en general, mejor evaluación y mejor rendimiento de los participantes en el curso.

Palabras clave: Educación a Distancia; Educación y Acción eficaz; Educación de la Nanociencia; Educación de la Nanotecnología; Aplicaciones en Ciencias de la Salud y Enfermería. 


\section{LISTA DE FIGURAS}

Figura 1. Diagrama simplificado das principais ideias motivadoras do trabalho, associadas ao estudo das ações de ensino a distância sobre a interface entre as áreas de Ciências da Saúde, Enfermagem e Nanociência e Nanotecnologia. Fonte: Próprio autor

Figura 2. Cronologia dos principais marcos e destaques históricos conceituais e instrumentais da Nanociência e Nanotecnologia, de 1959 até os anos atuais. Fonte: Adaptado de Instituto Inovação (2005).

Figura 3. Aplicações relacionadas com a Nanociência e Nanotecnologia em diversas áreas do conhecimento, como Medicina, Química, Física, Engenharia, Informática, Biologia e em muitas outras áreas (PUC-RJ, 2011).

Figura 4. Trabalho explicativo sobre ordem de grandeza. Uma visão geral do que é a escala manométrica e a sua comparação com as outras escalas (metro, milímetro e micrometro) (SILVA et al., 2009).

Figura 5. Esquema ilustrativo: (a) corte transversal de um lipossoma (PIMENTEL et al., 2007); (b) Nanopartículas de ouro recobertas pelo hormônio hCG (KATO et al., 2013); (c) Nanopartículas poliméricas em que o agente ativo está conjugado ou encapsulado em um polímero (DIMER et al., 2013); e (d) Nanopartículas recobertas com marcadores para diagnóstico e tratamento de enfermidades, em especial, oncologia (FALLEIROS et al., 2011).

Figura 6. Gráficos de produção científica: (a) Artigos publicados de 1991 a 2015 envolvendo nanomateriais e (b) Áreas de maior interesse de pesquisa. Pesquisa bibliográfica realizada com as palavras-chaves: nanomaterials OR nanoparticles (MARCONE, 2015).

Figura 7. Mostra o processo histórico de construção e evolução da Educação a Distância, estruturada em cinco tendências ou gerações. Fonte: Próprio autor.

Figura 8. Distribuição percentual dos alunos matriculados no ensino superior privado na modalidade presencial e EaD, entre os anos de 2004 e 2014. Fonte: Folha de São Paulo e Hoper Educação (2016).....

Figura 9. (a) Localização do menu Acesso à Plataforma Aprender. À direita da tela, o aluno acessa a plataforma informando o CPF e Senha. (b) Tela de abertura da 
ação de ensino aplicada aos alunos da Turma A, bem como mensagem de "Boas-vindas" e informações gerais sobre o curso: objetivo, breve contextualização da N\&N, entre outras.

Figura 10. Tela de abertura da ação de ensino aplicada aos alunos da Turma B, bem como informações gerais sobre o curso.

Figura 11. Tela de abertura da ação de ensino aplicada aos alunos da Turma $C$, bem como informações gerais sobre o curso.

Figura 12. Organograma simplificado das principais etapas executadas no trabalho. 66

Figura 13. Interface da Ambientação e Apresentação da Ação de Ensino aplicada à Turma A, acompanhada de recursos e atividades pedagógicas disponibilizados no ambiente Aprender UnB, a saber: (i) vídeo de "Boasvindas"; (ii) planejamento do curso; (iii) fórum de notícias; (iv) sala do cafezinho; (v) glossário; entre outros.

Figura 14. Interface do Módulo 1 da Ação de Ensino aplicada à Turma $A$, acompanhada de recursos e atividades pedagógicas disponibilizados, a saber: (i) guia do módulo; (ii) vídeo de introdução do módulo; (iii) fórum; (iv) leituras obrigatórias e complementares; (iv) atividade avaliativa; entre outros.

Figura 15. Interface do Módulo 2 da Ação de Ensino aplicada à Turma A. Acompanhada de recursos e atividades pedagógicas disponibilizados, a seguir: (i) guia do módulo; (ii) vídeo de introdução do módulo; (iii) fórum; (iv) leituras obrigatórias e complementares; (iv) atividade avaliativa; entre outros.

Figura 16. Interface do Módulo 3 da Ação de Ensino aplicada à Turma A, acompanhada de recursos e atividades pedagógicas disponibilizados, a saber: (i) guia do módulo; (ii) vídeo de introdução do módulo; (iii) leituras obrigatórias e complementares; (iv) atividade avaliativa; (v) wiki; entre outros.

Figura 17. Interface do Módulo 4 da Ação de Ensino aplicada à Turma A, acompanhada de recursos e atividades pedagógicas disponibilizados, a saber (i) guia do módulo; (ii) vídeo de introdução do módulo; (iii) fórum; (iv) leituras obrigatórias e complementares; (iv) atividade avaliativa; entre outros 
Figura 18. Interface do Módulo 5 da Ação de Ensino aplicada à Turma A, acompanhada de recursos e atividades pedagógicas disponibilizados, a saber: (i) guia do módulo; (ii) vídeo de introdução do módulo; (iii) fórum; (iv) leituras obrigatórias e complementares; (iv) atividade avaliativa; entre outros.

Figura 19. Interface do Módulo 6 da Ação de Ensino aplicada à Turma A, acompanhada de recursos e atividades pedagógicas disponibilizados, a saber: (i) guia do módulo; (ii) vídeo de introdução do módulo; (iii) fórum; (iv) leituras obrigatórias e complementares; (iv) atividade avaliativa; entre outros.

Figura 20. Interface do Módulo 7 da Ação de Ensino aplicada à Turma A, acompanhada de recursos e atividades pedagógicas disponibilizados, a saber: (i) guia do módulo; (ii) vídeo de introdução do módulo; (iii) atividade avaliativa final; entre outros.

Figura 21. Distribuição dos alunos inscritos no curso por procedência, nível de formação e área de atuação. Como esperado, as colunas vinculadas à graduação se destacam das demais.

Figura 22. (a) Índice percentual de sucesso ou aprovados (menções SS e MS) e (b) comparação entre os índices de sucesso ou aprovados, insucesso ou não aprovados (menções MM, MI e II) e evasão (sem realizar atividades) para as ações de ensino aplicadas às turmas $\mathrm{A}, \mathrm{B}$ e $\mathrm{C}$.

Figura 23. Estratificação por menções do processo de aprendizagem obtidas pelos alunos aprovados e não aprovados nas três ações de ensino: (a) aprovados com menções SS e MS e (b) não aprovados com menções MM, MI, II e SR.

Figura 24. Apresenta os valores percentuais apurados dos índices pela origem dos cursistas, para as três ações de ensino totalmente na modalidade $\mathrm{EaD}$ aplicadas para as turmas A, B e C, (a) Índice de Sucesso ou Aprovados, (b) Índice de Insucesso ou Não Aprovados e (c) Índice de Evasão.

Figura 25. Apresenta a média dos resultados obtidos acerca do conceito médio das turmas e conceito médio dos módulos, aplicados nas três ações de ensino sob a percepção dos cursistas: (a) tem-se o Conceito Médio das Turmas e (b) mostra o Conceito Médio por Módulo. 
Figura 26. Representação da média das notas dos cursistas na avaliação final das três ações de ensino aplicadas às turmas A, B e C: (a) tem-se a média da avaliação final das turmas; e (b) mostra o percentual das notas da avaliação final do curso.

Figura 27. (a) mostra a média percentual da avaliação de retenção do conhecimento em função da ação de ensino; e (b) exibe a evolução do parâmetro da avaliação de retenção do conhecimento em função do tempo, após o término dos três cursos, com intervalos de 20,60 e 100 dias. 


\section{LISTA DE TABELAS}

Tabela 1. Mostra a relação de alguns produtos disponíveis no mercado e fabricados no Brasil a partir de tecnologias desenvolvidas com base na nanotecnologia, bem como suas descrições e aplicações.

Tabela 2. Número de estudantes matriculados em cursos realizados na modalidade EaD classificados quanto à instituição de ensino, classificação curricular e número absoluto de aprendizes matriculados.

Tabela 3. Proporção entre o percentual de alunos matriculados em cursos de nível superior em instituições de ensino privada, entre 2004 e 2014, em função da modalidade de ensino escolhida: presencial e a distância.

Tabela 4. Lista do quantitativo absoluto e percentual de cursistas inscritos na ação de ensino por procedência, nível de formação e área de atuação.

Tabela 5. Lista de valores absolutos (frequência) e percentuais associados aos índices de sucesso, insucesso e evasão das ações de ensino na modalidade totalmente $\mathrm{EaD}$, aplicadas às turmas $\mathrm{A}, \mathrm{B} \mathrm{e} \mathrm{C}$.

Tabela 6. Lista de valores absolutos e percentuais associados aos índices de aprovados e não aprovados por meio de estratificação por menções "SS e MS" e "MM, MI, II e SR", respectivamente, nas ações de ensino aplicadas às turmas A, B e C. 82

Tabela 7. Lista os valores absolutos associados aos índices de sucesso, insucesso e evasão por procedência, nível de formação e área de atuação, das três ações de ensino totalmente na modalidade EaD.

Tabela 8. Lista o número de respostas e o conceito médio sobre cada módulo executado no curso, aplicadas nas ações de ensino, turmas A, B e C, e o conceito médio geral do curso.

Tabela 9. Lista os valores percentuais dos parâmetros analisados nas três ações de ensino aplicadas às turmas $\mathrm{A}, \mathrm{B}$ e $\mathrm{C}$ referentes à "Média da Avaliação Final do Curso" e "Avaliação Final do Curso" utilizando notas normalizadas de zero a dez (0-10). 
Tabela 10. Lista os valores absolutos e percentuais na Avaliação de Retenção do Conhecimento por ação de ensino, aplicadas às Turmas A, B e C........................ 91 


\section{LISTA DE SIGLAS}

ABED Associação Brasileira de Educação a Distância

ABNT Associação Brasileira de Normas Técnicas

ANVISA Agência Nacional de Vigilância Sanitária

BIREME Biblioteca Regional de Medicina

BVS Biblioteca Virtual de Saúde

C,T\&I Ciência, Tecnologia e Inovação

CAAE Certificado de Apresentação para Apreciação Ética

CAPES Coordenação de Aperfeiçoamento de Pessoal de Nível Superior

CEP Comitê de Ética em Pesquisa

CNPQ Conselho Nacional de Desenvolvimento Científico e Tecnológico

CNS Conselho Nacional de Saúde

CONEP Comissão Nacional de Ética em Pesquisa

DECS Descritores em Ciências da Saúde

EAD Educação a Distância

IBICT Instituto Brasileiro de Informação em Ciência e Tecnologia

IBN Iniciativa Brasileira em Nanotecnologia

LILACS Literatura Latino-Americana e do Caribe em Ciências da Saúde

MCTI Ministério da Ciência, Tecnologia e Inovação

MEDLINE Medical Literature Analysis and Retrieval System Online

MOODLE Modular Object-Oriented Dynamic Learning Environment

MS Ministério da Saúde

N\&N Nanociência e Nanotecnologia

OMS Organização Mundial da Saúde

PNN Programa Nacional de Nanotecnologia

PPGENF Programa de Pós-Graduação em Enfermagem

SCIELO Scientific Electronic Library Online

TCLE Termo de Consentimento Livre e Esclarecido

TIC Tecnologias da Informação e Comunicação 


\section{SUMÁRIO}

APRESENTAÇÃ

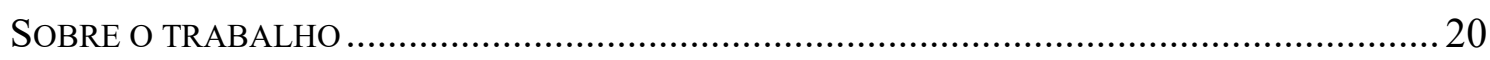

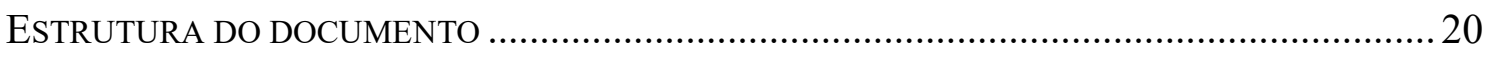

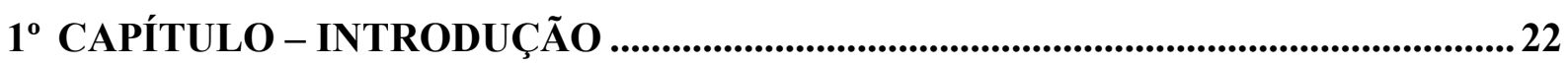

1.1. Apresentação da Problemática: Uso da Modalidade Ead para o Ensino da NANociênCia E Nanotecnologia, Aplicadas Às CiÊnCIAS DA

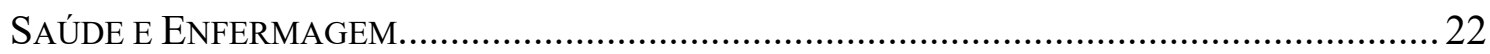

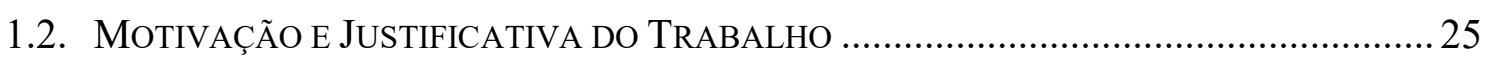

1.3. Problema Norteador da Pesquisa e Objetivos do Trabalho ........................ 26

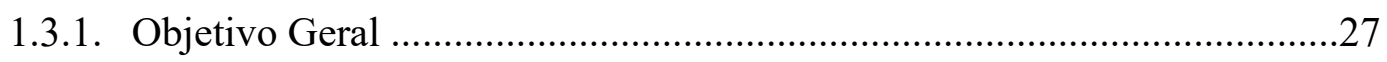

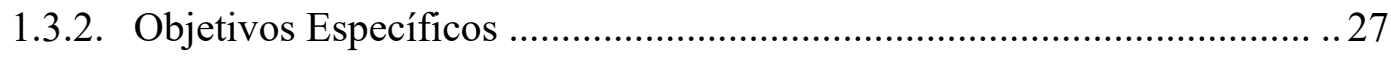

\section{$2^{\circ}$ CAPÍTULO - NANOCIÊNCIA E NANOTECNOLOGIA E SUA}

ABORDAGEM EM CURSOS DA SAÚDE .................................................................... 28

2.1. Aspectos Gerais da NANOCIÊNCIA E NANOTECNOLOGIA.................................... 28

2.2. Nanociência e Nanotecnologia Aplicadas Às CiênCias da Saúde E

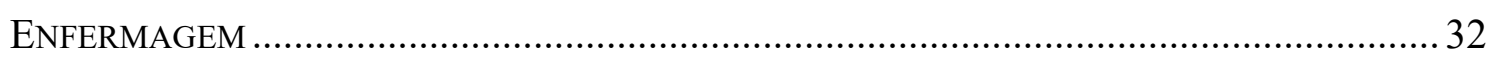

2.3. Potencial de Revolução de Nanociência e Nanotecnologia ......................... 36

2.4. EducaÇÃo a Distância no Ensino de NanociênCIA E NANOTECNOLOGIa E A IMPORTÂNCIA DA TEMÁTICA PARA ESTUdANTES E PROFISSIONAIS DA SAÚDE .............. 39

$3^{\circ}$ CAPÍTULO - EDUCAÇÃO A DISTÂNCIA ......................................................42

3.1. HistóRico, Possibilidades E MANiFESTAÇÕES da EduCAÇão A DistÂNCIA ........ 42

3.2. AÇõES DE ENSINO MEdiadas POR TECNOLOGIAS: EdUCAÇão A DistÂNCIA .......... 45

3.3. Ambiente Virtual de Aprendizagem (AVA): Plataforma Aprender............50

3.4. Dificuldades E OpORTUnidades do Ensino EAD DA NANOciÊnCIA E

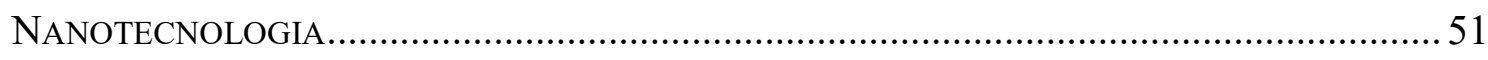

$4^{\circ}$ CAPÍTULO - ABORDAGEM METODOLÓGICA.....................................................54

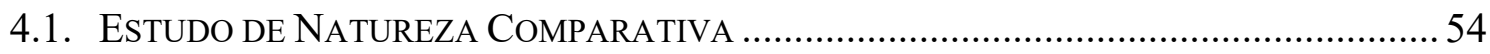

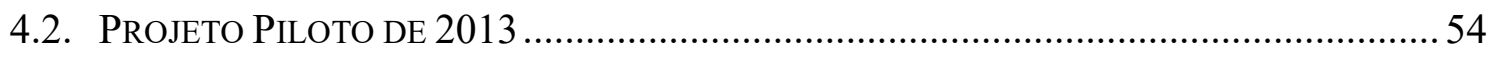

4.3. Principais ETAPAS DE DesenVolvimento do Trabalho........................................56

4.3.1. Etapa 1: Estudo Multidisciplinar E SEleÇÃo dos Módulos ...........................56

4.3.2. ETAPA 2: SEleÇão AMOSTRAL PARA AS TRÊS AÇÕES DE ENSINO .........................57

4.3.3. ETAPA 3: ElaboraÇ̃̃o E DESCRIÇÃo dA 1ª AÇÃO DE ENSINO - TURMA A ............ 58 
4.3.4. ETAPA 4: ELABORAÇÃO E DESCRIÇÃO DA 2a AÇÃO DE ENSINO - TURMA B.............61

4.3.5. ETAPA 5: ElABORAÇÃO E DESCRIÇÃO DA 2 $2^{\mathrm{a}}$ AÇÃO DE ENSINO - TURMA C..............63

4.3.6. ETAPA 6: VARIÁVEIS ANALISADAS NO ESTUdO COMPARATIVO ............................ 65

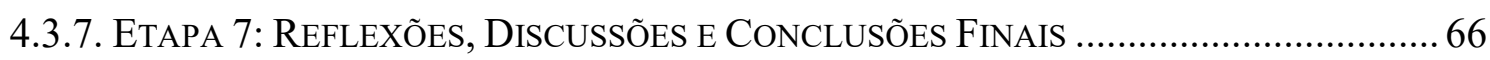

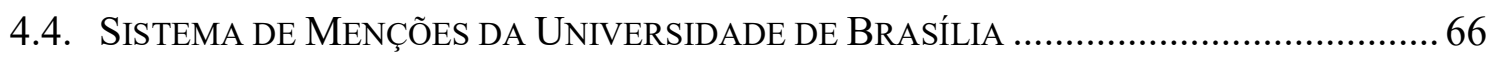

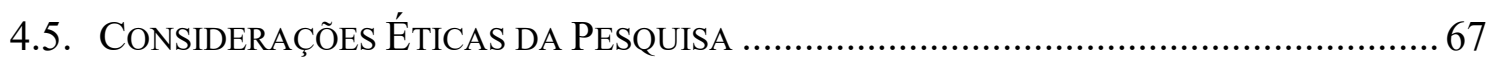

$5^{\circ}$ CAPÍTULO - ESTUDO COMPARATIVO ENTRE AS AÇÕES DE ENSINO ......... 69

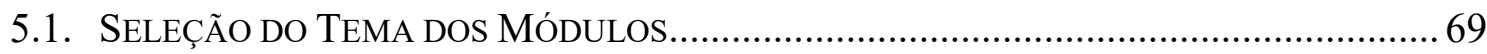

5.2. ANÁLISE do PÚBLICO-ALVO AtingIdo PELAS AÇÕES............................................ 77

5.3. AnÁlise dos ParÂmetros Índices de SuCESSO, InSUCESSO E EVASÃo ............... 78

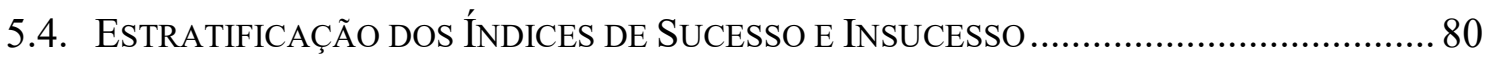

5.5. CORRELAÇÃO DOS ÍNDICES COM A ORIGEM DOS CURSISTAS ..................................... 82

5.6. AnÁlise dos ParÂmetros "PercepÇão Média sobre o Curso" E “PERCEPÇÃo SOBRE os Módulos” E “Avaliação Final do CurSO” ............................. 85

5.7. ANÁliSE do PARÂMETRO “RETENÇÃO do CONHECIMENTO” .................................... 89

5.8. RETOMADA DOS OBJETIVOS DO TRABALHO …........................................................ 92

$6^{\circ}$ CAPÍTULO - DISCUSSÕES E REFLEXÕES ACERCA DO ESTUDO

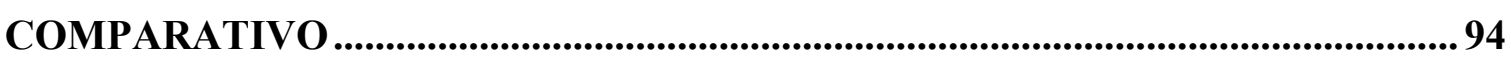

CONCLUSÕES E PERSPECTIVAS FUTURAS......................................................... 102

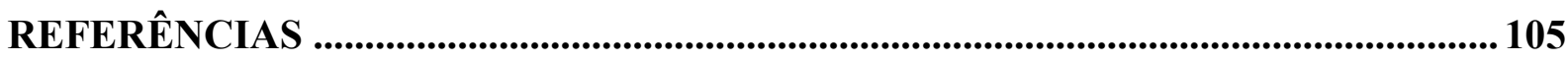

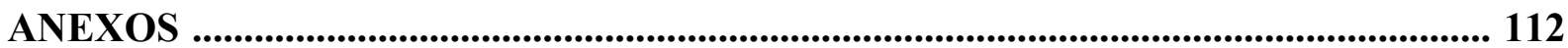




\section{APRESENTAÇÃO}

\section{Sobre o trabalho}

Este trabalho está associado à linha de pesquisa e interação científica de caráter multidisciplinar, que verte sobre ações educativas e de ensino no ambiente de Educação a Distância (EaD), na área de tecnologias convergentes, em específico, a Nanociência e Nanotecnologia, aplicadas às Ciências da Saúde e Enfermagem, iniciada aos princípios de 2013. Durante inúmeras discussões científicas realizadas no âmbito dos grupos Núcleo de Estudos em Educação, Promoção em Saúde e Projetos Inclusivos - NESPROM/UnB e Laboratório de Educação, EaD e Promoção da Saúde - LEPS/UnB, coordenados pelo Prof. Emérito Dr. Elioenai Dornelles Alves (in memoriam), e Ábaco - Grupo de Pesquisas Interdisciplinares sobre Tecnologias e Educação da UnB, coordenado pelo Prof. Dr. Gilberto Lacerda Santos, foi identificado um conjunto de lacunas nesta área, que motivaram os estudos no tema a partir de 2013, a seguir: (i) necessidade de mais pesquisas na área de educação a distância; (ii) escassez de iniciativas de formação continuada para os profissionais da saúde em áreas de alta tecnologia; (iii) escassez de informações sobre a utilização da modalidade EaD para ensinar Nanociência e Nanotecnologia para profissionais da saúde; e (iv) formação continuada e atualização.

\section{Estrutura do documento}

Esta dissertação é resultado de um projeto de pesquisa desenvolvido entre 2014 e 2016, no âmbito do Mestrado Acadêmico em Enfermagem oferecido pelo Programa de PósGraduação em Enfermagem (PPGEnf), da Universidade de Brasília (UnB). A Área de Concentração na qual o trabalho está inserido é Cuidado, Gestão e Tecnologia em Saúde e Enfermagem, na linha de pesquisa Gestão dos Sistemas e de Serviços em Saúde e Enfermagem. Nesse escopo, esta dissertação apresenta os seguintes capítulos:

$1^{\circ}$ Capítulo - Introdução: Apresenta a contextualização do tema, cenário de problematização, alinhamento entre os objetivos geral e específicos, o escopo do trabalho e o problema norteador. Assim, como mostra a importância do desenvolvimento do tema para a sociedade acadêmica da saúde, público em geral e as possíveis contribuições para a área; 
$2^{\circ}$ Capítulo - Nanociência e Nanotecnologia e sua Abordagem em Cursos da

Saúde: Apresenta o referencial teórico geral que servirá de base para o desenvolvimento dos tópicos do trabalho. Este item exibe tópicos como: Aspectos Gerais da Nanociência e Nanotecnologia, Nanociência e Nanotecnologia Aplicadas às Ciências da Saúde, entre outros;

$3^{\circ}$ Capítulo - Educação a Distância: Apresenta o referencial teórico específico, dedicado ao tema $\mathrm{EaD}$, que servirá de base para o desenvolvimento dos tópicos do trabalho. Este item exibe tópicos como: Histórico, possibilidades e manifestações da $\mathrm{EaD}$, ações de ensino mediadas por tecnologias, educação à distância, entre outros;

$4^{\circ}$ Capítulo - Abordagem Metodológica: Descreve as principais etapas metodológicas realizadas na execução do trabalho. A seguir, alguns tópicos abordados no estudo: Estudo de Natureza Comparativa, Projeto Piloto, Etapas e Desenvolvimento do Trabalho, entre outros;

$5^{\circ}$ Capítulo - Estudo Comparativo entre as Ações de Ensino: Apresenta o relato do desenvolvimento do estudo comparativo da eficácia das três ações de ensino e a indicação de qual das ações se mostrou mais eficaz;

$6^{\circ}$ Capítulo - Discussões e Reflexões Acerca do Estudo Comparativo: Apresenta os desdobramentos referentes à análise e à discussão dos pontos relevantes originados pela coleta de dados;

Conclusões e Perspectivas Futuras: Apresenta as conclusões obtidas relacionadas aos objetivos e questão norteadora propostas no trabalho baseadas nas evidências encontradas, bem como as perspectivas de trabalhos futuros; e

Referências: Consiste na relação das obras consultadas e citadas no trabalho. 


\section{$1^{\circ}$ CAPÍTULO - INTRODUÇÃO}

\subsection{Apresentação da Problemática: Uso da Modalidade EaD para o Ensino da Nanociência e Nanotecnologia, Aplicadas às Ciências da Saúde e Enfermagem}

Um processo de ensino e aprendizagem que se consolida a cada ano em diversas áreas da sociedade moderna, principalmente devido à popularização de meios de comunicação como a Internet, é a Educação a Distância (EaD) (NAIDU, 2016). Conceitualmente, educação a distância é o processo de ensino-aprendizagem, mediado por Tecnologias da Informação e Comunicação (TIC), no qual professores e alunos estão separados espacial e/ou temporalmente, mas podem estar conectados, interligados por tecnologias, principalmente as telemáticas, como a Internet (KENNEDY et al., 2015). O Instituto de Pesquisa Econômica Aplicada (Ipea), com o objetivo de divulgar as "possibilidades de futuro", apresenta à sociedade brasileira um conjunto de megatendências e de sementes de futuro nas áreas de população e sociedade, de geopolítica, de ciência e tecnologia, entre outras, e uma das cinco megatendências divulgadas é a mudança do perfil da sociedade. No Brasil, está ocorrendo um envelhecimento da população, aumento da classe média e uma busca maior por escolaridade, e a educação a distância surge como uma grande opção de alcance em massa e custos reduzidos (MARCIAL, 2015).

Entre as principais vantagens desta modalidade de educação, destaca-se flexibilização do tempo e o local da aprendizagem, eliminação do tempo de descolamento até locais tradicionais de ensino e aumento do quantitativo de alunos por turma. Na educação a distância, o processo de aprendizagem é construído principalmente pelo próprio aluno; ou seja, ele passa a ser o principal ator do conhecimento, e para isso ele conta com o professor como mediador desse processo, contribuindo para que a aprendizagem seja de fato eficaz. No entanto, grandes desafios ainda estão sendo superados - tais como o aperfeiçoamento das metodologias de ensino, avaliação do processo ensino-aprendizagem -, e, principalmente, a extensão maciça desta modalidade de educação a outras áreas do conhecimento como: das Ciências da Saúde, Enfermagem, Nanociência e Nanotecnologia e suas interfaces (ALVES et al., 2015; MCNEW et al., 2016).

A EaD é apontada como uma possibilidade viável na construção de mecanismos que favoreçam a aprendizagem e a formação profissional continuada, bem como apresenta, enquanto modalidade de educação, características relacionadas aos anseios da sociedade 
contemporânea, tais como interatividade, flexibilidade temporal e espacial, multissensorial, entre outras (LACERDA, 2014). Além disso, ações de ensino na modalidade EaD, por serem fortemente mediadas pelas TIC, estão sendo utilizadas exaustivamente no ambiente educacional, nos programas de qualificação e formação profissional, treinamento corporativo, uma vez que tais ações possibilitam o desenho de eventos educacionais focalizados em demandas específicas da sociedade, além de ampliar e democratizar o acesso às oportunidades de treinamento (RUSH, 2015).

Ainda que as ferramentas pedagógicas de ensino e avaliação EaD estejam em constante e dinâmico processo de desenvolvimento e aprimoramento, ao realizar uma análise da literatura científica no tema, há uma clara percepção da existência de lacunas e pontos de aprimoramento a serem explorados pela academia e setor produtivo. Tais lacunas e pontos de aprimoramento são ainda mais evidentes quando levada em consideração apenas a literatura científica nacional. Em particular, a análise da literatura específica revela escassez de estudos sistemáticos no tocante a importantes questões ligadas ao tema proposto; por exemplo: sobre a eficácia dos métodos e metodologias utilizadas em ações de ensino na modalidade EaD e como transmitir conhecimentos associados à Nanociência e Nanotecnologia via EaD (ALFONSO, 2011).

Nanociência e Nanotecnologia $(\mathrm{N} \& \mathrm{~N})$ são áreas emergentes e multidisciplinares destinadas ao estudo e aplicação de materiais com escala da ordem de nanômetros $\left(1 \times 10^{-9} \mathrm{~m}\right)$ (MULVANEY, 2015). Em específico, Nanociência estuda os fenômenos e sua influência sobre as propriedades dos materiais na nanoescala, enquanto a Nanotecnologia explora o conhecimento resultante da Nanociência para criar estruturas, dispositivos e sistemas que exibem novas propriedades e funções devido à escala dimensional utilizada (FEYNMAN, 1959). Os estudos em N\&N estão permitindo grandes avanços científicos e novas formas de compreender e criar materiais, dispositivos e sistemas. Do ponto de vista econômico, o Brasil já conta com quase 200 empresas de base nanotecnológica e esperam-se incrementos competitivos no setor empresarial com a utilização dessas tecnologias. Novas gerações de materiais estão em desenvolvimento e aprimoramento, tais como nanopartículas, filmes finos e nanocompósitos com aplicações nas áreas de eletrônica, telecomunicações, informática e biotecnologia. Aplicações desses materiais em pesquisa nas áreas das ciências da vida, particularmente em nível celular, define um novo palco e novos atores para a biotecnologia (SHRIVASTAVA; DASH, 2009). Os sistemas biológicos, tais como as células, são sistemas complexos e altamente funcionais e específicos. São compostos por macromoléculas que estão envolvidas em praticamente todos os processos celulares como, por exemplo, 
transferência de informações, metabolismo e transporte de substâncias. Assim, a Nanotecnologia oferece um novo conjunto de ferramentas nanométricas capazes de interagir com sistemas biológicos, abrindo um amplo espectro de possibilidades de atuação (BELLUCCI, 2008; CURTIS; WILKINSON, 2001).

Aplicações tecnológicas e inovadoras da N\&N nas ciências da vida estão concentradas, principalmente, no diagnóstico de enfermidades e células diferenciadas, terapia mais precisa, prevenção de doenças de alta complexidade, entendimento dos mecanismos biológicos e desenvolvimento de produtos cosméticos e cosmecêuticos. Nos últimos anos, o Brasil e o mundo têm avançado consistentemente no desenvolvimento de ações baseadas em Ciência, Tecnologia e Inovação (C,T\&I), com resultados concretos na produção científica de elevada qualidade tecnológica na geração de produtos oriundos da C,T\&I e na formação de recursos humanos $(\mathrm{RH})$ cada vez mais especializados em áreas consideradas estratégicas, particularmente em campos de N\&N (BRASIL, 2012/13). Como exemplo da temática, profissionais da saúde poderiam recomendar perfis moleculares específicos e regimes baseados em tratamentos moleculares em algumas práticas de oncologia, diagnóstico e tratamentos moleculares personalizados. Estudos científicos têm provado as vantagens da utilização de perfis moleculares para identificação de alvos tumorais específicos (BERKOWITZ; GODDARD, 2009). Assim, é importante que profissionais da saúde se familiarizem com conceitos tipo drug-delivery, ações de hipertermia, nanobiosenssores, entre outros, podendo assim apresentar aos seus pacientes novas opções de tratamento e proporcionar ações de saúde mais acertadas (FECYT, 2009). No entanto, análises e discussões sobre a utilização de ações de ensino totalmente a distância da temática "Nanociência e Nanotecnologia Aplicadas às Ciências da Saúde e Enfermagem” ainda são escassas na literatura científica.

O ensino formal da Nanociência e Nanotecnologia torna-se cada vez mais presente no ambiente acadêmico das universidades, principalmente públicas, em nível de atividade de extensão, cursos de graduação - como ofertados na UFRJ ${ }^{1}$ - e cursos de pós-graduação, como ofertados pela $\mathrm{UFRJ}^{2}$ e UFRGS ${ }^{3}$. Tais cursos, em geral, tratam dos principais conceitos da

\footnotetext{
${ }^{1}$ Curso de Graduação em Nanotecnologia (curso superior com duração de quatro anos) começou a ser oferecido a partir de 2010, inicialmente com 30 alunos, no Fundão, e 20 alunos, no campus de Xerém da UFRJ: http://www.nano.ufrj.br/graduacao.html.

${ }^{2}$ Curso de Mestrado e Doutorado em Engenharia de Nanotecnologia da Coppe/UFRJ. O Programa de Engenharia de Nanotecnologia (PENt) pretende contribuir para a criação de tecnologia própria no setor, gerando soluções para novos desafios e fomentando a inovação nesta área estratégica: http://www.pent.coppe.ufrj.br/.

${ }^{3}$ Curso de Pós-Graduação em Nanotecnologia Farmacêutica. O PPGNanofarma é uma associação de nove IES, a saber: UFG, UFRGS, UFSC, USP-Ribeirão Preto, UNESP-Araraquara, UFSM, UFOP, UFPE e UFRN: http://www.ufrgs.br/ppgnanofarma.
} 
N\&N sem direcionamento de área. Na modalidade parcial ou totalmente a distância, as experiências já realizadas de ações de ensino envolvendo o tema de Nanociência e Nanotecnologia ainda são insuficientes no Brasil e têm se concentrado principalmente em cursos de extensão e disciplinas de graduação e pós-graduação. Nesse sentido, devido às suas características intrínsecas, ações de ensino parcial ou totalmente a distância são promissoras para a abordagem do tema nanociência e nanotecnologia e sua interface com as Ciências da Saúde; mas ainda é eminente a necessidade de se identificar boas estratégias didáticas para o ensino da temática na modalidade EaD (ELLWANGER et al., 2012).

\subsection{Motivação e Justificativa do Trabalho}

A necessidade constante de atualização de habilidades, atitudes e conhecimentos dos profissionais de saúde requer reflexões sobre novas estratégias para a educação continuada na saúde, dada a rapidez e a abrangência do processo evolutivo do saber. No Brasil, ainda são insuficientes as experiências já realizadas de ações de ensino sobre a temática "Nanociência e Nanotecnologia aplicadas às Ciências da Saúde e Enfermagem”, que, por sua vez, apresenta grande potencial de ser abordada para complementar os currículos tradicionais das áreas de Ciências da Saúde, bem como ser ministrada utilizando ferramentas de EaD. Nesse contexto, pesquisas nesta modalidade de educação têm mostrado que a $\mathrm{EaD}$, além de diminuir os problemas de distância geográfica, pode também proporcionar formação de qualidade e pautada na prática social e no contexto do aprendiz (ELLWANGER et al., 2012).

As instituições de ensino e de pesquisa que formam profissionais de diversas áreas do conhecimento podem buscar, por intermédio da educação a distância, alternativas para ultrapassar as dimensões geográficas, possibilitando que cidadãos de diferentes regiões tenham acesso a boa formação, com a construção de uma educação aberta, democrática e de qualidade. Com isso, podem participar com segurança de um novo cenário educacional, no qual a $\mathrm{EaD}$ tem sido empregada e vista como promissora alternativa educacional para a sociedade brasileira (OTANI et al., 2016) As áreas de N\&N têm aportado avanços significativos em diversas áreas do conhecimento, em especial nas temáticas Ciências da Saúde e Enfermagem, consideradas a revolução tecnológica deste século. No entanto, ainda há uma grande distância entre tais temas e os alunos e profissionais da enfermagem e ciências da saúde. Dessa forma, faz-se necessário o desenvolvimento de rotinas e metodologias 
atrativas na modalidade totalmente $\mathrm{EaD}$, para o ensino e difusão da $\mathrm{N} \& \mathrm{~N}$ para as áreas das Ciências da Saúde e Enfermagem.

Diante desse panorama, o contexto motivador do trabalho foi estudar e analisar a utilização da modalidade de educação a distância para abordar a temática de interface entre as áreas de Nanociência e Nanotecnologia, Ciências da Saúde e Enfermagem e suas aplicações já consolidadas, bem como propor e testar diferentes ações de ensino, evidenciando a mais eficaz e identificando os elementos fundamentais para tal.

A Figura 1 mostra um diagrama simplificado sobre o contexto motivador do trabalho relacionado às ações de ensino na modalidade totalmente a distância, na temática de interface entre as áreas de Ciências da Saúde, Enfermagem e Nanociência e Nanotecnologia.

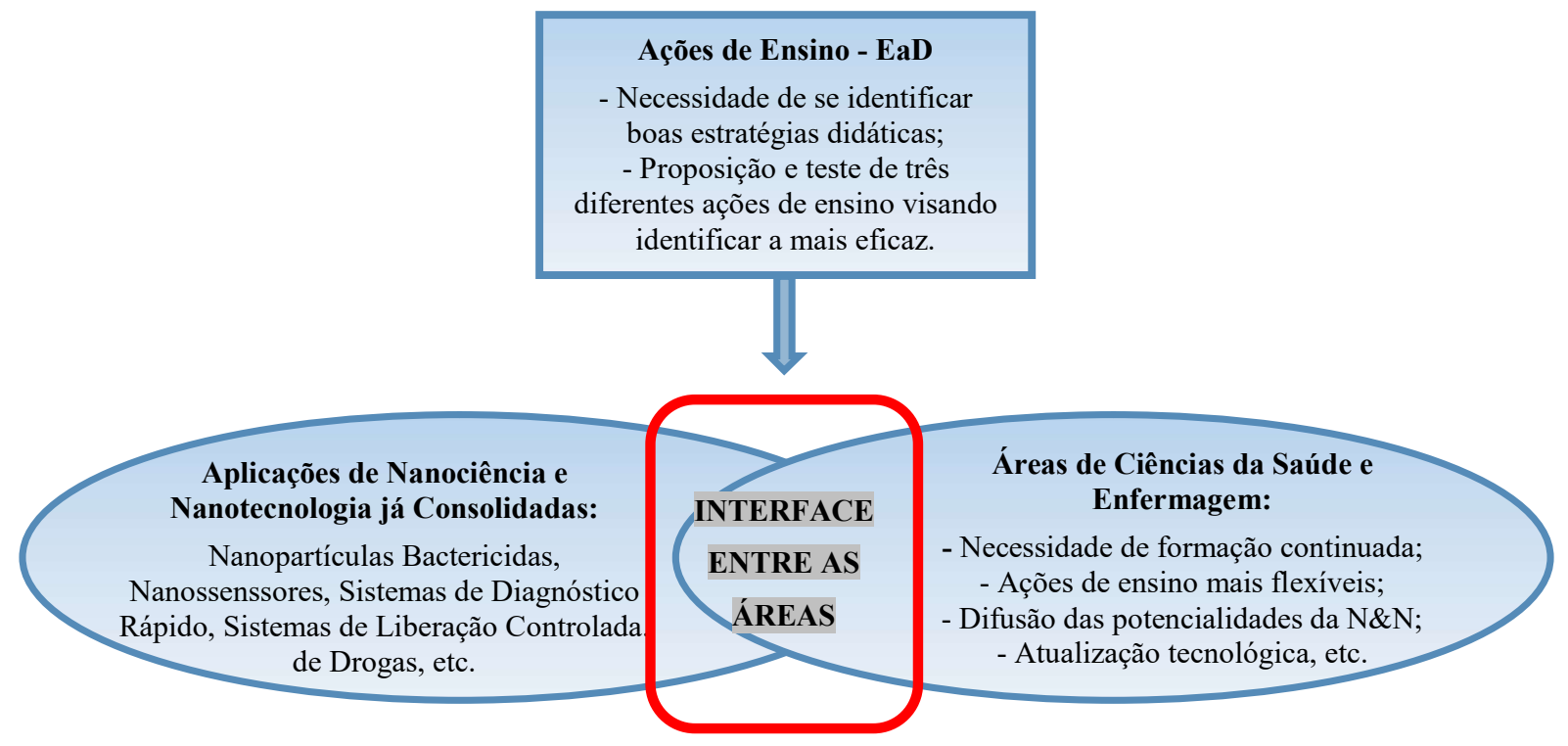

Figura 1. Diagrama simplificado das principais ideias motivadoras do trabalho, associadas ao estudo das ações de ensino a distância sobre a interface entre as áreas de Ciências da Saúde, Enfermagem e Nanociência e Nanotecnologia. Fonte: Próprio autor

\subsection{Problema Norteador da Pesquisa e Objetivos do Trabalho}

Diante do contexto exposto, torna-se eminente o alinhamento das ações de ensino de educação a distância na difusão e promoção da temática "Nanociência e Nanotecnologia Aplicadas às Ciências da Saúde e Enfermagem", na construção do conhecimento, sendo que o problema de pesquisa norteador deste estudo é: "Dentre as três ações de ensino da nanociência e nanotecnologia aplicadas às ciências da saúde e enfermagem na modalidade totalmente $\mathrm{EaD}$, elaboradas com base: (i) em conteúdos escritos (artigos e textos 
informativos); (ii) na utilização de vídeos das temáticas do curso; e (iii) na utilização de aulas expositivas sobre as temáticas do curso, qual delas e por que exibe o maior grau de eficácia?”.

\subsubsection{Objetivo Geral}

Este trabalho teve como principal objetivo propor três ações de ensino baseadas em diferentes estratégias didáticas, na temática "Nanociência e Nanotecnologia Aplicadas às Ciências da Saúde e Enfermagem", na modalidade totalmente a distância, e identificar a mais eficaz entre elas para a difusão e promoção do tema proposto.

\subsubsection{Objetivos Específicos}

(i) Conceber uma formação/curso na modalidade totalmente $\mathrm{EaD}$ na temática do trabalho que envolva três Ações de Ensino distintas, utilizando a "Plataforma Aprender" da Universidade de Brasília como Ambiente Virtual de Aprendizagem (AVA);

(ii) Efetuar um estudo comparativo da eficácia das três Ações de Ensino testadas, baseadas principalmente em conteúdos escritos, vídeos e aulas expositivas, utilizando parâmetros como "Índice de sucesso, insucesso e evasão do curso", "Avaliação geral do curso", "Retenção do conhecimento", entre outros; e

(iii) Dentre as três Ações de Ensino propostas, identificar a mais eficaz para o ensino da Nanociência e Nanotecnologia Aplicadas às Ciências da Saúde e Enfermagem, para estudantes e profissionais da saúde, bem como sugerir elementos decisivos para a eficácia da estratégia de ensino. 


\section{$2^{\circ}$ CAPÍTULO - NANOCIÊNCIA E NANOTECNOLOGIA E SUA ABORDAGEM EM CURSOS DA SAÚDE}

\subsection{Aspectos Gerais da Nanociência e Nanotecnologia}

No decorrer do encontro anual da American Physical Society(APS), em 1959, realizado no renomado California Institute of Technology (Calthec), o físico norte-americano Richard Philips Feymann ${ }^{4}$ proferiu uma conferência visionária, considerada atualmente como o marco inicial da Nanociência. Na conferência intitulada "There's plenty of room at the bottom" - (Tradução livre: Existe abundância de espaço lá em baixo), Feynman expôs um conjunto de novas ideias e reflexões sobre vários temas do conhecimento, dentre eles sobre a possibilidade de controle e manipulação da matéria em escala atômica. Em suma, o físico defendeu a hipótese de que não existia qualquer obstáculo teórico ou violação de leis físicas para o controle e a manipulação da matéria em nível atômico e, consequentemente, não havia impedimentos teóricos à construção de dispositivos compostos por átomos, moléculas ou estruturas na escala atômica. Dessa forma, para Feynman, tudo era apenas uma questão de tempo para que a sociedade desenvolvesse métodos para observar e atuar sobre a matéria na escala atômica (NOVO, 2013).

Como desdobramento dessa notória conferência, em 1974 a palavra "Nanotecnologia" foi utilizada pela primeira vez pelo professor Norio Taniguchi, da Tokyo University of Science, para designar o conjunto de estudos e aplicações referentes aos objetos e processos na escala de nanômetro. Em 1981, os cientistas Gerd Binnig e Heinrich Rohrer desenvolveram no Laboratório da IBM em Zurique (Suíça), o primeiro microscópio de varredura por tunelamento, equipamento conhecido pela sigla STM (Scanning Tunneling Microscope), com capacidade de criação, modificação e processamento de imagens eletrônicas da matéria na escala atômica. Desde então, a Nanociência e a Nanotecnologia compõem a agenda estratégica de C,T\&I dos principais países do mundo, e são apontadas como a nova revolução do conhecimento. Tais tópicos já exibem aplicações concretas em áreas como: aeroespacial, agronegócios, defesa, energia, meio ambiente, dispositivos e sensores, sistemas de diagnósticos, saúde e indústria têxtil (TANIGUCHI, 1974).

\footnotetext{
${ }^{4}$ Richard Feynman realizou contribuições significativas para inúmeras áreas do conhecimento e foi laureado em 1965 com o prêmio Nobel de Física, por suas contribuições na descrição de sistemas de partículas via diagramas (eletrodinâmica quântica).
} 
A Figura 2 mostra alguns dos marcos e destaques dentro da evolução das técnicas, conceitos, descobertas e tendências da Nanociência e Nanotecnologia, de 1959, com a palestra proferida pelo físico Richard Feymann, até os anos atuais.

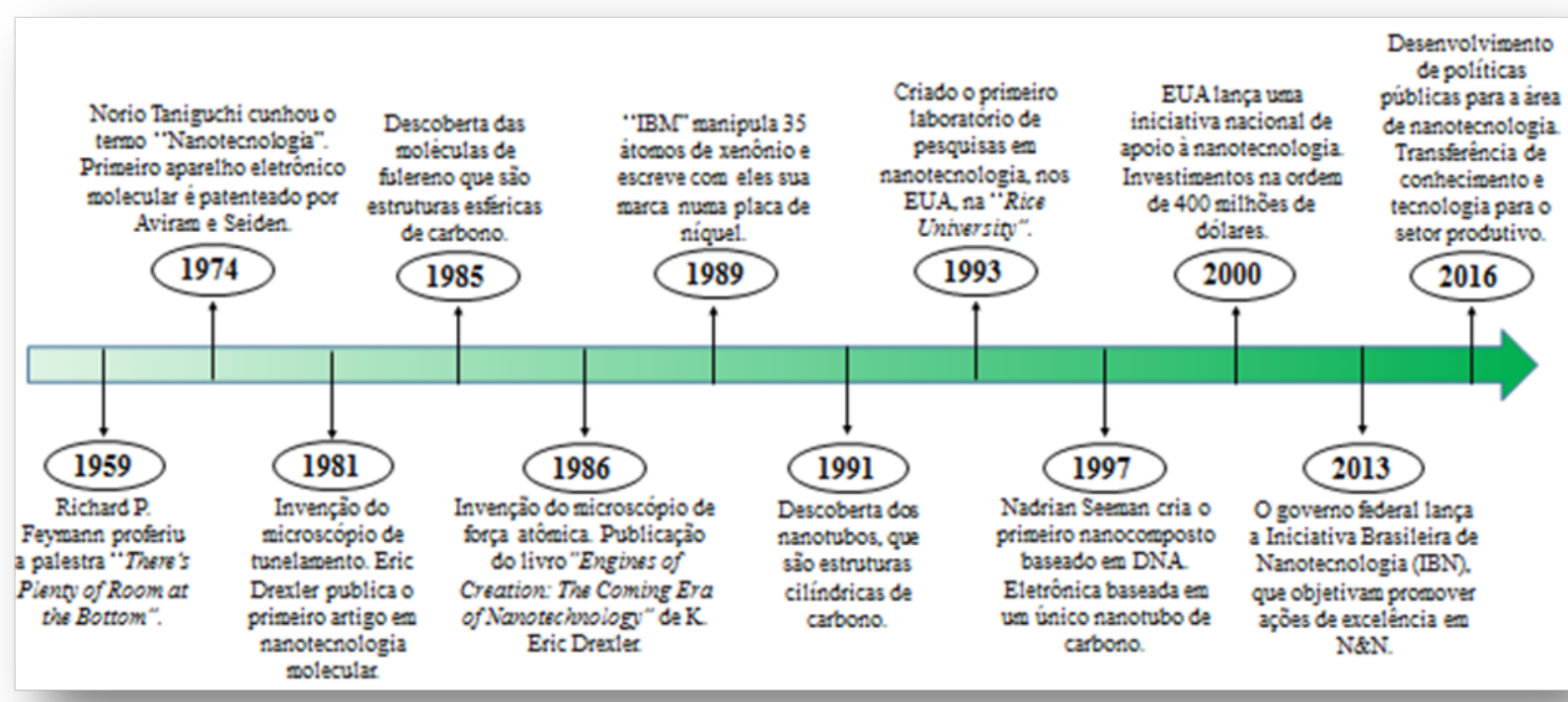

Figura 2. Cronologia dos principais marcos e destaques históricos conceituais e instrumentais da Nanociência e Nanotecnologia, de 1959 até os anos atuais. Fonte: Adaptado de Instituto Inovação (2005).

A Nanociência e Nanotecnologia são áreas emergentes e multidisciplinares destinadas ao estudo e aplicação de materiais com escala da ordem de nanômetros $\left(1 \times 10^{-9} \mathrm{~m}\right)$, surgiram nas últimas décadas, sendo, portanto, áreas relativamente recentes na história da ciência. $\mathrm{O}$ prefixo 'nano' refere-se a uma medida que significa um bilionésimo do metro, ou seja, é como dividir um metro em um bilhão de pedaços. Do ponto de vista científico, investigar as propriedades da matéria na escala nanométrica implica realizar uma análise multiconceitual da natureza da matéria, utilizando conceitos da Química, Engenharia, Física, Biologia e outros. Tal particularidade confere à N\&N caráter multidisciplinar (SPECIA et al., 2016). Nesse aspecto, a Figura 3 mostra as principais áreas de atuação relacionadas com a Nanociência e Nanotecnologia. 


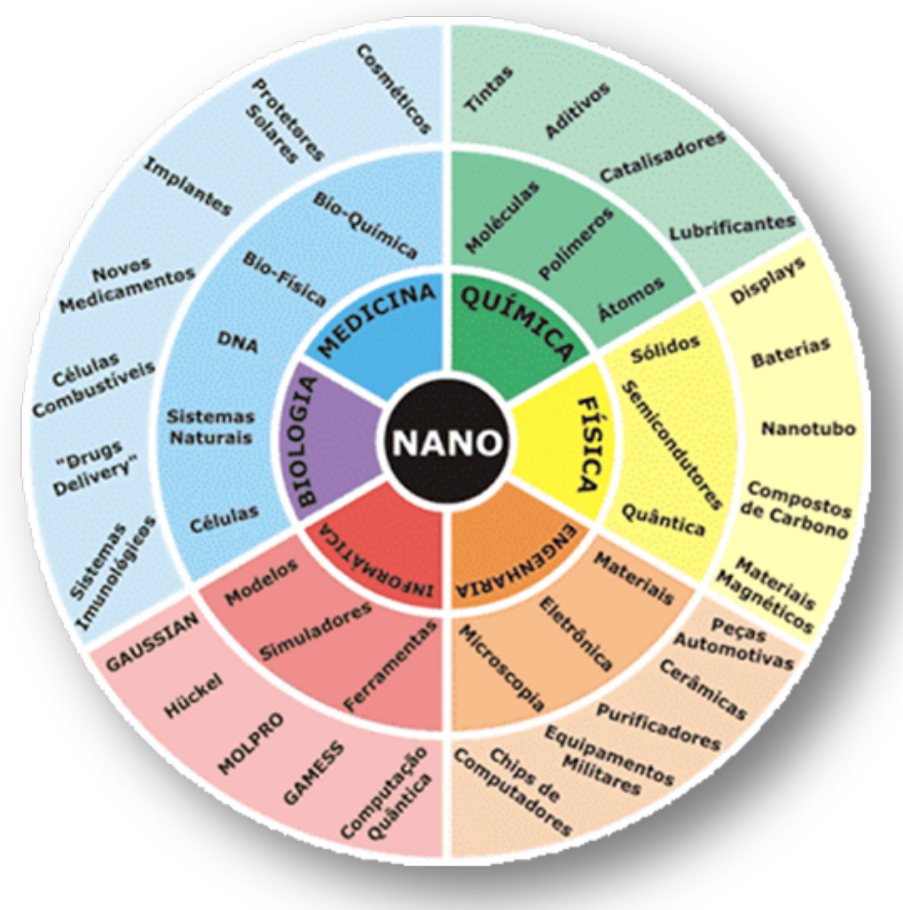

Figura 3. Aplicações relacionadas com a Nanociência e Nanotecnologia em diversas áreas do conhecimento, como Medicina, Química, Física, Engenharia, Informática, Biologia e em muitas outras áreas (PUC-RJ, 2011).

A Nanociência diz respeito aos estudos dos fenômenos e da manipulação dos materiais em escala atômica, molecular e macromolecular, em que as propriedades diferem dos de grande escala, ou seja, estuda os fenômenos e sua influência sobre as propriedades dos materiais na nanoescala. A Nanotecnologia, por sua vez, engloba a caracterização, produção e aplicação de estruturas, equipamentos e sistemas por meio do controle, forma e tamanho em escala manométrica; ou seja, explora o conhecimento resultante da nanociência para criar estruturas, dispositivos e sistemas que exibem novas propriedades e funções devido à escala dimensional utilizada (ADAMS; BARBANTE, 2013). A seguir, a Figura 4 ilustra a ordem de grandeza da escala manométrica. 


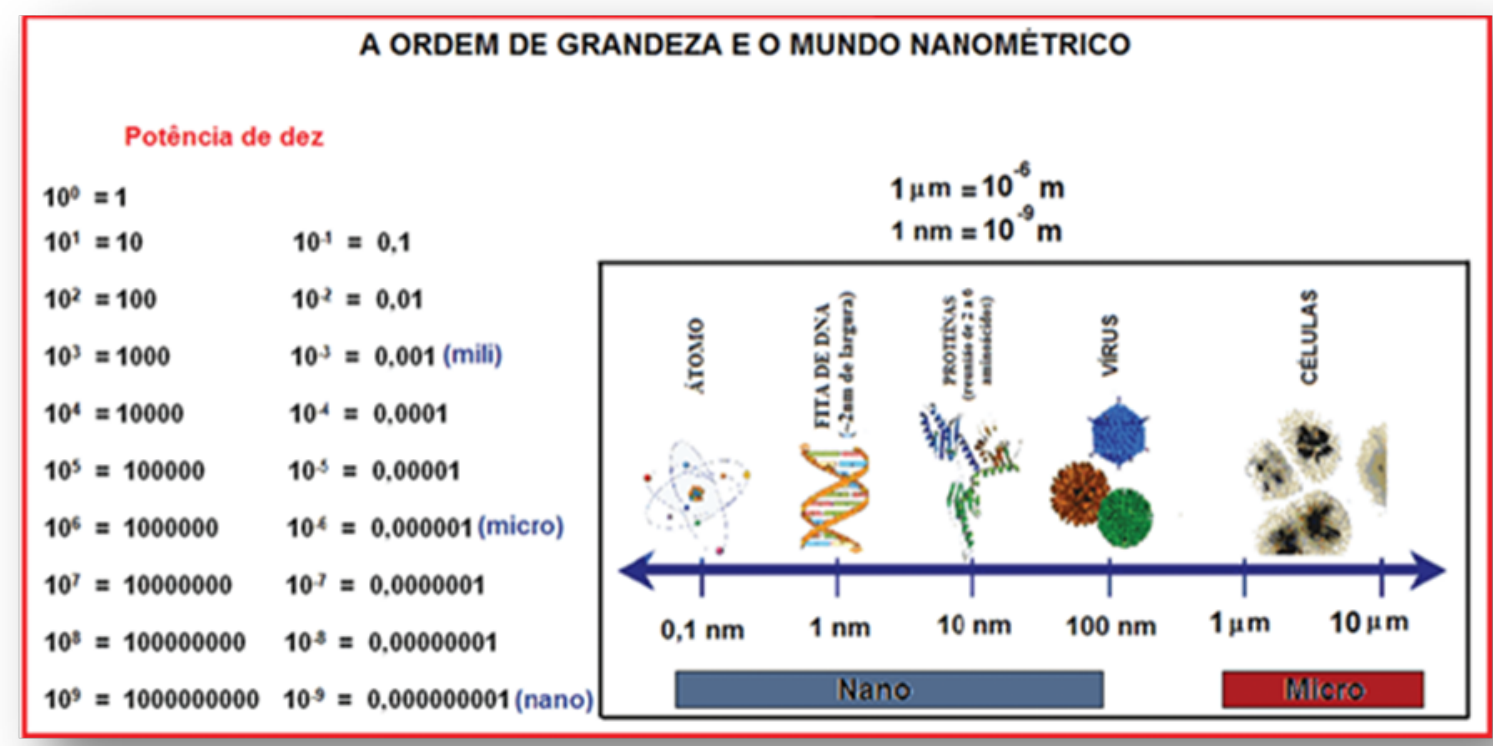

Figura 4. Trabalho explicativo sobre ordem de grandeza. Uma visão geral do que é a escala manométrica e a sua comparação com as outras escalas (metro, milímetro e micrometro) (SILVA et al., 2009).

Nos últimos anos, N\&N têm despertado interesse em diversos setores industriais, empresariais e acadêmicos. Devido aos benefícios e à diversificação que tais tecnologias podem proporcionar no desenvolvimento tecnológico e econômico em vários segmentos econômicos, tais áreas tornaram-se frequentemente citadas em diversos setores da sociedade. Tanto a Nanociência quanto a Nanotecnologia- a investigação da natureza e o desenvolvimento de aplicações na escala do nanômetro - tornaram-se possíveis devido ao desenvolvimento instrumental destinado à visualização e manipulação direta de átomos, moléculas e nanoestruturas. O grande diferencial desses materiais é potencializar ou adicionar propriedades e funcionalidades de diversas naturezas (físicas, químicas, eletrônica, entre outras), mesmo em concentrações extremamente reduzidas, e conferir características antes não apresentadas ou exploradas em um dado produto ou material. Esse alcance de propriedades se deve basicamente ao fato de tais estruturas possuírem dimensões nanométricas, que resultam em uma área superficial elevada, maior grau de dispersão e funcionalidades que são dependentes do tamanho da estrutura (ABDI, 2010a; ABDI, 2010b; ABDI, 2010c).

Nesse contexto, podemos observar que a nanotecnologia não configura uma promessa ou ficção futurista, ela já é uma realidade observada em vários produtos do cotidiano: 
protetores solares, calçados esportivos, telefones celulares, tecidos, cosméticos, automóveis e medicamentos, entre outros. Também é muito ativa em diferentes setores econômicos, por exemplo: no setor têxtil há tecidos resistentes à sujeira, antibacterianos, antichama e de alta resistência; no setor de cosméticos, protetores solares e produtos para maquiagem; no setor de fármacos, novas formas de administrar os remédios que reduzem os efeitos colaterais e potencializam as propriedades terapêuticas; no setor de saúde há sistemas portáteis capazes de realizar diagnósticos complexos de forma precisa; no setor energético há novos métodos de conversão de energia solar e de produção de biocombustíveis; no setor de eletrônica e fotônica há novos métodos e dispositivos que apontam para uma revolução na computação; no setor ambiental há soluções que permitem tanto o monitoramento como a remediação de poluição e contaminação; no setor de agricultura, pecuária e alimentos, nanotecnologias aumentam a produtividade e permitem ampliar a vida útil de alimentos (INSTITUTO INOVAÇÃO, 2005).

\subsection{Nanociência e Nanotecnologia Aplicadas às Ciências da Saúde e Enfermagem}

A Nanociência e a Nanotecnologia deixaram de compor o rol de promessas tecnológicas e potenciais aplicações científicas para integrar o arcabouço de aplicações tecnológicas reais, com produtos disponibilizados à sociedade, caracterizando a transferência de conhecimento para o setor produtivo, bem como a geração de valor econômico para a sociedade. Diversas funcionalidades agregadas a produtos já disponíveis e novos produtos nanotecnológicos já estão disponíveis em diversos setores econômicos, como têxtil, cosmético, energético, eletrônica, ambiental, agricultura e, como esperado, ciências da saúde (MULVANEY, 2015).

Cabe registrar que, no Brasil, as ações de fomento sistemáticas para $\mathrm{o}$ desenvolvimento da N\&N iniciaram em 2001, com o Edital CNPq Nano $n^{\circ}$ 01/2001, que previa a constituição de quatro redes de pesquisa em nanotecnologia - Rede de Nanobiotecnologia, Rede de Nanodispositivos, Rede Nacional de Materiais Nanoestruturados e Rede de Nanotecnologia Molecular e de Interfaces -, e atualmente conta com ações robustas providas pelo Governo Federal, tais como a Iniciativa Brasileira de Nanotecnologia (IBN), lançada em 2013, e o Sistema Nacional de Laboratórios em Nanotecnologia (SisNANO), lançado em 2012 (BRASIL, 2012/13).

Nas Ciências da Saúde já existe um conjunto de tecnologias desenvolvidas nas áreas de fármaco e administração de fármacos, cosméticos, sistemas portáteis para diagnósticos 
complexos de forma mais rápida e precisa, entre outros. Nesse sentido, exemplos de aplicações nanotecnológicas para Ciências da Saúde, com estágio de desenvolvimento avançado e possibilidade de grandes impactos diretos na qualidade de vida da população, estão listados a seguir:

(i) Fármaco antimalárico nanoencapsulado: Mesmo com o atual desenvolvimento científico e tecnológico, doenças negligenciadas, como a malária, permanecem como problemas de saúde a serem combatidos. O antimalárico artemeter, derivado da artemisinina, foi encapsulado em lipossomas (ver Fig. 5 (a)) para ensaios in vivo, utilizando coelhos machos "Nova Zelândia". Os resultados mostraram aumentos significativos, de aproximadamente $32 \%$ para $98 \%$, na biodisponibilidade do fármaco, quando administrado via oral (BAYOMI et al., 1998; PIMENTEL et al., 2007).

(ii) Nanopartículas de Ouro usadas em testes de gravidez: $O$ teste de gravidez realizado a partir da urina é um diagnóstico bastante utilizado devido à sua facilidade de uso e baixo custo. A rotina dessa classe de testes de gravidez é baseada no princípio da imunocromatografia, e nanopartículas de ouro podem ser utilizadas para este fim. Anticorpos capazes de reagir à presença do hormônio hCG (gonadotrofina coriônica humana) têm sua capacidade de interação potencializadas quando recobrem nanopartículas de ouro (ver Fig. 5 (b)). Esse sistema pode tornar o teste de gravidez mais barato, rápido, sensível e preciso (KATO et al., 2013).

(iii) Nanopartículas poliméricas como carregadores de fármacos contra o câncer de mama: Nanopartículas poliméricas representam uma solução tecnológica capaz de agregar excelente biocompatibilidade, resposta não imunogênica e não tóxica, bem como ser biodegradável. $\mathrm{O}$ agente bioativo paclitaxel foi eficientemente nanoencapsulado em nanopartículas de albumina para o tratamento do câncer de mama. Uma das principais vantagens desta utilização é o menor tempo para início do efeito medicamentoso, aliado a vetorização do fármaco até o tecido tumoral (ver Fig. 5 (c)) (DIMER et al., 2013).

(iv) Marcadores nanométricos para diagnóstico e tratamento de enfermidades: As técnicas que utilizam nanopartículas recobertas com marcadores para identificação e terapia de enfermidades, em especial oncologia, podem ser usadas no interior do organismo (in vivo), que podem ser divididas em diagnósticas (imagens de ressonância magnética) ou terapêuticas (marcação celular, vetorização de medicamentos e hipertermia magnética); ou fora do organismo (in vitro), principalmente para diagnóstico (separação e seleção) (ver Fig. 5 (d)) (FALLEIROS et al., 2011). 
(a)

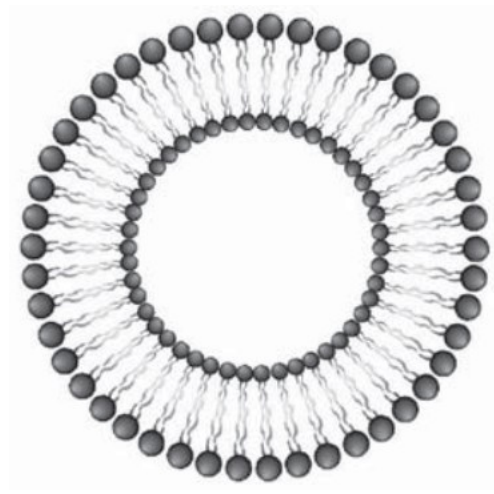

(b)

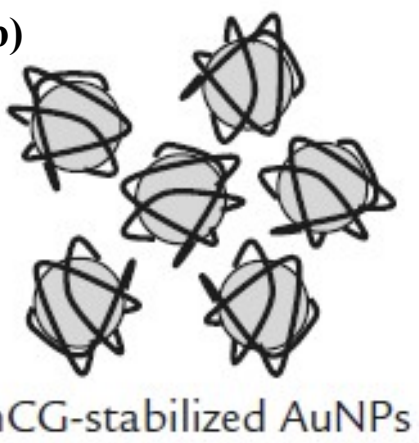

(c)
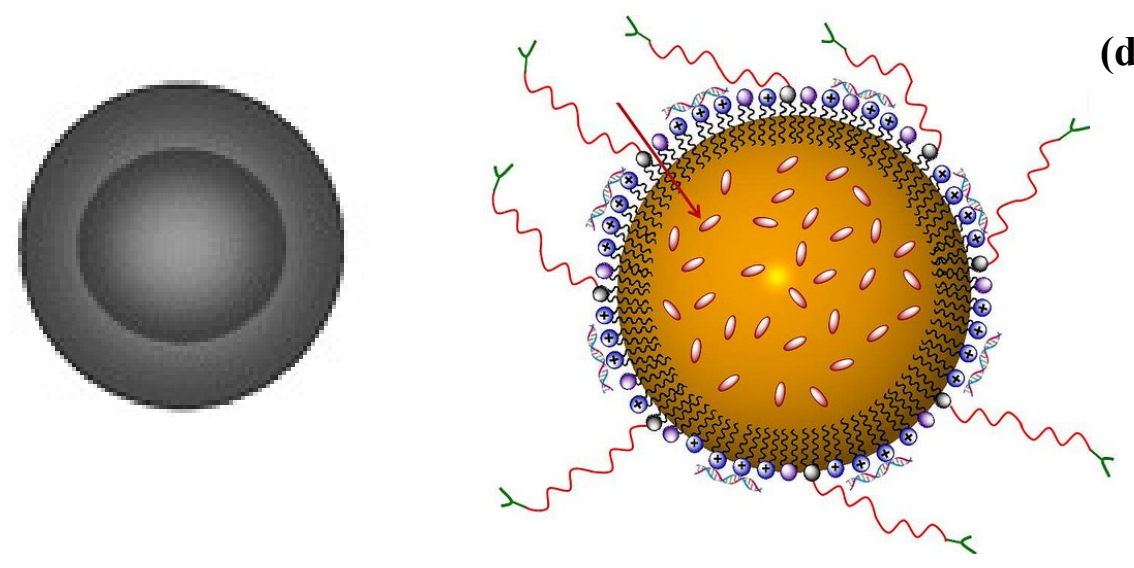

Figura 5. Esquema ilustrativo: (a) corte transversal de um lipossoma (PIMENTEL et al., 2007); (b) Nanopartículas de ouro recobertas pelo hormônio hCG (KATO et al., 2013); (c) Nanopartículas poliméricas em que o agente ativo está conjugado ou encapsulado em um polímero (DIMER et al., 2013); e (d) Nanopartículas recobertas com marcadores para diagnóstico e tratamento de enfermidades, em especial, oncologia (FALLEIROS et al., 2011).

N\&N relacionadas à saúde humana têm possibilitado a criação e transformação de uma grande variedade de produtos e serviços passíveis de agregar valor e conhecimento à prática clínica e à saúde pública. Nesse sentido, a utilização da N\&N está focada, principalmente, no diagnóstico, na terapia e na prevenção de doenças, no entendimento dos mecanismos biológicos e no desenvolvimento de produtos cosméticos e cosmecêuticos. No Brasil, as principais áreas de pesquisa são: síntese e caracterização de novos nanomateriais avançados, farmacêutica, cosméticos e cosmecêuticos e agronegócio (FIGUEIRAS et al., 2014).

Em Farmacêutica, os avanços encontram-se no desenvolvimento de novos fármacos; de sistemas de liberação controlada (controlled drug delivery systems); de novas formulações, entre outras. As vantagens destes fármacos são o reduzido tamanho e direcionamento da droga para o alvo específico, que reduzem significativamente os efeitos colaterais; a 
substituição das formas de administração, veículos semissólidos (pomadas) em substituição aos injetáveis, por exemplo; sistemas de diagnósticos precisos e preventivos; a substituição de medicamentos tradicionais por novas fórmulas mais efetivas e com menor tempo de tratamento (BRASIL, 2012/13). Em cosmética e cosmecêutica, o desenvolvimento está direcionado para novas formulações de bloqueadores solares, de cremes (hidratantes, antissinais, antioxidantes), de produtos para tratamentos capilares.

No agronegócio, a nanotecnologia abre a possibilidade de inserir genes específicos nos cultivares com o auxílio de nanopartículas, nanofibras ou nanocápsulas, em substituição a vírus e bactérias, tradicionalmente utilizados para este fim, e na incorporação de aditivos nutricionais por meio de nanopartículas, nanoemulsões, nanocápsulas e lipossomas, além de embalagens inteligentes, que detectam microrganismos contaminantes e aumentam a vida útil dos materiais. Na área do meio ambiente, as expectativas estão voltadas para o desenvolvimento de sensores para monitoramento de poluentes e microrganismos com potencial de danos aos seres vivos e na fabricação de embalagens biodegradáveis (BRASIL, 2012/13).

De acordo com um levantamento realizado pela Agência Nacional de Vigilância Sanitária (ANVISA), foram listados cerca de 637 produtos considerados-nanotecnológicos e/ou que são feitos com a utilização de procedimentos ou conceitos nanotecnológicos. Dentre eles, 599 cosméticos, 20 saneantes, 10 medicamentos, sete produtos para a saúde e um alimento (ANVISA, 2014; MARCONE, 2015; SANTOS et al., 2016). Na Tabela 1, estão listados alguns produtos fabricados no Brasil que envolvem a nanotecnologia, bem como suas descrições e aplicações.

Tabela 1. Mostra a relação de alguns produtos disponíveis no mercado e fabricados no Brasil a partir de tecnologias desenvolvidas com base na nanotecnologia, bem como suas descrições e aplicações.

\begin{tabular}{|c|c|c|}
\hline \hline Produto & Descrição & Aplicação \\
\hline \hline Língua eletrônica & Sensor gustativo & $\begin{array}{c}\text { Avalia a qualidade de líquidos e } \\
\text { identifica sabores. }\end{array}$ \\
\hline Grafite & $\begin{array}{c}\text { Lápis com nanopartículas } \\
\text { organometálicas }\end{array}$ & $\begin{array}{c}\text { Mais resistência, maciez e intensidade } \\
\text { de cor. }\end{array}$ \\
\hline Prótese arterial & $\begin{array}{c}\text { Endoprótese para cirurgia } \\
\text { aórtica }\end{array}$ & $\begin{array}{c}\text { Sistema nanoestruturado que diminui o } \\
\text { tempo de internação dos pacientes. }\end{array}$ \\
\hline Secador de cabelo & $\begin{array}{c}\text { Primeiro secador de cabelo } \\
\text { desenvolvido à base de } \\
\text { nanotecnologia }\end{array}$ & $\begin{array}{c}\text { Nanopartículas de titânio que } \\
\text { eliminam bactérias e fungos do ar. }\end{array}$ \\
\hline $\begin{array}{c}\text { Sistema de liberação controlada } \\
\text { de drogas }\end{array}$ & Nanocápsulas & $\begin{array}{c}\text { Menores concentrações e toxicidade; } \\
\text { maior efetividade da droga; efeito } \\
\text { terapêutico local. }\end{array}$ \\
\hline
\end{tabular}




\begin{tabular}{|c|c|c|}
\hline Revestimentos & $\begin{array}{c}\text { Resistência a altas temperaturas, } \\
\text { corrosão, contaminação biológica, } \\
\text { Revestimentos } \\
\text { água, produtos químicos. Aumentam } \\
\text { em } 100 \% \text { a vida útil do equipamento. } \\
\text { Aplicação no setor petroquímico, } \\
\text { farmacêutico, automobilístico e da } \\
\text { construção civil. }\end{array}$ \\
\hline Vitactive nanoserum antissinais & Nanocosmético. & $\begin{array}{c}\text { Possui sistema de "liberação } \\
\text { direcionada" dos ingredientes ativos } \\
\text { nas camadas da pele: Comucel } \\
\text { (complexo antienvelhecimento); Priox- } \\
\text { in (complexo antioxidante); } \\
\text { Lumiskin® (clareador e atenuador de } \\
\text { olheiras) e vitaminas A, C e K. }\end{array}$ \\
\hline $\begin{array}{c}\text { Nanocompósitos de } \\
\text { polipropileno e polietileno }\end{array}$ & $\begin{array}{c}\text { Aplicaça no setor de embalagens, } \\
\text { automobilístico, engrenagens, } \\
\text { máquinas e equipamentos, } \\
\text { eletroeletrônicos, eletrodomésticos, } \\
\text { etc.; Maior durabilidade, resistência ao } \\
\text { calor, impermeabilidade à umidade e } \\
\text { óleo. }\end{array}$ \\
\hline \hline
\end{tabular}

Fonte: Adaptada de ABDI (2010b).

Esta tecnologia tem alterado a forma como as doenças são diagnosticadas, tratadas e prevenidas. Nos últimos anos, a aposta no campo da N\&N aplicadas às áreas da saúde cresceram significativamente e prevê-se que assim continue nos próximos anos. Como perspectiva futura, estudos estão sendo realizados na expectativa de encontrar soluções interessantes para várias doenças que ameaçam a vida humana, como doenças cardiovasculares, pulmonares, sanguíneas, neurodegenerativas, Alzheimer ou Parkinson, infecciosas, diabetes e problemas ortopédicos (MARCONE, 2015; NOVO, 2003; OLIVEIRA et al., 2016).

\subsection{Potencial de Revolução de Nanociência e Nanotecnologia}

Nos últimos anos, dentre as estratégias de desenvolvimento de ações em C,T\&I, a Nanociência e a Nanotecnologia têm se destacado pelo aspecto de tecnologia inovadora de natureza transversal - que atua na fronteira do conhecimento -, o que lhe confere a capacidade de impactar grandes setores econômicos que demandam desenvolvimentos tecnológicos e inovadores. N\&N atuam em diferentes setores e podem ser incorporadas nas linhas de produção e/ou nos produtos desenvolvidos por setores como energia, saúde, farmácia, recursos hídricos, petroquímica, automobilística, entre outros (BRASIL, 2012/13).

O mercado da N\&N tem proporcionado altos investimentos nestes últimos anos pelos governos de 14 países, a saber: Estados Unidos, Canadá, Reino Unido, Alemanha, Rússia, 
Israel, Arábia Saudita, África do Sul, Índia, China, Japão, Coreia do Sul, Taiwan e Austrália, que totalizam mais de US\$ 67 bilhões desde 2000. Com base em projeções futuras de consultorias de tecnologias emergentes, a Nanotecnologia deve movimentar cerca de US\$2,5 trilhões em 2020. Em 2009, este mercado já alcançou US\$ 250 bilhões. O investimento do governo americano no âmbito da sua Iniciativa Nacional de Nanotecnologia (NNI) foi de US\$ 1,8 bilhões em Pesquisa e Desenvolvimento (P\&D). Junto com o investimento do setor privado em P\&D (US\$ 2.1 bilhões), estima-se a geração de 220.000 empregos, retorno de aproximadamente US\$ 22 bilhões aos cofres públicos e produção de aproximadamente US\$ 110 bilhões em produtos finais (BRASIL, 2012/13).

A Agência Brasileira de Desenvolvimento Industrial (ABDI) e o Centro de Gestão e Estudos Estratégicos (CGEE), com o objetivo de subsidiar a Iniciativa Nacional de Inovação em Nanotecnologia, divulgaram conjuntamente um panorama sobre pesquisa, desenvolvimento e inovação de N\&N no Brasil e no Mundo. Essas ações mostram que o Brasil tem avançado consistentemente em áreas estratégicas, como energia, agronegócio, meio ambiente, biotecnologia e nanotecnologia, assim como realizado investimentos em recursos humanos, políticas sistematizadas de financiamento e marcos regulatórios de apoio ao setor de nanotecnologia. Com isso, tem alcançado uma posição de destaque no cenário de C,T\&I (ABDI, 2010a; BRASIL, 2012/13).

Nesse contexto, a Nanotecnologia é um dos principais focos das atividades de pesquisa, desenvolvimento e inovação na grande parte dos países industrializados, em especial nos países da União Europeia. Em 2012, a União Europeia lançou o documento "Uma estratégia europeia para as Tecnologias Facilitadoras Essenciais" (A European strategy for Key Enabling Technologies - A bridge to growth and Jobs) (COMUNICAÇÃO PARA O PARLAMENTO EUROPEU, 2009), apresentando seis áreas estratégicas para o crescimento e expansão da economia, aumento da competitividade e emprego. Essas tecnologias foram batizadas de Tecnologias Facilitadoras Essenciais (Key Enabling Technologies - KET). Destaca-se que das seis KETs, micro e nanoeletrônica, nanotecnologia, fotônica, materiais avançados, manufatura avançada e biotecnologia, duas são diretamente relacionadas com a Nanotecnologia. Para esse programa, estão previstos mais de dois bilhões de dólares/ano e o seu desenvolvimento tem sido apontado como uma nova revolução tecnológica, simbolizando temáticas estratégicas para economias consolidadas e emergentes, promovendo uma competição tecnológica mundial, dentro do mercado de um trilhão de dólares estimados para o período entre 2010 e 2015 (COMUNICAÇÃO PARA O PARLAMENTO EUROPEU, 2009). 
As publicações em nanociências têm quase triplicado durante a última década (crescimento de 1,5\% a 4,2\%), confirmando que a Nanociência, como campo de conhecimento em nível mundial, está se desenvolvendo muito mais rápido que o científico nos demais campos. O Brasil vem apresentando grande potencial científico no que se refere a pesquisas científicas nas áreas de N\&N. Em geral, existem diversas publicações científicas realizadas por pesquisadores brasileiros em revistas de rigorosas políticas editoriais e de expressividade científica, tais como Nature e Science. Além disso, conta com pós-graduações bem estruturadas nas áreas-chave de Nanotecnologia - Química, Física, Biologia e Engenharia -, com uma quantidade importante de pós-graduandos, que realizam significativos estudos em diferentes aspectos da nanotecnologia. Além, de estudantes e pesquisadores estarem vinculados há programas de mestrado, doutorado e de estágios de pós-doutorado, no exterior; ou seja, em todos os importantes aspectos da nanotecnologia existem grupos de pesquisa atuantes (MARCONE, 2015).

A produção científica envolvendo a N\&N, dos últimos 25 anos, indica claramente o avanço desta tecnologia. A Figura 6 mostra gráficos de produção científica: (a) artigos publicados de 1991 a 2015 envolvendo nanomateriais e (b) áreas de maior interesse de pesquisa. Observa-se que houve um crescimento muito significante acerca do número de trabalhos publicados entre 1991 e 2015. Das áreas de maior interesse, destacam-se os periódicos ligados especificamente à ciência dos materiais (52\%), seguidos das revistas com foco específico na nanotecnologia (18\%) e nas ciências aplicadas (11\%) (MARCONE, 2015).

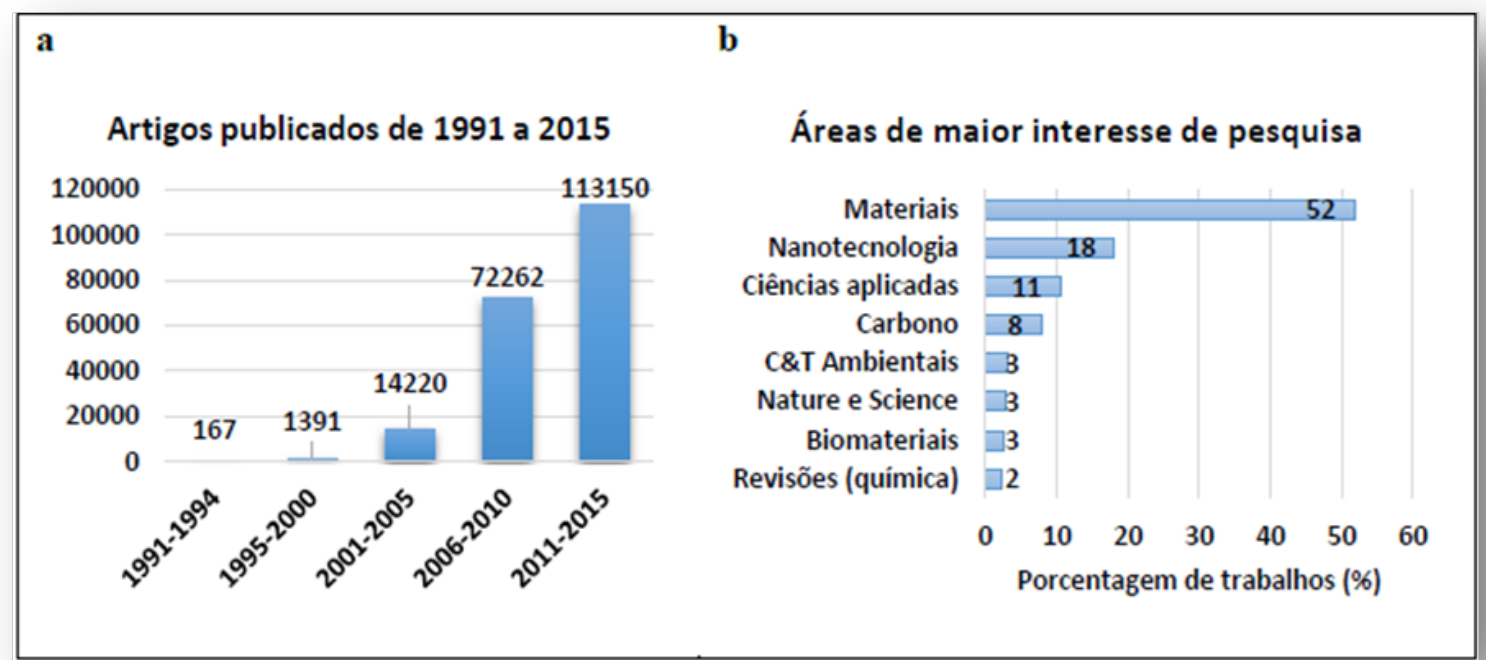

Figura 6. Gráficos de produção científica: (a) Artigos publicados de 1991 a 2015 envolvendo nanomateriais e (b) Áreas de maior interesse de pesquisa. Pesquisa bibliográfica realizada com as palavras-chaves: nanomaterials OR nanoparticles (MARCONE, 2015). 


\subsection{Educação a Distância no Ensino de Nanociência e Nanotecnologia e a Importância da Temática para Estudantes e Profissionais da Saúde}

Em geral, no Brasil são poucos os cursos de extensão na temática "Nanociência e Nanotecnologia Aplicadas às Ciências da Saúde", oferecidos na modalidade totalmente EaD em nível de graduação e pós-graduação. Dessa forma, N\&N, por serem áreas consideradas promissoras para produção de novos dispositivos tecnológicos com grande potencial para mudar o modo como vivemos, os rumos econômicos e sociais de um país, pela realidade e crescimento considerável de pesquisas nessas áreas - a maioria desenvolvida nas universidades e nos institutos de pesquisa -, foi que se percebeu a necessidade da compreensão desta tecnologia, de seus princípios básicos e mais amplos. Sabendo que N\&N são áreas multidisciplinares, esses conceitos podem ser abordados para diferentes áreas, utilizando a ferramenta de ensino online (BRASIL, 2012/13).

O ensino formal da N\&N tem se tornado cada vez mais presente no ambiente acadêmico das universidades, principalmente públicas, nas áreas de Física, Química e Biologia que abordam temas de N\&N. Para conhecimento, apenas três cursos mencionam explicitamente os termos "Nanociência ou Nanotecnologia": (i) Engenharia em Nanotecnologia, oferecido pela Pontifícia Universidade Católica do Rio de Janeiro (PUCRio); (ii) Nanotecnologia (Licenciatura), oferecido pela Universidade Federal do Rio de Janeiro (UFRJ); e (iii) Mestrado em Nanociências, oferecido pelo Centro Universitário Franciscano (Unifra) (AFONSO, 2011). Na modalidade parcial ou totalmente a distância, ações de ensino da Nanociência e Nanotecnologia não são numericamente abundantes no Brasil, e têm se concentrado principalmente em cursos de extensão e disciplinas de graduação e pós-graduação.

No entanto, devido às suas características intrínsecas, ações de ensino parcial ou totalmente a distância são promissoras para a abordagem do tema Nanociência e Nanotecnologia e sua interface com as Ciências da Saúde. Estão listados abaixo os principais pontos fortes que justificam a potencialidade de abordar temas da N\&N por meio de ações de ensino totalmente EaD:

(i) Facilitadora de Conhecimento Complementar: Devido à multidisciplinaridade inerente dos temas Nanociência e Nanotecnologia, faz-se necessário o domínio básico de conceitos em diversas áreas do conhecimento - Química, Física, Matemática e Biologia para a compreensão dos conceitos da $N \& N$, bem como seu potencial de revolução tecnológica. Nesse sentido, os AVA facilitam a disponibilização de conhecimentos 
complementares nas principais áreas correlatas, que podem ser acessados pelo aluno, à medida que surgirem dúvidas ou dificuldades (SANTOS; ROSA, 2016);

(ii) Ações de Ensino Flexíveis e de Formação Continuada: Uma vez que a temática N\&N não compõe a parte obrigatória, em geral totalmente presencial, dos cursos/currículos de ciências da saúde estabelecidas pelo Ministério da Educação (MEC) do Brasil, no Plano Nacional de Educação (PNE), esta pode ser encaixada nas ações de formação continuada, aperfeiçoamento e atualização de profissionais da saúde. Nesse sentido, iniciativas totalmente $\mathrm{EaD}$ são interessantes por serem flexíveis temporalmente, exibirem baixo custo per capita, não possuírem limitações geográficas, passíveis de ofertar um grande número de vagas, entre outros (OTSUKA et al., 2011);

(iii) Ambiente Multimídia como Facilitador da Aprendizagem: A escala nanométrica $\left(1 \times 10^{-9} \mathrm{~m}\right)$ e os fenômenos da matéria nesta escala apresentam um conjunto de especificidades que nem sempre podem ser bem representados pelos nossos sentidos cognitivos e subsunçores conceituais. Nesse sentido, para facilitar a correlação, visualização e aprendizagem dos conceitos da Nanociência e Nanotecnologia e suas interfaces com as ciências da saúde, faz-se necessário usar diferentes mídias, vídeos, áudios, websites, ações interativas, simulações, organogramas, interações dinâmicas aluno-aluno e aluno-tutor, entre outras. Nesse contexto, ações de ensino na modalidade a distância são ambientes intrinsicamente propícios para a utilização de atividades multimídias/multimeios, facilitadoras do processo ensino-aprendizagem e aprendizagem significativa (OTSUKA et al., 2011).

Assim como nas diversas atividades educativas, as ações de ensino na modalidade $\mathrm{EaD}$, parcial ou total, exibem intrinsicamente barreiras a serem superadas pelo indivíduo, representando, assim, os pontos fracos conhecidos desta modalidade. Tais pontos podem ser potencializados ou minimizados quando o objeto da ação educativa é complexo e contemporâneo, como o caso do tema Nanociência e Nanotecnologia aplicadas às Ciências da Saúde. Estão listadas abaixo alguns dos principais desafios a serem superados em ações de N\&N na modalidade EaD (SANTOS; ROSA, 2016);

(iv) Escassez de Conteúdos Específicos de N\&N para EaD: A indisponibilidade de teorias de ensino-aprendizagem voltadas especificamente para a modalidade $\mathrm{EaD}$, metodologias de ensino específicas para $\mathrm{EaD}$, diversidade de processos de acompanhamento e avaliação eficazes, entre outros, ainda se configura como ponto de atenção na área de EaD. Esse ponto de atenção é ainda mais latente quando os temas a serem ensinados são complexos e contemporâneos, como o caso de N\&N aplicadas às Ciências da Saúde. Atualmente, não há abundância de conteúdos disponíveis nesta temática (ELLWANGER et al., 2012); 
(v) Barreira idiomática e baixa disponibilidade de mão de obra especializada: Por se tratar de uma temática relativamente recente, na vanguarda e fronteira do conhecimento, bem como em ampla expansão mundial, a esmagadora parte da bibliografia disponível sobre N\&N está em língua inglesa, e o quantitativo da mão de obra especializada na temática ainda está em consolidação no Brasil. Tais fatores refletem diretamente nas ações de ensino do tema na modalidade $\mathrm{EaD}$, já que restringem a disponibilidade e acesso a conteúdos de fronteira para o grande público e a oferta de mão de obra especializada em N\&N para atuarem no ensino via EaD (AFONSO, 2011).

(vi) Alteração Cultural do Aprendizado e Maturidade Educacional: Nas ações de ensino utilizando a modalidade parcial ou totalmente a distância, há um deslocamento do protagonismo do aprendizado do professor para o aluno. Esse deslocamento também está associado à mudança cultural de postura do aluno, saindo da postura predominantemente passiva para postura mais ativa. Para superar essa mudança de postura, pressupõe-se que o estudante exiba uma maturidade educacional mínima relacionada às dificuldades encontradas no aprendizado, falta de disciplina e de organização dos estudantes. Na abordagem de N\&N utilizando rotinas $\mathrm{EaD}$, os fatores alteração cultural e maturidade educacional são ainda mais desafiadores devido à complexidade do tema e a necessidade de busca e correlação de conhecimento extra (SANTOS; ROSA, 2016). 


\section{$3^{\circ}$ CAPÍTULO - EDUCAÇÃO A DISTÂNCIA}

\subsection{Histórico, Possibilidades e Manifestações da Educação a Distância}

Acerca das considerações históricas sobre a Educação a Distância no Brasil e no mundo, e como esta modalidade de educação se desenvolveu ao longo dos anos, pode ser considerado, como uma das principais ações de ensino $\mathrm{EaD}$, o oferecimento de formação por correspondência na área de taquigrafia em 1728 pelo jornal Gazeta de Boston. A partir de então, o Instituto Líber Hermondes, da Suécia, ofertou em 1829 cursos na modalidade EaD, via correspondências, a mais de 150.000 e, em 1840, a primeira escola por correspondência da Europa foi inaugurada no Reino Unido (SILVA; CAMPOS, 2016).

Em seguida das cartas, começou o ensino por rádio e televisão. Em 1935, o Japanese National Public Broadcasting Service iniciou seus programas escolares nesse meio de comunicação como complemento da escola oficial. Nos Estados Unidos, a Chicago TV College, em 1956, iniciou a veiculação de programas educativos pela televisão. Todos esses acontecimentos e instituições foram fundamentais para a consolidação da $\mathrm{EaD}$, que passou a ser mais frequente em diferentes locais do mundo (ALVES, 2011).

Já no Brasil, as primeiras experiências em EaD datam do século XX, decorrentes do iminente processo de industrialização, que gerou uma demanda por políticas educacionais que formassem o trabalhador para a ocupação industrial. Nesse contexto, o registro pioneiro do ensino por correspondência aconteceu no Jornal do Brasil, em 1904, oferecendo cursos de datilografia. Ações EaD pelo sistema radiofônico brasileiro tiveram início em 1923, na Rádio Sociedade do Rio de Janeiro e, em 1979, a UnB, pioneira no uso da EaD, no ensino superior no Brasil, criou cursos veiculados por jornais e revistas, que em 1989 foram transformados no Centro de Educação Aberta, Continuada, a Distância (CEAD) (ALVES, 2011).

No tocante à legislação da $\mathrm{EaD}$ no Brasil, as bases legais para a modalidade foram estabelecidas no ano de 1996, pela Lei de Diretrizes e Bases da Educação Nacional (LDB), Lei $\mathrm{n}^{\circ}$ 9.394, de 20 de dezembro de 1996, regulamentada pelo Decreto $\mathrm{n}^{\circ}$ 5.622, que reconheceu a educação a distância como uma forma de ensino. A difusão e consolidação da EaD aconteceu em todos os níveis de ensino, marcada especialmente pela criação, em 2005, da Universidade Aberta do Brasil, que integrou cursos, pesquisas e programas de educação superior a distância (ALVES, 2011). 
Em 2006, entrou em vigor o Decreto $n^{0} 5.773$, de 09 de maio de 2006, que dispõe sobre o exercício das funções de regulação, supervisão e avaliação de instituições de educação superior e cursos superiores de graduação e sequenciais no sistema federal de ensino, incluindo os da modalidade a distância (BRASIL, 2006). Já no ano de 2007, entrou em vigor o Decreto $\mathrm{n}^{\circ}$ 6.303, de 12 de dezembro de 2007, que alterou dispositivos do Decreto $\mathrm{n}^{\circ} 5.622$, que estabeleceu as Diretrizes e Bases da Educação Nacional (BRASIL, 2007).

Em 2008, uma Lei permitiu o ensino médio a distância, em que até 20\% da carga horária poderia ser não presencial. No ano de 2009 , entrou em vigor a Portaria $\mathrm{n}^{\mathrm{o}} 10$, de 02 julho, que fixou critérios para a dispensa de avaliação in loco e deu outras providências para a educação a distância no ensino superior no Brasil (BRASIL, 2009). A Secretaria de Educação a Distância foi extinta em 2011. Cabe destacar, que o desenvolvimento histórico da EaD no Brasil esteve sempre ligado à formação profissional, capacitando pessoas ao exercício de certas atividades ou ao domínio de determinadas habilidades, sempre motivadas por questões de mercado.

A Figura 7 mostra o processo histórico de construção e evolução da Educação a Distância, estruturada em cinco tendências ou gerações: (i) cursos por correspondência ou metodologia de ensino por correspondência, caracterizados pelo uso de material impresso entregues aos alunos por meio dos serviços dos correios; (ii) integração de novas mídias (rádio, televisão, fitas de áudio e vídeo e telefone), permitindo uma comunicação sincrônica; (iii) universidade aberta, caracterizada por expandir e interiorizar a oferta de cursos e programas de educação superior por meio da EaD; (iv) teleconferências, configurando-se em modalidade de educação presencial virtual; e (v) educação a distância online, que passou a contar com novos recursos tecnológicos e o grande crescimento da Internet, criando um novo espaço de interação (OLIVEIRA; SILVA, E., 2015; SILVA, F.; CAMPOS, 2016). 


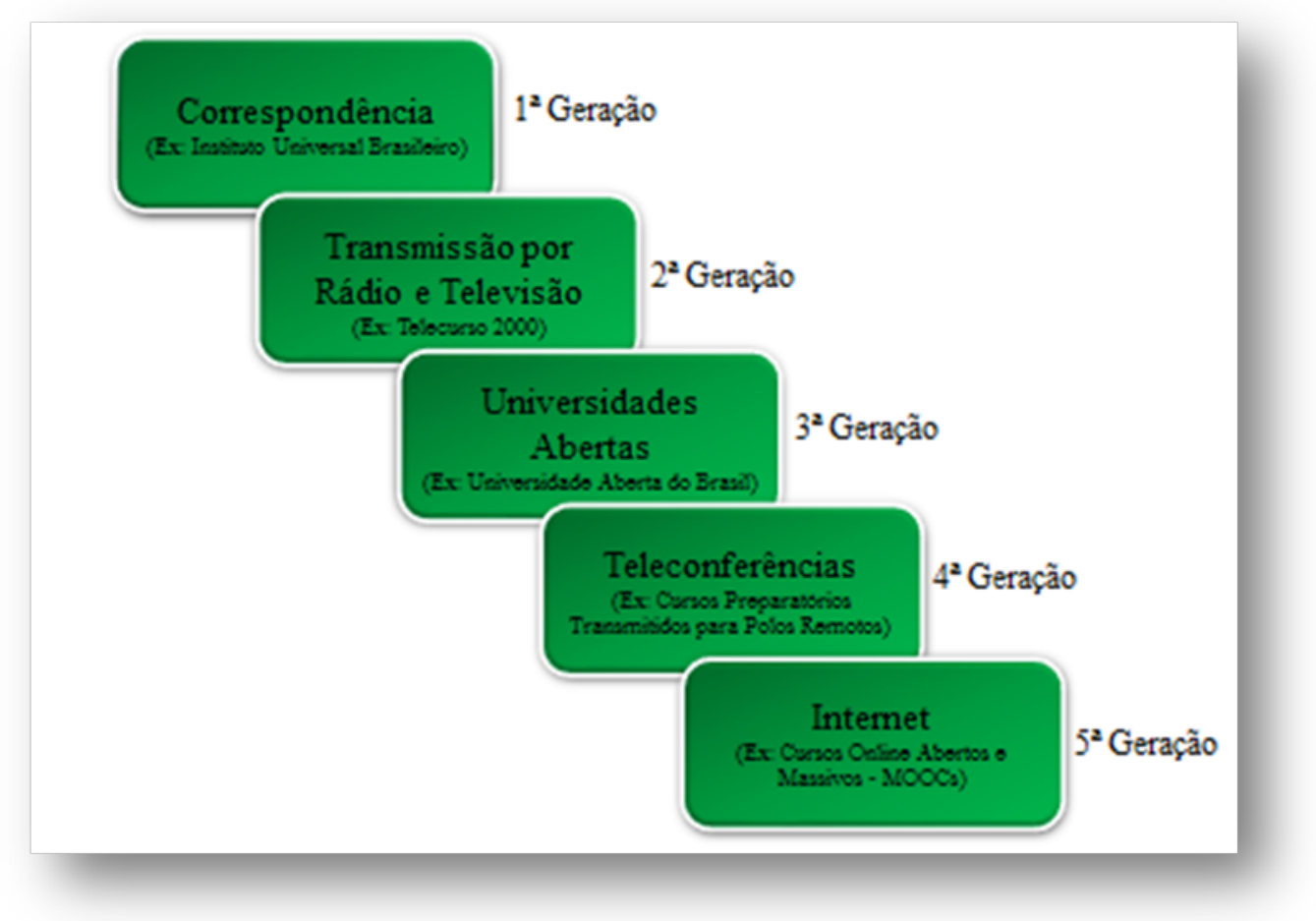

Figura 7. Mostra o processo histórico de construção e evolução da Educação a Distância, estruturada em cinco tendências ou gerações. Fonte: Próprio autor.

Torna-se importante citar um recente desenvolvimento na área de educação a distância, os MOOCs (Massive Open Online Courses), disponibilizados em várias plataformas, como, por exemplo a plataforma edX, Coursera, entre outras. Os MOOCs da plataforma edX são cursos online, em geral, de nível superior, gratuitos e massivos, introduzidos no mercado e academia por universidades de ponta dos Estados Unidos - como Harvard e o Instituto de Tecnologia de Massachusetts (MIT) -, sendo que cada instituição se comprometeu a investir US\$ 30 milhões nessa iniciativa. O principal objetivo dessas plataformas é disponibilizar conhecimento a grande número de pessoas de forma fácil e eficaz. Devido ao grande sucesso da plataforma edX entre os jovens norte-americanos, esses cursos vêm sendo ofertados a outros países e, não à toa, o ano de 2012 foi eleito o ano dos MOOCs pelo jornal The New York Times (JORDAN, 2015).

Nesse contexto, cabe destacar também as mais recentes formas de educação a distância, que são: (i) Ações Diretas - atendem especificamente ao público interessado em $\mathrm{EaD}$, como em cursos totalmente a distância, blended, híbridos ou semipresenciais e disciplinas realizadas a distância; e (ii) Ações Indiretas - não envolvem a implantação de cursos ou disciplinas a distância, mas geram produtos (objetos de aprendizagem, textos, conteúdos brutos ou pedagogicamente tratados, entre outros) ou serviços (hospedagem de 
sites, tutoria, produção de conteúdos, entre outros) que viabilizam ou tornam mais efetivas as ações diretas (ABED, 2015).

Ações de ensino totalmente a distância costumam ser caracterizadas por mais de $70 \%$ do conteúdo desenvolvido para disciplinas a distância. Os alunos estudam por meio de materiais impressos, áudio, vídeo, conteúdo emitido via satélite ou por tecnologias digitais, como computador, tablets e celulares, e realizam atividades síncronas ou assíncronas. Esses cursos podem ser realizados por correspondência, via satélite ou online. As ações de ensino blended, híbridos ou semipresenciais combinam atividades presenciais e a distância, com proporção variada de $30 \%$ a $70 \%$ de uma forma em relação à outra. Enquanto que as disciplinas realizadas a distância consistem em cursos de graduação autorizados e presenciais, correspondendo a até $20 \%$ do currículo na modalidade $\mathrm{EaD}$, de acordo com a legislação nacional (ABED, 2015).

\subsection{Ações de Ensino Mediadas por Tecnologias: Educação a Distância}

As Tecnologias de Informação e Comunicação (TIC), incorporadas à Educação a Distância, podem atuar de maneira mais significativa no processo de ensino e aprendizagem, promovendo importantes contribuições no que se refere ao planejamento e mediação pedagógica aplicados a ações de ensino a distância. Assim sendo, cada vez mais os gestores educacionais percebem a importância das TIC no processo de obtenção do conhecimento, pois proporcionam um novo modo de se comunicar, os alunos têm a possibilidade de se relacionar, trocar informações e experiências, bem como os professores e/ou tutores de realizar trabalhos em grupos, debates, fóruns, entre outros. Nesse entendimento, estudos mostram que as ferramentas tecnológicas proporcionam uma educação sem barreiras geográficas, mais livres no tempo, mais inclusiva e multissensoriais, levando o sistema educacional a assumir um papel de formação de cidadãos de forma mais eficiente, fornecendo recursos mais eficazes para atender e motivar os atores envolvidos no processo de ensino-aprendizagem (OTANI et al., 2016).

$\mathrm{O}$ atual panorama da EaD vem passando por transformações a partir do contexto de mudança de valores, em que os diferentes aspectos da diversidade cultural e geracional estão presentes e precisam se fazer ouvidos. O alto índice de globalização, comunicação e informação sem fronteiras ao qual estamos expostos por meio da sociedade em geral, Internet e da mídia, gera necessidade de mudanças nos atuais paradigmas educativos. Tais alterações de paradigmas são, em parte, atendidas com a utilização de TIC nas ações de ensino, gerando 
práticas educativas mediadas por tecnologias. Contudo, a simples inserção de tecnologias no processo educacional não representa a garantia de aumento na eficácia educacional. Processos associados à integração dos atores da aprendizagem (aluno, meio, professor, tutor, coordenação) precisam ser fomentados para que suas ações sejam coordenadas e alcancem os objetivos propostos (ANDERSON et al., 2015).

$\mathrm{Na}$ área da saúde, iniciativas de formação e qualificação profissional estão sendo instituídas gradualmente e, considerando que o país vive a situação de grande diversidade regional - tanto em relação às condições socioeconômicas quanto de acesso à informação -, o ensino na modalidade $\mathrm{EaD}$ passa a ser incentivado por instituições de ensino públicas e privadas, bem como por iniciativas governamentais, que utilizam como apoio a legislação brasileira por meio do Decreto $\mathrm{n}^{\mathrm{o}} 5.622 / 2005$, que regula a $\mathrm{EaD}$ e que reconhece a abrangência desta modalidade de ensino (BRASIL, 2005). Diante dessa realidade, estudos sobre o tema descrevem uma visão positiva em relação à $\mathrm{EaD}$, apresentando em seus resultados atitudes de satisfação com essa modalidade de educação, facilitada pelo avanço tecnológico e o acesso ao computador e à Internet. Mais especificamente em relação aos profissionais de enfermagem, que consideram a EaD uma ferramenta educacional capaz de melhorar a qualificação profissional (OTANI et al., 2016).

Diante dessa realidade, a EaD é considerada uma relevante modalidade de ensinoaprendizagem, capaz de complementar o sistema regular de ensino presencial apoiando-se em práticas pedagógicas atuais e em recursos tecnológicos que facilitam a comunicação e interação entre professor e aluno, ultrapassando limites de tempo e distância, facilitando o acesso e a equidade. A crescente complexidade das sociedades, o avanço tecnológico em diversas frentes do conhecimento, por exemplo, informática, telecomunicações, nanotecnologia, entre outros, e suas potenciais aplicações no mundo do trabalho motivam um crescimento por mais vagas educacionais de maior qualidade. A sociedade vem passando por transformações significativas ao longo dos tempos e cada vez mais se busca conhecimento nas mais variadas áreas. Diversidades culturais, socioeconômicas e cognitivas de populações de estudantes exigem profundas transformações nos sistemas de educação do país, em suas estratégias e finalidades sociais e, sobretudo, em suas metodologias de ensino (MCNEW et al.,2016).

Nesse contexto, conceitos como e-learning (educação a distância), microlearning (dispositivos miniaturizados para e-learning), mobile-learning (e-learning via smartphones) surgem como recursos, caminhos para a inovação, não apenas por responder às demandas quantitativas de democratização do acesso ao ensino, mas também por contribuir para a 
melhoria da qualidade da educação, ao favorecer a integração das TIC aos processos educacionais, o que possibilita aos estudantes e professores desenvolverem atividades educativas em lugares ou tempos diversos, as quais estimulam e possibilitam a inovação metodológica, permitindo que os sistemas educacionais estejam sempre se modernizando e oferecendo um ensino mais sintonizado com as culturas das novas gerações e com as demandas da sociedade. A sala de aula virtual tem apresentado relevantes potenciais de inclusão de pessoas em regiões mais afastadas e com menos acesso à educação, bem como revelado ser abrangente, rompendo fronteiras e promovendo aprendizagens mais efetivas. Nesse sentido, a EaD tende a se tornar um elemento regular dos sistemas educativos, assumindo funções de crescente importância na educação de jovens e adultos que inclui o ensino superior e a formação continuada (MCNEW et al.,2016).

Pesquisas realizadas pelo Comitê Gestor da Internet no Brasil (CGI.br), Centro Regional de Estudos para o Desenvolvimento da Sociedade da Informação (Cetic.br) e Núcleo de Informação e Coordenação do Ponto BR (NIC.br) apresentam produções de estatísticas sobre o acesso e uso das tecnologias de informação e comunicação nos mais diversos segmentos da sociedade brasileira. A TIC Domicílios 2015 (BARBOSA, 2015a) aponta que 58\% da população brasileira usa a Internet. O índice representa 102 milhões de usuários de Internet e a proporção é 5\% superior à registrada no levantamento de 2014 . Na edição de 2014 da TIC Educação (BARBOSA, 2015b), constatam que os professores brasileiros demonstram interesse em utilizar recursos educacionais digitais, mas nem sempre existem condições de infraestrutura e capacitação para o uso da Internet com o propósito pedagógico. Apenas 30\% dos professores de escolas públicas fazem da sala de aula o principal local de uso das TIC, que se mantem estável em relação a 2013. Já no segmento da Saúde (BARBOSA, 2015c), em 2014, os resultados apontam que a disponibilidade de infraestrutura básica de TIC avançou nos estabelecimentos de saúde em relação a 2013; 92\% utilizaram computador nos 12 meses que antecederam a realização da pesquisa e $85 \%$ possuíam acesso à Internet. No levantamento de 2013 , tais proporções eram de $83 \%$ e $77 \%$, respectivamente.

O Ipea apresentou à sociedade brasileira um estudo contendo um conjunto de quatro megatendências até 2030 (MARCIAL, 2015). Uma das megatendências está associada à mudança do perfil sociodemográfico da população brasileira nas últimas décadas e sua tendência de mudança continuada para os próximos anos. Nesse sentido, espera-se que o sistema de ensino se adeque às necessidades da sociedade moderna, em constante remodelamento, bem como absorva os permanentes avanços das TIC, que continuarão 
contribuindo com o acesso facilitado à informação, com a melhoria do processo educacional e com a manutenção da educação continuada de qualidade.

A título de referência, já que não foram identificadas atualizações superiores a 2008, o levantamento feito pelo Anuário Brasileiro Estatístico de Educação Aberta e a Distância (AbraEAD) mostra que um em cada 73 brasileiros fez uso de ações de aprendizado parcialmente ou totalmente a distância em 2007. Seguindo esse índice, infere-se que pouco mais de 2,5 milhões de brasileiros estudaram em cursos com metodologias a distância no mesmo ano. A tabela abaixo mostra os resultados do observatório de projetos de EaD da AbraEAD 2008, em termo das instituições educadoras, nível de ensino e número absoluto de alunos matriculados (SANCHEZ, 2008).

Tabela 2. Número de estudantes matriculados em cursos realizados na modalidade EaD classificados quanto à instituição de ensino, classificação curricular e número absoluto de aprendizes matriculados.

\begin{tabular}{|c|c|c|}
\hline Instituição & "Classificação Curricular & $\mathrm{N}^{\circ}$ de Matriculados \\
\hline $\begin{array}{c}\text { Instituições credenciadas e cursos } \\
\text { autorizados pelo Sistema de } \\
\text { Ensino (AbraEAD/2008) }\end{array}$ & $\begin{array}{c}\text { EJA, Fundamental, Médio, Técnicos, Graduação, } \\
\text { Pós-graduação }\end{array}$ & 972.826 \\
\hline $\begin{array}{c}\text { Educação corporativa e } \\
\text { Treinamento em } 41 \text { empresas } \\
(\text { AbraAED } / 2008)\end{array}$ & $\begin{array}{l}\text { Formação de funcionários, colaboradores e } \\
\text { fornecedores }\end{array}$ & 582.985 \\
\hline Senai & $\begin{array}{l}\text { Formação inicial e continuada de trabalhadores } \\
\text { (exclui os cursos de formação técnica de nível } \\
\text { médio e de pós-graduação) }\end{array}$ & 53.304 \\
\hline Sebrae & \begin{tabular}{|c|} 
Cursos para empreendedores: Análise e \\
planejamento financeiro, Aprender a apreender, \\
Como vender mais e melhor, De olho na qualidade, \\
Iniciando um pequeno grande negócio e Desafio \\
Sebrae
\end{tabular} & 218.575 \\
\hline Senac & $\begin{array}{l}\text { Programas compensatórios de matemática e } \\
\text { português e cursos de formação inicial e } \\
\text { continuada, nas áreas de informática, gestão, } \\
\text { comércio, saúde e turismo e hospitalidade }\end{array}$ & 29.000 \\
\hline CIEE & Cursos de iniciação profissional & 148.199 \\
\hline Fundação Bradesco & Escola Virtual & 164.866 \\
\hline OI Futuro & Tonomundo & 175.398 \\
\hline $\begin{array}{l}\text { Secretaria de Educação a } \\
\text { Distância do Ministério da } \\
\text { Educação (Seed/MEC) }\end{array}$ & $\begin{array}{c}\text { Proformação, Proinfantil, Tecnologias na Educação } \\
\text { e Formação pela Escola }\end{array}$ & 8.552 \\
\hline
\end{tabular}


Capítulo 3 - Educação a Distância

\begin{tabular}{||c||c||c||}
\hline Governo do Estado de São Paulo & $\begin{array}{c}\text { Rede do Saber: Crônica na Sala de Aula, Viva } \\
\text { Japão, PEC Formação Universitária Município, } \\
\text { Curso de Pregão Eletrônico, Convênio com Escola } \\
\text { Paulista de Magistratura, Videoconferências do } \\
\text { Centro Paula Souza, Curso de Iniciação Funcional } \\
\text { para Assistentes Sociais do Tribunal de Justiça. } \\
\text { Departamento de Informática Educativa } \\
\text { (DIE/FDE): Interaction Teachers, Interaction } \\
\text { Students }\end{array}$ & 119.225 \\
\hline \hline Fundação Telefônica & $\begin{array}{c}\text { Educarede (Projetos Minha Terra, Memórias em } \\
\text { Rede, Coisas Boas 2007 e Rede de Capacitação) }\end{array}$ & 9.000 \\
\hline \hline Fundação Roberto Marinho & $\begin{array}{c}\text { Telecurso TEC e Multicurso Ensino Fundamental, } \\
\text { Tecendo o Saber, Projetos de Formação } \\
\text { Educacional, Travessia e Poronga }\end{array}$ & 22.553 \\
\hline \hline TOTAL & & $\mathbf{2 . 5 0 4 . 4 8 3}$ \\
\hline \hline
\end{tabular}

Fonte: As próprias instituições citadas e AbraEAD (2008).

O segmento de cursos a distância é hoje uma aposta das grandes instituições devido ao custo mais baixo para quem oferta os cursos e para o aluno. Segundo o MEC, o modelo saiu de uma fatia de $0,8 \%$ do mercado privado em 2004 para 20,5\% em 2014. Para 2016, a estimativa é que esse índice se aproxime de 30\%, segundo a consultoria Hoper Educação, principalmente em decorrência das reduções de financiamento governamentais, como o FIES (Fundo de Financiamento Estudantil), para o ensino presencial (CUNHA, 2016). A Figura 8 mostra a distribuição percentual dos alunos matriculados no ensino superior privado na modalidade presencial e EaD, entre os anos de 2004 e 2014:

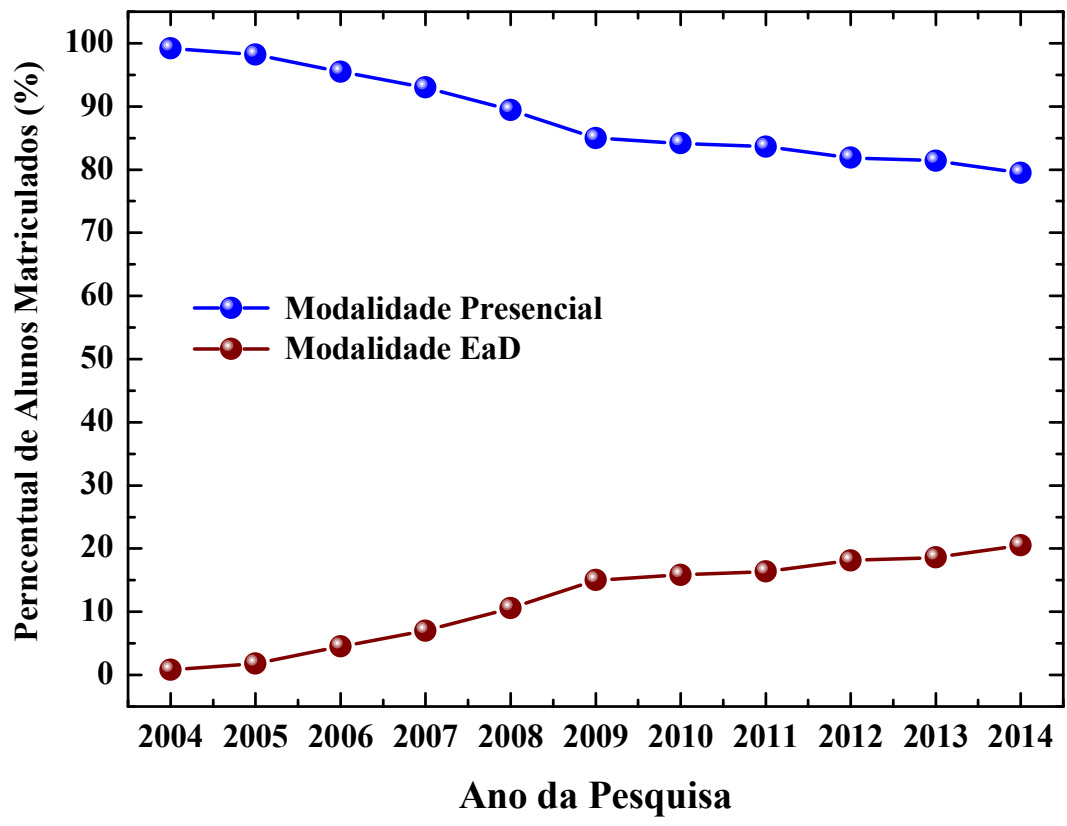

Figura 8. Distribuição percentual dos alunos matriculados no ensino superior privado na modalidade presencial e EaD, entre os anos de 2004 e 2014. Fonte: Folha de São Paulo e Hoper Educação (2016). 
Tabela 3. Proporção entre o percentual de alunos matriculados em cursos de nível superior em instituições de ensino privada, entre 2004 e 2014, em função da modalidade de ensino escolhida: presencial e a distância.

\begin{tabular}{|c|c|c|c|c|c|c|c|c|c|c|c|}
\hline \hline \multirow{2}{*}{$\begin{array}{c}\text { Modalidade de } \\
\text { Ensino }\end{array}$} & \multicolumn{10}{|c|}{ Ano de Avaliação } \\
\cline { 2 - 13 }$y$ & $\mathbf{2 0 0 4}$ & $\mathbf{2 0 0 5}$ & $\mathbf{2 0 0 6}$ & $\mathbf{2 0 0 7}$ & $\mathbf{2 0 0 8}$ & $\mathbf{2 0 0 9}$ & $\mathbf{2 0 1 0}$ & $\mathbf{2 0 1 1}$ & $\mathbf{2 0 1 2}$ & $\mathbf{2 0 1 3}$ & $\mathbf{2 0 1 4}$ \\
\hline \hline Presencial (\%) & 99,2 & 98,2 & 95,5 & 93,0 & 89,4 & 85,0 & 84,2 & 83,6 & 81,9 & 81,4 & 79,5 \\
\hline A Distância (\%) & 0,8 & 1,8 & 4,5 & 7,0 & 10,6 & 15,0 & 15,8 & 16,4 & 18,1 & 18,6 & 20,5 \\
\hline \hline
\end{tabular}

Ações de ensino em nível de graduação e pós-graduação nas áreas de ciências exatas e da saúde abordam, em geral, os temas fundamentais de cada área para a formação de qualidade dos futuros profissionais (PINTO et al., 2016). Cabe à universidade proporcionar, via cursos de extensão e pesquisa científica, um conjunto de conhecimentos aplicados que complementem e gerem um diferencial para a formação dos discentes. Estudos recentes têm demonstrado que um grande número de instituições de ensino superior tem implantado em suas grades curriculares a modalidade $\mathrm{EaD}$, para atender demandas de um novo mercado educacional. Com o desenvolvimento das metodologias de ensino e avaliação na modalidade $\mathrm{EaD}$, tem-se aberto a oportunidade de abordar temas tecnicamente mais complexos como, por exemplo, neurociências, teorias do direito, engenharias menos populares e Nanociência e Nanotecnologias.

\subsection{Ambiente Virtual de Aprendizagem (AVA): Plataforma Aprender}

A Plataforma Aprender é um AVA idealizada para apoiar os docentes e discentes nas atividades de ensino e aprendizagem nas disciplinas da UnB. Este recurso é utilizado pelos professores para disponibilizar conteúdos e ferramentas que permitem o acesso a um curso ou disciplina, facilitando a interação entre alunos, professores, tutores e monitores envolvidos no processo de ensino-aprendizagem. Esta Plataforma rompe os limites da sala de aula presencial, favorecendo e enriquecendo a formação dos estudantes e apoiando o acesso ao conhecimento (UNB, 2004).

A Diretoria de Ensino de Graduação a Distância (DEGD) é a atual responsável pelo suporte tecnológico aos usuários da Plataforma Aprender dentro das ofertas regulares de disciplinas dos cursos presenciais de graduação, extensão e pós-graduação da UnB. Vinculada ao Decanato de Ensino de Graduação (DEG), a DEGD desenvolve um trabalho colegiado na tomada de decisões no que diz respeito à Plataforma Aprender como ferramenta de apoio ao ensino e à pesquisa. O público-alvo da Plataforma Aprender é composto por: (i) alunos 
matriculados regulamente nos cursos presenciais da graduação, pós-graduação e/ou da extensão da UnB; e (ii) servidores públicos da UnB, enquanto alunos de cursos de formação/capacitação continuada (UNB, 2004).

No que se refere ao aspecto histórico, o acesso à Plataforma Aprender UnB foi disponibilizado aos seus usuários em abril de 2004, caracterizando-se como uma iniciativa que surgiu da demanda de professores, sendo alimentada pela rápida adesão dos alunos. Inicialmente, contou com o apoio do Departamento de Matemática, da Faculdade de Tecnologia do Instituto de Ciências Exatas e da Finatec para se consolidar; posteriormente, ainda em 2004 foi aberta à comunidade. De 2005 até o primeiro semestre de 2011, esteve sob a administração da Diretoria de Tecnologias de Apoio à de Aprendizagem e do Centro de Educação a Distância da Universidade de Brasília (CEAD-UnB). Já a partir do segundo semestre de 2011, a Plataforma Aprender está sob a administração da DEGD (UNB, 2004).

Desde então a equipe responsável por administrar a Plataforma Aprender realiza atualizações nas versões do Moodle de acordo com as necessidades tecnológicas e demandas dos docentes e discentes e, paralelamente, em 2013, foi disponibilizada à comunidade uma nova versão da Plataforma Aprender (Moodle 2.4). Já em 2015, houve atualização para versão do Moodle 2.7, a criação de uma política para melhor utilização do Aprender e o início das suas atividades com cerca de 2 mil cursos/disciplinas, com um valor que superou 33 mil registros de usuários cadastrados (UNB, 2004).

\subsection{Dificuldades e Oportunidades do Ensino EaD da Nanociência e Nanotecnologia}

Ações de ensino na modalidade EaD têm crescido consideravelmente em termos de expressividade. Porém, devido a um processo natural de desenvolvimento, o conjunto de ferramentas para a funcionalização e alguns dos seus principais pontos estratégicos ainda não foram discutidos com a profundidade necessária. Alguns pontos controversos na EaD, destacados a seguir, estão em processo de desenvolvimento e, principalmente, aprimoramento: (i) melhor modelo de gestão; (ii) avaliação de desempenho e aprendizagem; (iii) os provedores da tecnologia; (iv) a população-alvo dos cursos ofertados; (v) a formação e organização dos projetos pedagógicos; (vi) os métodos de avaliação de aprendizagem; (vii) o sistema de acompanhamento do aprendizado dos alunos; (viii) a formação dos professores; (ix) as diferentes metodologias utilizadas, entre outros (HOLANDA et al., 2015).

Com relação aos obstáculos enfrentados pelas instituições formadoras na oferta de ações de ensino EaD, em 2014, de acordo com 116 instituições, o maior obstáculo foi a 
evasão dos estudantes. A resistência dos educadores à modalidade $\mathrm{EaD}$, combinada aos desafios organizacionais de uma instituição presencial que passa a oferecer essa modalidade de educação, aparecem em segundo lugar, sendo consideradas obstáculos para 80 instituições. Em terceiro lugar aparecem os custos de produção dos cursos, apontados por 77 instituições como obstáculo (CHAN, 2014).

Os principais pontos positivos indicados, como aqueles que sustentam a utilização da modalidade EaD no ensino da "Nanociência e Nanotecnologia Aplicadas às Ciências da Saúde e Enfermagem", estão listados a seguir: (i) a flexibilidade de horário de realização do curso, o que permite que os estudantes e profissionais da saúde estejam sempre complementando a grade curricular e se reciclando; (ii) a facilidade de ajustar o tema com a metodologia $\mathrm{EaD}$ contribui para o desenvolvimento e aperfeiçoamento das áreas de Ciências da Saúde; (iii) novas contribuições técnico-científicas para a interface da temática acima citada; (iv) difusão de ambas as áreas e de sua interface; (v) desenvolvimento de metodologias mais eficazes e atrativas, informações sistemáticas e conclusivas para a área de EaD aplicadas às Ciências da Saúde; (vi) produção e aplicação de materiais didáticos de qualidade capazes de ampliar o espectro de conhecimento dos estudantes e profissionais da saúde e os estimule a manter a formação continuada; (vii) desenvolvimento de um produto final que possa ser caracterizado como um produto tecnológico passível de ser protegido intelectualmente; (viii) formação mais ampla, sólida, multidisciplinar e completa dos estudantes e profissionais das áreas das ciências da saúde; (ix) formação mais completa e ampla no quesito alta tecnologia aplicada ao tema; e (x) baixo custo por aluno (SOUZA et al., 2014).

Já os principais pontos negativos que demandam reflexões e aperfeiçoamentos na utilização da modalidade EaD no ensino da "Nanociência e Nanotecnologia Aplicadas às Ciências da Saúde e Enfermagem", estão indicados a seguir: (i) a temática anteriormente citada poderia ser trabalhada de forma mais construtiva se fosse utilizada aulas experimentais e aulas em campo, mas infelizmente tais tipos de intervenções ainda não são possíveis em cursos totalmente $\mathrm{EaD}$; (ii) a cultura de utilização de aulas presenciais ainda está muito enraizada nas metodologias de ensino; (iii) as metodologias EaD ainda são pouco atrativas para a área da saúde; (iv) a diversidade de formações da área de ciências da saúde dificulta desenvolver uma metodologia que seja atrativa para todos; (v) os processos avaliativos precisam ser aprimorados para se tornarem mais eficazes e conseguirem avaliar se o aluno está realmente aprendendo; (vi) o cenário atual vem passando por transformações a partir de um contexto de mudanças de valores, em que a postura do professor ainda está amparada na cultura da educação tradicional; (vii) existem áreas do país que não disponibilizam acesso à 
Internet e/ou a infraestrutura necessária de informática; (viii) baixa interação no ambiente $\mathrm{EaD}$ entre os aprendizes e professores tutores; e (ix) dificuldade dos aprendizes em serem os atores de formação do próprio conhecimento (SOUZA et al., 2014).

Como alternativas para atacar os principais pontos negativos, sugere-se que as metodologias semipresenciais sejam mais utilizadas, nas quais a parte presencial fosse destinada a discutir de forma resumida os principais pontos da temática em escopo, aulas experimentais e atividades em campo. Já no porte à distância do curso, poderiam estar previstas as discussões mais específicas via fórum, os estudos de caso e as leituras complementares. Do ponto de vista da relevância social, estudos e pesquisas sobre o ensino na modalidade $\mathrm{EaD}$ proporcionarão avanços nas reflexões e fundamentações de potencial utilização desta modalidade de educação na formação continuada e disseminação do conhecimento técnico na área de ciências da saúde. Assim, mesmo com os desafios, acreditase na $\mathrm{EaD}$ como modalidade de ensino-aprendizagem em novas perspectivas para área de saúde (KAKUSHI; ÉVORA, 2016).

Como apontam as reflexões, em um mundo conectado em redes, a educação a distância vem expandindo e ganhando robustez na sua utilização e, desse modo, essa tendência possibilita aos acadêmicos e profissionais da saúde buscarem conhecimentos e habilidades por meio de ambientes digitais de aprendizagem. O processo de ensino e aprendizagem na EaD é construído pelo próprio aluno, o que exige esforço e dedicação, e para isso ele conta com o professor como mediador desse processo, contribuindo para que a aprendizagem seja de fato eficaz. A satisfação e o prazer da aprendizagem vêm ao final do curso, quando o esforço do aluno é recompensado com o domínio do conhecimento e a aplicação, na prática, dos saberes adquiridos ao longo do processo. É importante alertar que a EaD flexibiliza o tempo e o local da aprendizagem, mas é necessária, para essa modalidade de ensino, uma dedicação séria aos estudos (ABED, 2015; HOLANDA et al., 2015). 


\section{$4^{\circ}$ CAPÍTULO - ABORDAGEM METODOLÓGICA}

Neste capítulo, estão descritos a abordagem metodológica e os aspectos éticos da coleta e análise dos dados. O trabalho exibe características de pesquisa aplicada, desenvolvida por meio de abordagens metodológicas qualitativas e quantitativas, podendo ser classificada como uma abordagem mista. A pesquisa de métodos mistos é definida por Creswell (2010) "como aquela que o investigador coleta e analisa os dados, integra abordagem isoladamente", que coleta e analisa tanto os dados qualitativos quanto os quantitativos de modo persuasivo e rigoroso, tendo por base a questão norteadora da pesquisa.

\subsection{Estudo de Natureza Comparativa}

Para levantar informações e realizar a construção das etapas deste trabalho, foi adotado estudo de natureza comparativa. Para os autores Lakatos e Marconi (2007), o método comparativo ocupa-se da busca por padrões sistêmicos, convergências e divergências de fenômenos entre dois ou mais grupos amostrais. Examina semelhanças e diferenças entre diversos tipos de grupos, não necessariamente de mesma natureza, contribuindo para uma melhor compreensão da relação e evolução temporal dos grupos. Neste método, o investigador procura determinar a causa ou a razão que justifique a existência de diferenças no comportamento ou condição de grupos de indivíduos ou espaços amostrais.

O método comparativo é usado tanto para comparações de grupos no presente, no passado, ou entre os existentes e os do passado, quanto entre sociedades de iguais ou de diferentes estágios de desenvolvimento. Centrado em estudar semelhanças e diferenças, nesse método o investigador procura determinar a causa ou a razão pela existência de diferenças no comportamento ou condição de grupos de indivíduos (LAKATOS; MARCONI, 2007).

\subsection{Projeto Piloto de 2013}

Em 2013/14, foi oferecida, a título de Projeto Piloto, a "1 ${ }^{a}$ Edição do Curso: Tópicos de Nanociência e Nanotecnologia Aplicadas às Ciências da Saúde". O curso foi ofertado para os alunos da UnB, tendo como público-alvo os discentes de graduação e pós-graduação. No total, foram ofertadas 50 vagas para a o curso, sendo que foram considerados aptos para a realização do curso um total de 30 alunos (60\%). As inscrições evidenciaram claramente o 
caráter multidisciplinar da iniciativa, uma vez que foram recebidas inscrições de alunos dos cursos de enfermagem, nutrição, biotecnologia, medicina, farmácia, farmácia industrial, entre outros cursos. O período de inscrição para o curso ocorreu de 01 a 23/09/2013, e os critérios de seleção foram por ordem dos inscritos e perfil do candidato por área e experiência prévia de atuação. As informações referentes às inscrições foram disponibilizadas no site do núcleo NESPROM (www.nesprom.unb.br).

O curso foi dividido em duas partes: a primeira parte do curso abordou do ponto de vista informativo e dos conceitos básicos a Nanociência e a Nanotecnologia Aplicadas às Ciências da Saúde; a segunda parte, destinada aos 30\% dos alunos com melhor desempenho e que demonstrassem interesse em realizá-la, foi selecionado um dos temas abordados no curso, para que fosse produzido um artigo de revisão bibliográfica destinado à publicação em jornal de considerável circulação ou revista classificada segundo os QUALIS/CAPES.

Realizando uma análise geral sobre o desenvolvimento e execução do curso de extensão proposto, salienta-se que os resultados obtidos foram muito bons, uma vez que todas as atividades propostas foram realizadas e o nível da resposta dos alunos foi de alta qualidade. Um fator a ser destacado foi a multidisciplinaridade das discussões realizadas nos fóruns do curso, oriunda dos diversos níveis e áreas de formação. Esta diversidade de áreas aportou uma grande riqueza às discussões fomentadas durante o curso.

Ao término do curso, apenas (17\%) dos alunos inscritos o concluíram satisfatoriamente. Associa-se esse baixo quantitativo de cursistas concluintes principalmente a três fatores: (i) a complexidade dos temas abordados no curso; (ii) grande fluxo de atividades propostas pelo curso, que visaram garantir a qualidade da formação dos cursistas; e principalmente (iii) a época do ano em que o curso foi realizado (entre outubro e dezembro). Como o curso só foi autorizado e iniciado na última semana de setembro/2013, não havia semanas extras e o calendário teve que ser executado sem alterações, coincidindo com o fechamento do semestre acadêmico.

Os resultados do Projeto Piloto foram apresentados na VII Reunión de Jóvenes Investigadores Iberoamericanos, realizada em Tordesilhas/Espanha. O título da apresentação foi "Desarrollo de una estrategia multidisciplinar de enseñanza/aprendizaje en nanociencia y nanotecnología aplicadas en la ciencia de la salud", e o trabalho foi premiado como um dos três melhores trabalhos da Jornada.

Um projeto mais amplo sobre a temática também teve seu mérito avaliado e aprovado na oportunidade da Chamada Universal - CNPq $n^{\circ} 14 / 2014$, com o Projeto de Pesquisa $n^{\circ}$ 449999/2014-9, intitulado "Nanociência e Nanotecnologia Aplicadas às Áreas das Ciências da 
Saúde e Enfermagem: desenvolvimento de metodologias multidisciplinares de ensino no ambiente EaD". O Projeto de Pesquisa esteve em vigência por oito meses, período entre a assinatura do Termo de Compromisso e o falecimento do proponente do Projeto, Prof. Emérito Dr. Elioenai Dornelles Alves (in memoriam).

\subsection{Principais Etapas de Desenvolvimento do Trabalho}

Para melhor sistematização das etapas experimentais e metodológicas realizadas para a execução deste trabalho, o item "Abordagem Metodológica" foi dividida em sete etapas:

\subsubsection{Etapa 1: Estudo Multidisciplinar e Seleção dos Módulos}

Foi realizado um estudo multidisciplinar do estado da arte na temática "Nanociência e Nanotecnologia e suas aplicações nas áreas de Ciências da Saúde e Enfermagem”, bem como um estudo integrativo sobre o tema educação a distância, sua evolução histórica e aprendizagem colaborativa. A interface entre a principal temática do trabalho $\mathrm{e}$ as especificidades da modalidade a distância foram investigadas e são consideradas essenciais para o sucesso da utilização da EaD no tema N\&N aplicadas às Ciências da Saúde. Os parágrafos a seguir apresentam as principais informações bibliográficas associadas aos estudos introdutórios:

Repositórios Científicos Consultados: O estudo do atual estado da arte apresentado neste trabalho foi realizado na base de dados da Capes, utilizando as fontes bibliográficas obtidas nos seguintes repositórios/bibliotecas científicas: (i) Web Of Science; (ii) SciELO; (iii) MEDLINE; (iv) Biblioteca Virtual em Saúde (BVS); (v) Literatura Latino-Americana e do Caribe em Ciências da Saúde (LILACS); (vi) OCHRANE; e (vii) PubMed.

Descritores Utilizados: Os descritores/palavras-chave foram selecionados visando a maior concordância pesquisa/escopo do estudo, sendo eles: (i) educação a distância; (ii) eficácia de ações de ensino; (iii) ensino da nanociência; (iv) ensino da nanotecnologia; e (v) aplicações em ciências da saúde e enfermagem. A busca foi realizada utilizando-se os descritores acima por meio dos operadores booleanos "AND” para relacionar as palavras (restringe o escopo da pesquisa) e/ou "OR" para somar as palavras (amplia o escopo da pesquisa). 
Estatística Bibliográfica: Para a composição deste estudo, foram selecionadas e analisadas 76 obras científicas (artigos científicos provenientes de periódicos nacionais e internacionais de considerável fator de impacto, teses e dissertações).

Critério de Seleção: O material bibliográfico encontrado a partir dos descritores técnicos mencionados anteriormente foi selecionado de acordo com os seguintes critérios: (i) relevância do tema e do conteúdo; (ii) qualidade técnica da pesquisa; (iii) atualidade do material bibliográfico, preferencialmente de 2010 a 2016; (iv) método e confiabilidade dos resultados; e (v) conclusões da pesquisa. Aqueles critérios que não contemplaram os de inclusão foram excluídos.

Sistematização da Informação: O material bibliográfico selecionado foi fichado segundo as normas de arquivologia, visando a organização, conservação e sistematização da informação. Durante a realização do fichamento, informações tais como ideia principal, contribuição científica aportada pelo estudo, autores, método, confiabilidade dos resultados e conclusões da pesquisa foram evidenciados e correlacionados.

Ao final, com base nas informações colhidas, foram selecionados seis temas que passaram a compor os seis módulos finalísticos do curso, acrescentando o Módulo 7 de avaliação.

Módulo 1 - Aspectos Gerais sobre Nanociência e Nanotecnologia;

Módulo 2 - Aplicações Consolidadas em Nanociência e Nanotecnologia;

Módulo 3 - Nanomateriais Projetados para Sistemas Tipo Drug-Delivery;

Módulo 4 - Nanociência Aplicada à Tecnologia do Câncer, Oncologia e Radiologia;

Módulo 5 - Nanomateriais Aplicados como Biomateriais e Nanobiossensores;

Módulo 6 - Perspectivas da Utilização de Nanobiomáquinas e Nanobaterias nas Ciências da Saúde; e

Módulo 7 - Avaliação Final.

\subsubsection{Etapa 2: Seleção Amostral e Recrutamento para as Três Ações de Ensino}

Com o intuito de selecionar uma amostra de alunos/cursistas estatisticamente expressiva para o estudo, foram inscritos gratuitamente no curso intitulado "Tópicos de Nanociência e Nanotecnologia Aplicados às Ciências da Saúde" 311 alunos, divididos em três turmas (A, B e C), e ainda formou uma grande lista de espera, para caso houvesse desistentes. No entanto, somente 230 alunos realizaram o cadastro na plataforma onde o curso foi disponibilizado e concretizaram o acesso. O período de inscrição ocorreu de 01/03/2015 a 
10/04/2015, e o critério de seleção foi por ordem de inscrição e perfil do candidato por área e experiência prévia de atuação. As informações referentes às inscrições foram disponibilizadas por meio de informativos e cartazes, e as inscrições foram efetivadas pelo preenchimento da Ficha padrão de inscrição do INTERFOCO, e posteriormente enviadas eletronicamente para o e-mail do curso: nanotecnologia.nesprom@gmail.com até o preenchimento total das vagas. $\mathrm{O}$ Anexo A mostra o folder encaminhado por e-mail e fixado nos murais da UnB para divulgação das ações de ensino.

O critério de distribuição dos alunos em cada turma foi o da homogeneidade. Para garantir a homogeneidade das turmas, o perfil dos inscritos foi mapeado e as três turmas foram divididas de acordo com o nível de formação, área de atuação e procedência; por exemplo, se havia 30 alunos de Enfermagem, cada turma recebeu 10 destes alunos. Assim, todas as turmas ficaram aproximadamente com o mesmo padrão.

Foram utilizados os seguintes critérios de inclusão: alunos de graduação e pósgraduação da UnB da área de ciências da saúde e enfermagem. No entanto, os interessados de áreas afins do conhecimento ou instituições de ensino similares às solicitações foram analisadas caso a caso. Como principais critérios de exclusão, não foram aceitos alunos inscritos fora do prazo, alunos não contemplados como critérios de inclusão e alunos inscritos que tivessem iniciado suas atividades no curso após o término do primeiro módulo.

As principais iniciativas de recrutamento foram por meio de cartazes em pontos de grande circulação, fácil visualização e acesso, nas instituições de ensino de nível superior de Brasília-DF, em específico na UnB, bem como a divulgação das ações de ensino via correio eletrônico, para as coordenações e secretarias de programas de graduação e pós-graduação, para ampliar o alcance e obter número expressivo de alunos. O conteúdo das informações contidas nos cartazes e e-mails estava relacionado ao número de vagas, público-alvo, período do curso, carga horária, certificação e investimento (gratuito).

\subsubsection{Etapa 3: Elaboração e Descrição da $1^{a}$ Ação de Ensino - Turma A}

Nesta etapa, baseado no estado da arte visto na Etapa 1, foi elaborada a $1^{\text {a }}$ Versão (Turma A) da Ação de Ensino de Nanociência e Nanotecnologia Aplicadas às Ciências da Saúde e Enfermagem, em que as principais estratégias didáticas foram baseadas em conteúdos escritos (artigos e textos informativos). Esta ação foi executada totalmente na modalidade EaD, na Plataforma Aprender da UnB, do ambiente MOODLE, na forma de curso de extensão de $42 \mathrm{~h}$ para alunos de graduação e pós-graduação da UnB, externos à UnB, profissionais da 
área de ciências da saúde e das agências reguladoras da Nanociência e Nanotecnologia, no período de 10/04/2015 a 30/06/2015. O acesso à plataforma pelos participantes inscritos no curso ocorreu pelo endereço www.aprender.unb.br. A Figura 9 (a) mostra imagem da página de acesso à Plataforma Aprender, enquanto a (b) mostra imagem da página de abertura do curso aplicado à Turma A.

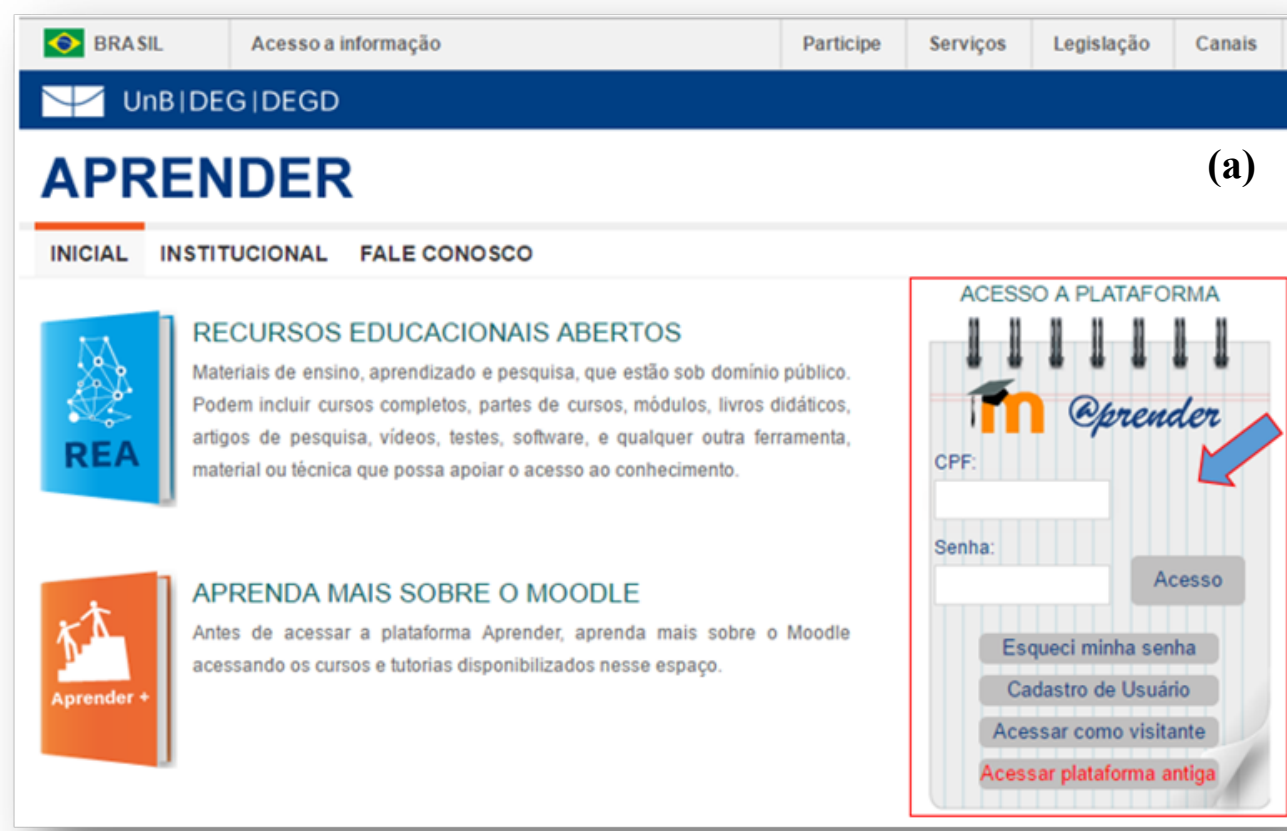

Tópicos de Nanociência e Nanotecnologia Aplicados as Ciências da Saúde (Turma A)

(b)

\begin{abstract}
Estimados Cursistas da Turma A,
Sejam bem vindos a $2^{\mathrm{a}}$ Edição do curso de extensão "Tópicos de Nanociência e Nanotecnologia Aplicados as Ciências da Saúde".

O objetivo principal deste curso é disponibilizar para a comunidade acadêmica uma ação de aprendizagem multidisciplinar $100 \% \mathrm{EaD}$ abordando os conceitos básicos da Nanociência $\mathrm{e}$ Nanotecnologia aplicadas as Ciências da Saúde.

A Nanociência e a Nanotecnologia são áreas emergentes da ciência com aplicações em praticamente todas as áreas do conhecimento e com potencial para revolucionar a tecnologia do século XXI. As aplicações em ciências da saúde vão desde o tratamento do câncer até a geraçăo de imagens de altissima qualidade.

Nosso curso é aberto a toda a comunidade (alunos de graduação e pós-graduação da UnB e de outras instituiçōes, vinculados as áreas afins do conhecimento) e as inscriçōes podem ser realizadas pelo email: nanotecnologia.nesprom@gmail.com

Você vai ficar de fora dessa?

Bom curso a todos!
\end{abstract}

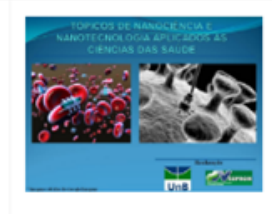

Professor. Felipe Bellucci Professor. Elioenai Dornelles Alves Professor. Jackeline Neres dos Santos

Figura 9. (a) Localização do menu Acesso à Plataforma Aprender. À direita da tela, o aluno acessa a plataforma informando o CPF e Senha. (b) Tela de abertura da ação de ensino 
aplicada aos alunos da Turma A, bem como mensagem de "Boas-vindas" e informações gerais sobre o curso: objetivo, breve contextualização da N\&N, entre outras.

Núcleo Comum: Além das principais estratégias didáticas citadas acima, utilizaramse também diversos recursos digitais comuns às três ações de ensino (Turmas $\mathrm{A}, \mathrm{B}$ e C), tais como: (i) ferramentas tecnológicas de comunicação; (ii) espaço destinado às "Boas-vindas" dos alunos (vídeos, slides utilizados no vídeo); (iii) espaço para o aluno expressar a utilidade do vídeo "se ele foi útil ou não"; (iv) espaço para o planejamento do curso, destinado para registros das principais informações do curso; (v) espaço denominado "fórum de notícias", destinado à postagem de informações relevantes sobre o tema; (vi) espaço chamado "sala do cafezinho", destinado a discussões de temas gerais; (vii) espaço da "NETIqueTA - Regras Básicas de Escrita para Educação a Distância”, no qual estão contidas algumas informações básicas de escritas para educação a distância; (viii) espaço destinado ao glossário de N\&N; (ix) espaço chamado "guia do módulo", para anunciar o passo a passo a ser executado em cada módulo; (x) vídeos de introdução para cada módulo; (xi) espaço de pesquisa de opinião, em que o aluno avalia a utilidade do vídeo de introdução do módulo em uma escala de 0 (totalmente inútil) a 10 (totalmente útil); (xii) espaço para atividade avaliativa do módulo, apresentado no conjunto de 10 questões de falso e verdadeiro sobre as atividades dos módulos; (xiii) item "vídeo de encerramento do curso"; (xix) enquete para avaliação de cada módulo, o aluno demonstra um grau de satisfação em uma escala de 0 (totalmente inútil) e 10 (totalmente útil); e (xx) espaço de retenção do conhecimento, destinado para o aluno testar o conhecimento em N\&N.

Durante o período do curso, algumas atividades foram realizadas pelo aluno, tais como: debates e discussões nos fóruns, leitura crítica de textos, realização de atividades e avaliações, e outros. O modelo acima corresponde a uma média de quatro horas de estudos semanais pelos participantes. Considerando as características individuais, alguns alunos levaram mais tempo que outros para desenvolver as atividades propostas. Além disso, as atividades assíncronas (fórum, trabalhos) puderam ser realizadas em qualquer hora e tempo, tendo em vista a característica de flexibilidade de horário dessa modalidade de educação. $\mathrm{O}$ curso também contou com a equipe de apoio de professores do NESPROM/UnB, quando necessário, no monitoramento do ambiente MOODLE, para avaliar o andamento do curso e auxiliar no seu desenvolvimento. Mesmo sendo um curso de extensão, totalmente $\mathrm{EaD}$, o aluno realizou atividades avaliativas disponíveis no próprio MOODLE. 
O espaço destinado para a retenção do conhecimento foi monitorado por meio de questionários aplicados aos alunos que concluíram satisfatoriamente o curso, com questões diversas sobre os temas abordados nos módulos nos períodos de 20,60 e 100 dias após a sua conclusão, que foram respondidas voluntariamente.

Núcleo Específico: A estratégia de ensino adotada para a Turma A foi baseada em conteúdos fundamentalmente escritos (POSSARI; NEDER, 2009). Os principais textos apresentados aos alunos, contendo os fundamentos de cada módulo, consistiram em artigos científicos com contribuições originais e de revisão, livros, reportagens, guias, manuais, estudos de casos e textos informativos, nacionais e internacionais, bem como imagens, gráficos, tabelas, fotografias essenciais para facilitar a compreensão do aluno em relação aos conteúdos propostos nos objetivos de cada módulo. Os textos de referência foram também classificados em "Leituras Obrigatórias", sendo a leitura imprescindível para o aluno realizar as atividades propostas, e os textos de "Leitura Complementar", caso o aluno desejasse aprofundar seus conhecimentos no tema. A seguir, alguns exemplos:

(i) Leituras Básicas (Obrigatórias): (a) Feynman, o profeta da nanotecnologia, Ciência Hoje; (b) Nanotecnologia: um estudo sobre seu histórico, definição e principais aplicações desta inovadora tecnologia; (c) Review - Nanobiotecnologia para Biomateriais; e (d) Book - Biomateriais An Introduction (Park);

(ii) Leituras para Aprofundamento (Complementares): (a) Transcrição da palestra de Feynman em 1959 (Plenty of Room at the Bottom); (b) Nanociência aplicada à tecnologia contra o câncer; (c) Drug delivery and transport to solid tumors; e (d) Livro sobre os INCTs de N\&N.

O material didático disponibilizado ao aluno durante o curso estava alinhado aos objetivos específicos de cada módulo, bem como ao objetivo curricular geral da ação de ensino. Nesse sentido, foram disponibilizados: cinco textos obrigatórios e quatro complementares para o Módulo 1; três textos obrigatórios e quatro complementares para o Módulo 2; três textos obrigatórios e três complementares Módulo 3; três textos obrigatórios e cinco complementares para o Módulo 4; seis textos obrigatórios e cinco complementares para o Módulo 5; e três textos obrigatórios e 10 complementares para o Módulo 6.

\subsubsection{Etapa 4: Elaboração e Descrição da $2^{a}$ Ação de Ensino - Turma B}

Nesta etapa, foi elaborada uma nova versão da Ação de Ensino (Turma B), baseada na utilização de vídeos das temáticas do curso. Essa versão também foi executada totalmente 
EaD na Plataforma Aprender da UnB do ambiente MOODLE, na forma de curso de extensão de $42 \mathrm{~h}$ para alunos de graduação e pós-graduação da $\mathrm{UnB}$, externos à UnB, profissionais da área de Ciências da Saúde e das agências reguladoras da Nanociência e Nanotecnologia, do período de 01/06/2015 a 20/08/2015. O acesso à plataforma, pelos participantes inscritos no curso, também ocorreu por meio do endereço www.aprender.unb.br. A Figura 10 mostra a imagem da página de abertura da ação de ensino, aplicada aos alunos da Turma B.

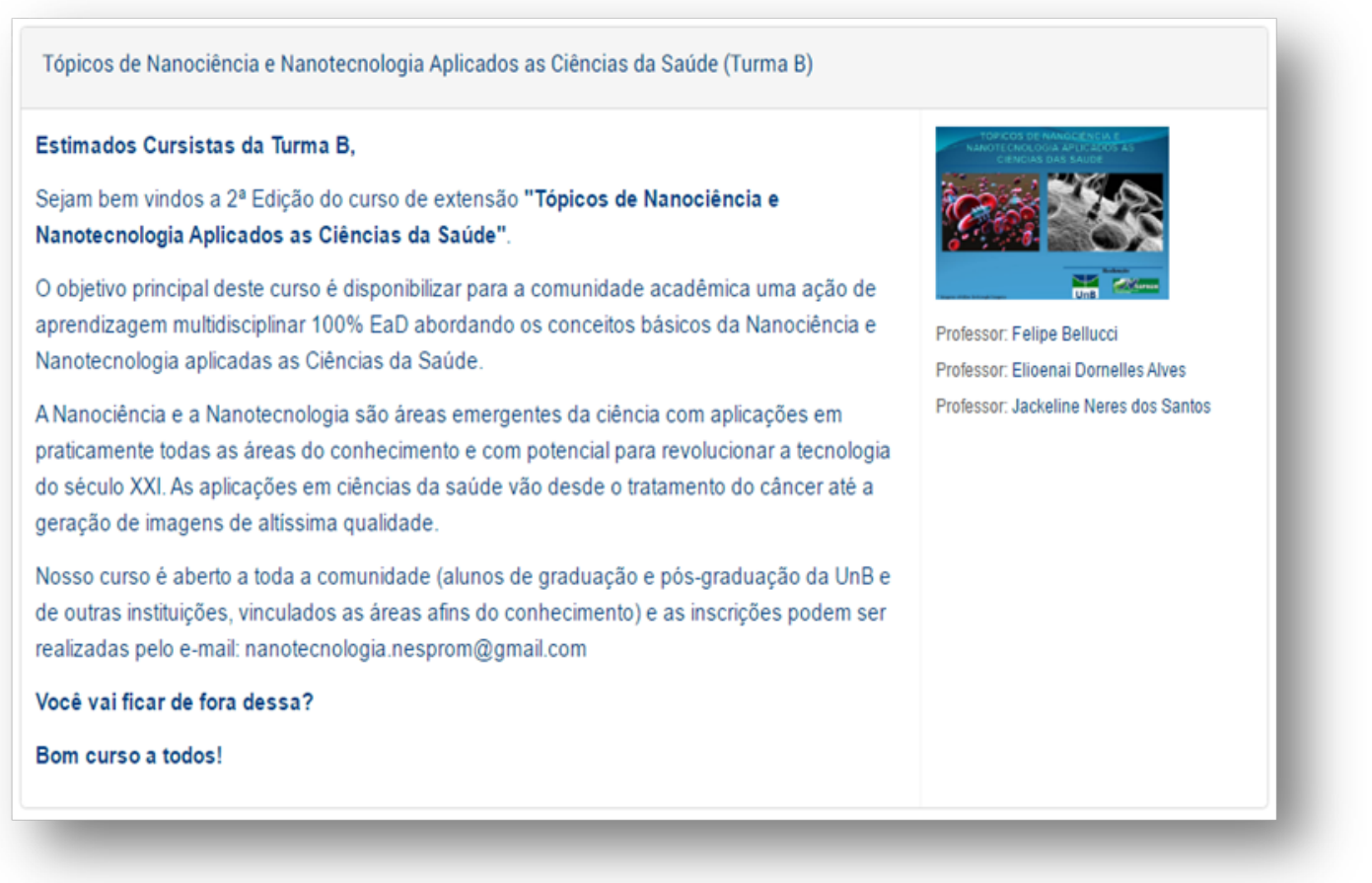

Figura 10. Tela de abertura da ação de ensino aplicada aos alunos da Turma B, bem como informações gerais sobre o curso.

Núcleo Comum: Mesmos conteúdos ministrados para a Turma A e descritos no item 4.3.3.

Núcleo Específico: A estratégia de ensino adotada para a Turma B foi baseada fundamentalmente na utilização de vídeos nas temáticas específicas de cada módulo do curso. Os vídeos consistiram em documentários, animações, simulações, entrevistas, palestras e reportagens, nacionais e internacionais. A qualidade técnico-científica de cada vídeo foi previamente analisada e atestada pela equipe do curso. Os vídeos em EaD são ferramentas dinâmicas de grande poder, que podem auxiliar no processo de ensino-aprendizagem do aluno, proporcionando caminho mais amigável de compreender, desenvolver e construir o conhecimento, bem como estimular a pesquisa, incentivar o compartilhamento de experiências, aprendizagem colaborativa e desenvolver competências individuais 
(OLIVEIRA, 2013). Os vídeos de referência foram extraídos, em geral, do site YouTube, que permitiu aos alunos terem o controle sobre o ritmo do vídeo, podendo pausá-lo, retrocedê-lo e avançá-lo, quando necessário. Os vídeos também foram classificados em "Vídeos Obrigatórios", no qual seu conteúdo era imprescindível para que o aluno conseguisse realizar as atividades, e os vídeos categorizados como "Vídeos Complementares", caso o aluno desejasse aprofundar seus conhecimentos na temática do módulo. A seguir, alguns exemplos:

$\begin{array}{llllll}\text { (i) Vídeos } & \text { Básicos } & \text { (Obrigatórios): } & \text { (a) } \mathrm{O} & \text { que é }\end{array}$ Nanotecnologia: https://www.youtube.com/watch?v=36WpkdUy9x4; (b) INCTs e MCTI Estudam Ações de Divulgação do Conhecimento: https://www.youtube.com/watch?v=Bb3CQlbtuew; (c) Nanotecnologia e Suas Aplicações: https://www.youtube.com/watch?v=DMPAnD1Evow; e (d) Nanotecnologia Contra o Câncer: https://www.youtube.com/watch?v=ZOUSy7Nn8Sw.

(ii) Vídeos para Aprofundamento (Complementares): (a) Nanomedicine: nanotechnology for cancer treatment: https://www.youtube.com/watch?v=kxSX6YJTS2I; (b) Biomaterial para Acelerar la Recuperación de Traumas Óseos: https://www.youtube.com/watch?v=_oWzw5oOTPI; (c) Instructive Supramolecar $\begin{array}{llllll}\text { Scaffolds } & \text { for } & \text { In } & \text { Situ } & \text { Cardiovascular } & \text { Tissue }\end{array}$ Engineering: https://www.youtube.com/watch?v=HU pgHlWsdc; e (d) Pesquisa da Nasa revolucionará a medicina no mundo, nanotecnologia: https://www.youtube.com/watch?v=X_M1kT7vKAg.

Para compreender e internalizar a temática do curso, diversas atividades com vídeos foram disponibilizadas em cada módulo. Nesse sentido, foram disponibilizados: cinco vídeos obrigatórios e três complementares para o Módulo 1; oito vídeos obrigatórios e quatro complementares para o Módulo 2; cinco vídeos obrigatórios e dois complementares para o Módulo 3; quatro vídeos obrigatórios e dois complementares para o Módulo 4; cinco vídeos obrigatórios e cinco complementares para o Módulo 5; e seis vídeos obrigatórios e três complementares para o Módulo 6.

\subsubsection{Etapa 5: Elaboração e Descrição da $2^{a}$ Ação de Ensino - Turma C}

Foi elaborada, nesta etapa, uma nova e última versão da Ação de Ensino (Turma C), baseada na utilização de aulas expositivas sobre as temáticas do curso. Esta versão também foi executada totalmente EaD no ambiente MOODLE, por meio da Plataforma Aprender da UnB, na forma de curso de extensão de $42 \mathrm{~h}$ para alunos de graduação e pós-graduação da 
UnB, externos à UnB, profissionais da área de ciências da saúde e das agências reguladoras da nanociência e nanotecnologia, no período de 01/08/2015 a 20/10/2015. O acesso à plataforma, pelos alunos inscritos no curso, também ocorreu pelo do endereço www.aprender.unb.br. A Figura 11 mostra imagem da página de abertura da ação de ensino aplicada aos alunos da Turma C.

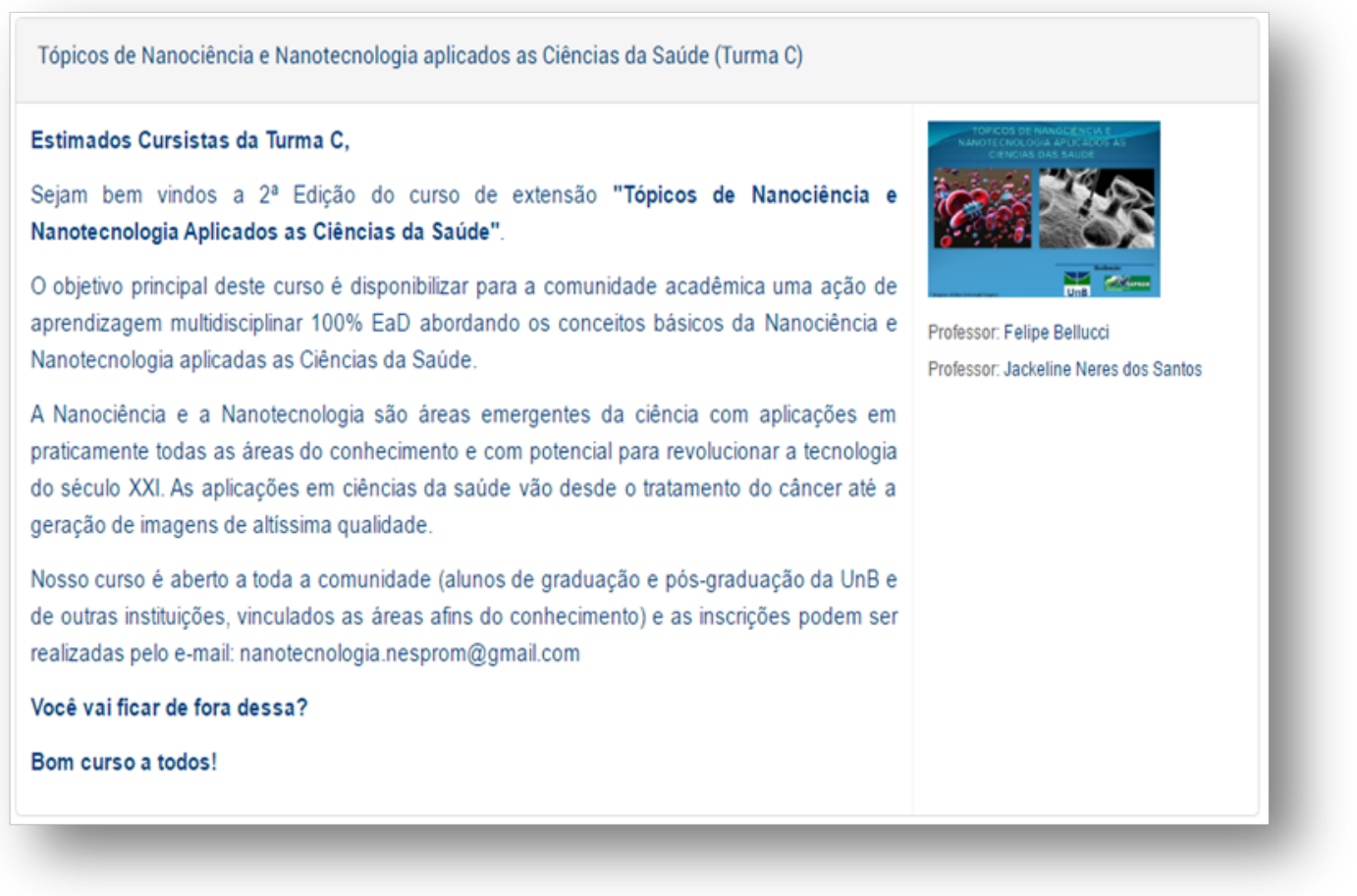

Figura 11. Tela de abertura da ação de ensino aplicada aos alunos da Turma $\mathrm{C}$, bem como informações gerais sobre o curso.

Núcleo Comum: Mesmos conteúdos ministrados para a Turma A e descritos no item 4.3.3.

Núcleo Específico: A estratégia de ensino adotada para a Turma C foi baseada fundamentalmente na utilização de aulas expositivas, utilizando recursos de apresentação, filmadas e disponibilizadas aos alunos, sobre a temática do curso (OLIVEIRA; STADLER, 2014). As videoaulas utilizadas consistiram na apresentação de um dos professores do curso, abordando os principais conteúdos de cada módulo. Simulando uma aula expositiva tradicional, o professor introduziu o tema aos alunos e, sempre que possível, ilustrou os conceitos de forma prática, contextualizada e, quando pertinente, relacionando o conceito com alguma situação vivenciada no cotidiano profissional. O processo de produção das videoaulas teve como referência o conteúdo programático do curso e planos pedagógicos de cada módulo. As videoaulas apresentaram características específicas, a saber: (i) duração máxima 
de 30 minutos para cada videoaula, com o intuito de manter a máxima atenção do aluno nos conceitos-chave relacionados ao módulo; (ii) recursos audiovisuais como imagens, esquemas, organogramas e similares, com o objetivo de apresentar o conteúdo de forma mais didática e atrativa aos alunos; e (iii) maior articulação entre os conceitos, práticas e subsunçores associados ao tema dos módulos para tornar o processo de aprendizagem mais efetivo. Nesta ação de ensino, todas as videoaulas foram classificadas como "Videoaulas Obrigatórias", nas quais seu conteúdo era imprescindível para o aluno realizar as atividades do módulo. A seguir, alguns exemplos:

(i) Videoaulas

(Obrigatórias):

(a) https://youtu.be/ODW5oGEkaTY;

https://youtu.be/V-SbiZjbh_A;

https://youtu.be/wShx71mJrwQ;

https://youtu.be/RU9PYHZb6-c; e (d) https://youtu.be/-6wpEp0dLIk.

A fim de transmitir o conteúdo em um curto período de tempo e estimular a compreensão do aluno sobre a temática do curso, várias atividades utilizando aulas expositivas à distância foram disponibilizadas em cada módulo. Nesse sentido, foram disponibilizados: uma videoaula para o Módulo 1; uma videoaula para o Módulo 2; uma videoaula para o Módulo 3; uma videoaula para o Módulo 4; uma videoaula para o Módulo 5; uma videoaula para o Módulo 6.

\subsubsection{Etapa 6: Variáveis Analisadas no Estudo Comparativo}

Ao término das três ações de ensino foi realizada uma comparação de parâmetros, dos seus valores característicos e da influência da variação destes no processo de ensinoaprendizagem dos alunos. A seguir, uma breve descrição sobre os parâmetros analisados:

(i) Análise do Público-alvo Atingido pelas Ações: Neste item, foi analisada a origem e o perfil educacional dos alunos que demonstraram interesse em participar das ações de ensino. A classificação foi realizada entre: alunos provenientes, não provenientes da UnB e profissionais; alunos de graduação, mestrado, doutorado; e cursista proveniente de áreas das Ciências da Saúde e afins;

(ii) Análise dos Parâmetros Índices de Sucesso, Insucesso e Evasão: Neste item, foram analisados os fatores que influenciam na eficácia da aplicação do curso;

(iii) Estratificação dos Índices de Sucesso e Insucesso: Neste item, foi analisado o processo de aprendizagem obtido pelos alunos aprovados e não aprovados nas ações de ensino por meio da estratificação das menções; 
(iv) Correlação dos Î́ndices com a Origem dos Cursistas: Neste item, foi analisada a correlação dos índices de sucesso ou aprovados, insucesso ou não aprovados e evasão com a origem dos cursistas, por procedência, nível de formação e área de atuação;

\section{(v) Análise dos Parâmetros "Percepção Média sobre o Curso" e "Percepção} sobre os Módulos" e "Avaliação Final do Curso": Neste item, foram analisados os parâmetros acima citados, referentes à média das avaliações de percepção realizadas pelos alunos ao final de cada módulo, e a média das notas dos alunos na avaliação final do curso, respectivamente;

(vi) Análise do Parâmetro "Retenção do Conhecimento": Neste item foi estimada a efetividade da retenção dos conteúdos abordados nas ações de ensino, visando quantificar o nível de aprendizagem significativa dos alunos.

\subsubsection{Etapa 7: Reflexões, Discussões e Conclusões Finais}

Análise, comparação, reflexão e discussão acerca dos resultados obtidos durante o desenvolvimento e aplicação das três ações de ensino (Turmas A, B e C), na modalidade totalmente a distância, com a finalidade de inferir sobre a eficácia de cada uma das ações.

A Figura 12 mostra um organograma das principais etapas desenvolvidas no trabalho desde o estudo multidisciplinar do Estado da Arte (Etapa 1) até as conclusões finais (Etapa 7).

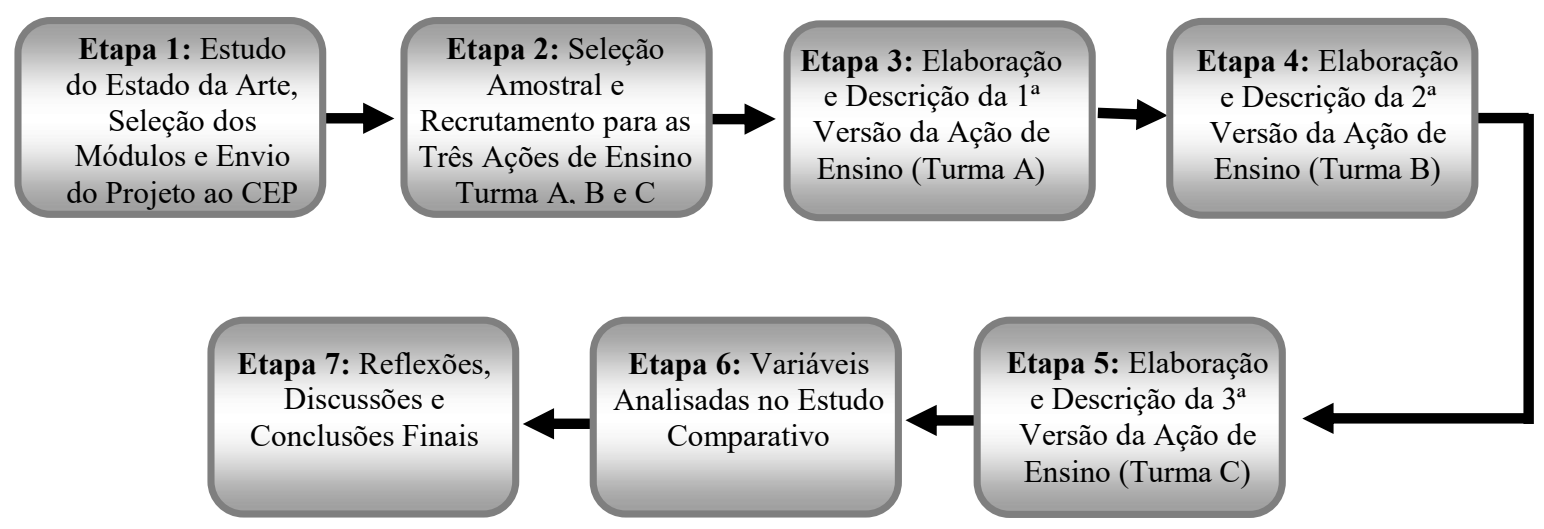

Figura 12. Organograma simplificado das principais etapas executadas no trabalho.

\subsection{Sistema de Menções da Universidade de Brasília}

Com o objetivo de facilitar o entendimento de leitores não familiarizados com o sistema de menções da UnB, registra-se que: (i) SS - Superior (9,0 a 10,0); (ii) MS - Médio 
superior (7,0 a 8,9); (iii) MM - Médio (5,0 a 6,9); (iv) MI - Médio inferior (3,0 a 4,9); (v) II Inferior (0,1 a 2,9); (vi) SR - Sem rendimento (zero). As menções para aprovação são SS, MS e MM, enquanto que as menções MI, II referem-se aos não aprovados e, por último, a menção SR é atribuída à reprovação por faltas, quando o aluno não compareceu ao mínimo de $75 \%$ das aulas. Para efeitos de aprovação nas ações de ensino empreendidas neste trabalho, consideraram-se como menções mínimas para aprovação SS e MS e, por consequência, as menções MM, MI, II e SR como menções insuficientes para aprovação.

\subsection{Considerações Éticas da Pesquisa}

Procedimentos e Aspectos Éticos em Pesquisas com Seres Humanos: O Projeto de Pesquisa da Dissertação obteve aprovação do Comitê de Ética em Pesquisa da Faculdade de Saúde da Universidade de Brasília (CEP-FS/UnB), conforme previsto na Resolução do Conselho Nacional de Saúde (CNS) n 466/2012 e suas complementares, sob o Número do Comprovante: $010355 / 2015$ e o identificador do projeto CAAE $\mathrm{n}^{\circ} 41860815.0 .0000 .0030$ (Anexo B). A proposta de submissão foi inserida na base nacional e unificada de registros de pesquisas envolvendo seres humanos para todo o sistema CEP/CONEP, denominado Sistema Plataforma Brasil, para apreciação do CEP-FS/UnB, na qual foram ressaltadas as principais informações da pesquisa:

Critério de Inclusão: Como critério de inclusão, os alunos matriculados no curso de extensão foram convidados a colaborar com a pesquisa sem a utilização de dados pessoais, apenas informações numéricas do curso para a melhor compreensão do processo de ensinoaprendizagem no tema. Antes de iniciarem a pesquisa, os cursistas acessaram a sala virtual em que estava acessível o Termo de Consentimento Livre e Esclarecido (TCLE) online (Anexo C), disponível por meio de um questionário online, configurado da seguinte forma: o participante da pesquisa, ao acessar a ferramenta, visualizou o TCLE com opção de aceite ou não aceite de sua participação de forma voluntária, ficando resguardado o IP do participante na ferramenta de auditoria presente no Ambiente Virtual de Aprendizagem MOODLE, assim como suas respostas na plataforma, sendo garantido o sigilo e restrito à sua participação. $\mathrm{O}$ TCLE foi redigido em forma de convite, obedecendo todos os parâmetros da Resolução CNS no $466 / 2012$.

Riscos: Os riscos decorrentes da participação na pesquisa estão associados à complexidade e multidisciplinaridade do tema, o que demanda do cursista estudos paralelos em temas fora de sua área de formação, tornando a conclusão do curso um grande desafio. 
Uma vez que o curso de extensão é totalmente $\mathrm{EaD}$, há o risco associado à não administração adequada do tempo, o que pode comprometer a concentração e a conclusão de atividades em tempo hábil ao longo do curso. Para minimizar os riscos, foram disponibilizadas leituras complementares de temas correlatos, tutoriais e tutorias e mensagens de reforço de datas e monitoramento de frequência de acesso dos alunos.

Benefícios: Contribuição para o avanço das áreas de tecnologias didáticas de ensino da Nanociência e Nanotecnologia aplicadas às ciências da saúde e enfermagem, na modalidade de educação a distância. 


\section{$5^{\circ}$ CAPÍtULO - ESTUdO COMPARATIVO ENTRE AS AÇÕES DE ENSINO}

Os principais resultados técnico-científicos se concentraram nos itens: (i) Seleção do Tema dos Módulos; (ii) Análise do Público-alvo Atingido pelas Ações; (iii) Análise dos Parâmetros Índices de Sucesso, Insucesso e Evasão; (iv) Estratificação dos Índices de Sucesso e Insucesso; (v) Correlação dos Índices com a Origem dos Cursistas; (vi) Análise dos Parâmetros "Percepção Média sobre o Curso" e "Percepção sobre os Módulos" e "Avaliação Final do Curso"; e (vii) Análise do Parâmetro "Retenção do Conhecimento". Tais itens visam estimar ou comparar a eficácia entre diferentes estratégias de ensino $\mathrm{EaD}$ de tópicos de Nanociência e Nanotecnologia aplicadas às Ciências da Saúde e Enfermagem, bem como identificar e refletir quais parâmetros e motivações são determinantes ou afetam a eficácia.

\subsection{Seleção do Tema dos Módulos}

Com base nas características específicas da educação a distância, foi realizada uma busca dos temas considerados com maior potencial de interesse pelos acadêmicos e profissionais da saúde na formação continuada. Foi levantado um conjunto de 12 temas, tais como: (i) Aspectos gerais sobre nanociência e nanotecnologia e suas aplicações já consolidadas nas ciências da saúde; (ii) Sistemas tradicionais aplicados em ciências da saúde; (iii) Nanomateriais projetados para sistemas tipo Drug-Delivery; (iv) Nanociência aplicada à tecnologia contra o câncer; (v) Nanomateriais aplicados como biomateriais; (vi) Nanotecnologia aplicada à oncologia e radiologia; (vii) Perspectivas da utilização de nanobiomáquinas nas ciências da saúde; (viii) Nanobaterias; (ix) Aplicação de nanomateriais na área alimentícia e perigos da aplicação; (x) Utilização de nanomateriais para a saúde; (xii) Aplicação na área de cosméticos.

Ao final, com base nas buscas sobre temas de maior potencial e interesse para a área, considerados também que melhor se ajustam ao ensino na modalidade de educação a distância, foram selecionados os seis temas mais relevantes que passaram a compor os seis módulos finalísticos do curso, acrescentado do Módulo 7 de avaliação, a seguir:

\section{Espaço de Ambientação e Apresentação}

Descrição: Espaço destinado às "Boas-vindas" e Apresentação dos alunos (vídeo, slides utilizados no vídeo, planejamento do curso, glossário, fóruns, entre outros), ferramentas 
que proporcionam de maneira prática a exploração do AVA mediada pelas tecnologias digitais.

Justificativa: A ambientação e apresentação proporcionam ao aluno reconhecer os atores envolvidos no processo de ensino-aprendizagem, professores, tutores e suporte técnico, fazendo com que o aluno tenha visão pontual de como e a quem recorrer em seu curso, de acordo com suas necessidades, técnicas ou pedagógicas.

A Figura 13 mostra a interface de Ambientação e Apresentação da primeira Ação de Ensino.

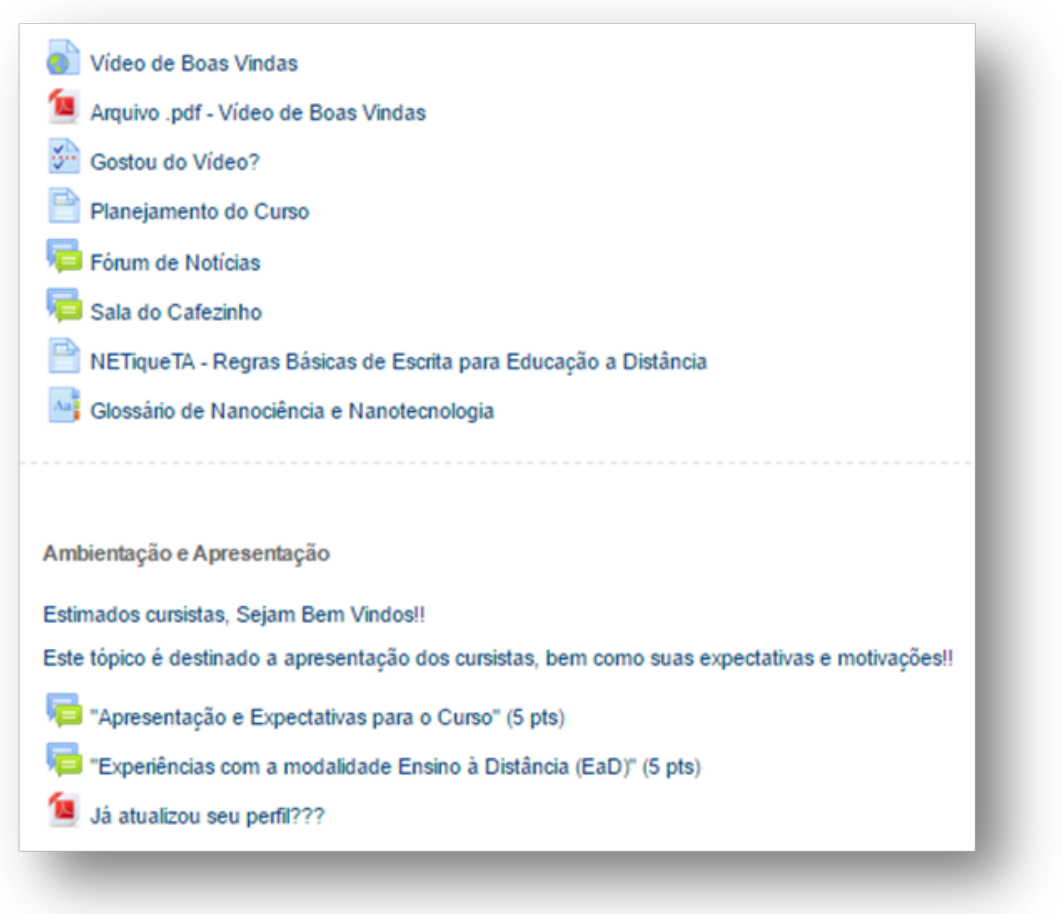

Figura 13. Interface da Ambientação e Apresentação da Ação de Ensino aplicada à Turma $A$, acompanhada de recursos e atividades pedagógicas disponibilizados no ambiente Aprender UnB, a saber: (i) vídeo de "Boas-vindas"; (ii) planejamento do curso; (iii) fórum de notícias; (iv) sala do cafezinho; (v) glossário; entre outros.

\section{Módulo 1 - Aspectos Gerais sobre Nanociência e Nanotecnologia}

Descrição: Nesse módulo, foram apresentados e discutidos os conceitos básicos sobre N\&N (o que é e suas diferenças), concepções espontâneas sobre "nano", palestra de Richard Feynman e áreas de aplicações já consolidadas nas ciências da saúde.

Justificativa: Os tópicos foram selecionados para o aluno conhecer o que é N\&N e suas diferenças, ter clara a escala métrica que relaciona diversos objetos e suas respectivas 
dimensões, bem como conhecer algumas aplicações já bem desenvolvidas da N\&N aplicadas às Ciências da Saúde.

A Figura 14 mostra o sumário do Módulo 1 - Aspectos Gerais sobre Nanociência e Nanotecnologia da primeira Ação de Ensino.

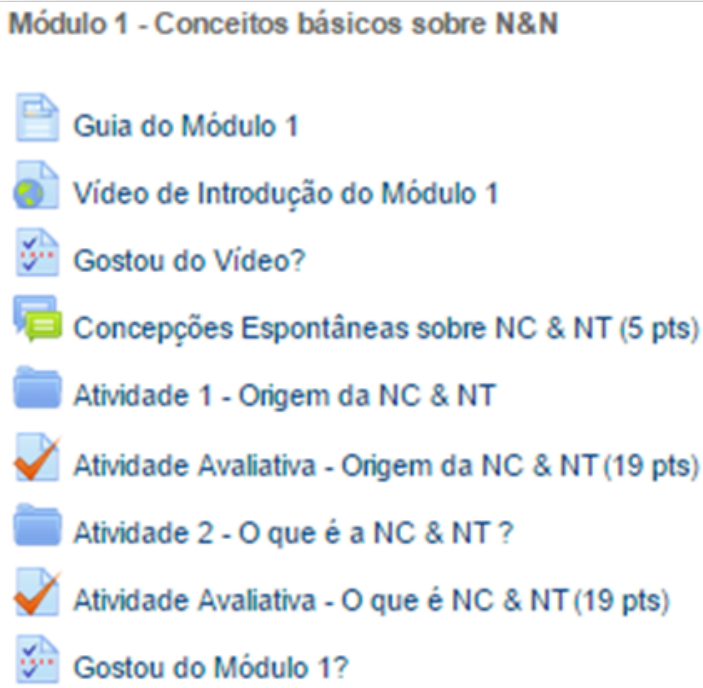

Figura 14. Interface do Módulo 1 da Ação de Ensino aplicada à Turma $A$, acompanhada de recursos e atividades pedagógicas disponibilizados, a saber: (i) guia do módulo; (ii) vídeo de introdução do módulo; (iii) fórum; (iv) leituras obrigatórias e complementares; (iv) atividade avaliativa; entre outros.

\section{Módulo 2 - Aplicações Consolidadas em Nanociência e Nanotecnologia}

Descrição: Nesse módulo, foram apresentados e discutidos os conceitos básicos sobre as propriedades intrínsecas da matéria quando se altera a escala de tamanho analisada, bem como a principal política pública brasileira para a área de nanotecnologia e suas aplicações tradicionais.

Justificativa: Os tópicos foram selecionados para o aluno compreender a sutileza de alteração das propriedades intrínsecas da matéria quando se altera a escala de tamanho, conhecer a principal política pública brasileira para o desenvolvimento da nanotecnologia no Brasil, bem como conhecer as principais aplicações atuais da $\mathrm{N} \& \mathrm{~N}$.

A Figura 15 mostra o sumário do Módulo 2 - Aplicações Consolidadas em Nanociência e Nanotecnologia da primeira Ação de Ensino. 


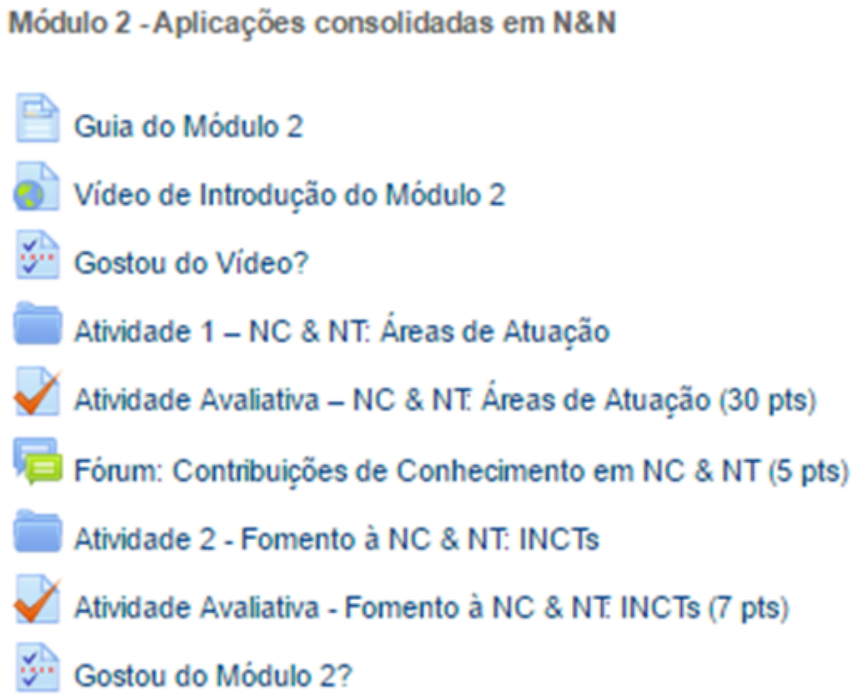

Figura 15. Interface do Módulo 2 da Ação de Ensino aplicada à Turma A. Acompanhada de recursos e atividades pedagógicas disponibilizados, a seguir: (i) guia do módulo; (ii) vídeo de introdução do módulo; (iii) fórum; (iv) leituras obrigatórias e complementares; (iv) atividade avaliativa; entre outros.

\section{Módulo 3 - Nanomateriais Projetados para Sistemas Tipo Drug-Delivery}

Descrição: Nesse módulo, foram apresentados e discutidos os conceitos básicos associados aos sistemas tipo Drug-Delivery, suas correlações com a nanotecnologia, aplicações em ciências da saúde e os principais desafios para a área.

Justificativa: Os tópicos foram selecionados para o aluno entender o que são os sistemas tipo Drug Delivery e suas principais partes, conhecer algumas aplicações para os sistemas tipo Drug Delivery nas áreas de Ciências da Saúde, bem como compreender as relações pré-existentes entre os sistemas tipo Drug-Delivery e a nanotecnologia.

A Figura 16 mostra o sumário do Módulo 3 - Nanomateriais Projetados para Sistemas Tipo Drug-Delivery da primeira Ação de Ensino. 
Módulo 3 - Sistemas tipo Drug-Delivery

Guia do Módulo 3

Vídeo de Introdução do Módulo 3

Gostou do Video?

Atividade 1 - Sistemas Tipo Drug Delivery

Atividade Avaliativa - Sistemas Tipo Drug Delivery (34 pts)

Wiki - Sistemas tipo Drug-Delivery (8 pts)

Gostou do Módulo 3?

Figura 16. Interface do Módulo 3 da Ação de Ensino aplicada à Turma $A$, acompanhada de recursos e atividades pedagógicas disponibilizados, a saber: (i) guia do módulo; (ii) vídeo de introdução do módulo; (iii) leituras obrigatórias e complementares; (iv) atividade avaliativa; (v) wiki; entre outros.

\section{Módulo 4 - Nanociência Aplicada à Tecnologia do Câncer, Oncologia e}

\section{Radiologia}

Descrição: Nesse módulo, foram apresentados e discutidos conceitos associados às principais linhas de ação da N\&N aplicadas contra o câncer. Itens como vetorização de medicamentos, hipertermia magnética e geração de imagens utilizando nanomateriais.

Justificativa: Os tópicos foram selecionados para o aluno compreender as principais linhas de atuação da N\&N no combate ao câncer, entender os principais conceitos e princípios associados aos processos de vetorização de medicamentos, hipertermia magnética e geração de imagens, bem como conhecer os principais desafios associados à área da N\&N aplicadas no combate ao câncer.

A Figura 17 mostra o sumário do Módulo 4 - Nanociência Aplicada à Tecnologia do Câncer, Oncologia e Radiologia da primeira Ação de Ensino. 


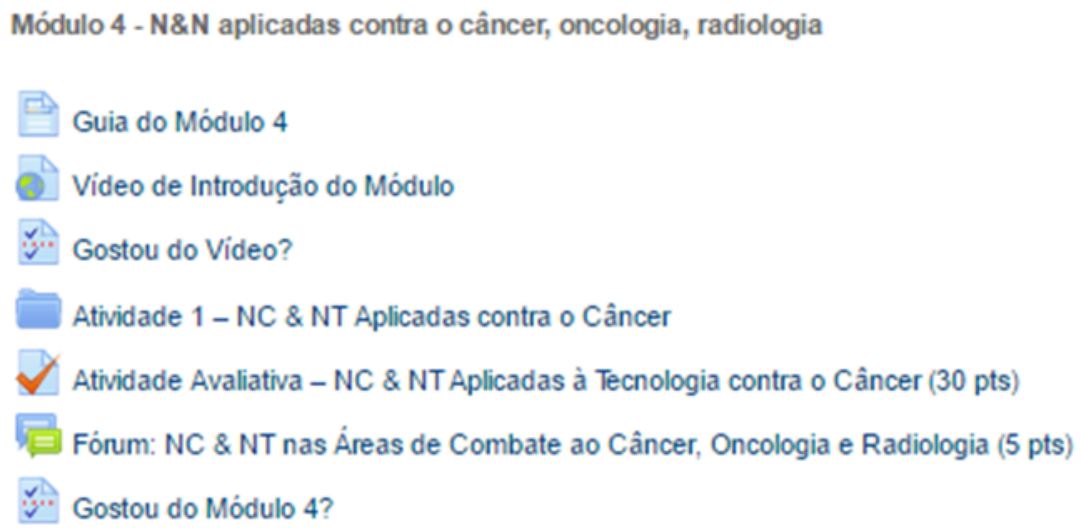

Figura 17. Interface do Módulo 4 da Ação de Ensino aplicada à Turma $A$, acompanhada de recursos e atividades pedagógicas disponibilizados, a saber (i) guia do módulo; (ii) vídeo de introdução do módulo; (iii) fórum; (iv) leituras obrigatórias e complementares; (iv) atividade avaliativa; entre outros.

\section{Módulo 5 - Nanomateriais Aplicados como Biomateriais e Nanobiossensores}

Descrição: Nesse módulo, foram apresentados e discutidos os conceitos básicos relacionados aos biomateriais e nanobiossensores, o que inclui: histórico, definições, normatização, desafios, princípios de funcionamento, principais características e tipos disponíveis no mercado.

Justificativa: Os tópicos foram selecionados para o aluno compreender os conceitos de biomateriais e nanobiossensores, incluindo histórico, definições, normatização e desafios da área, bem como conhecer os principais biomateriais e nanobiossensores e suas principais partes constituintes.

A Figura 18 mostra o sumário do Módulo 5 - Nanomateriais Aplicados como Biomateriais e Nanobiossensores da primeira Ação de Ensino. 


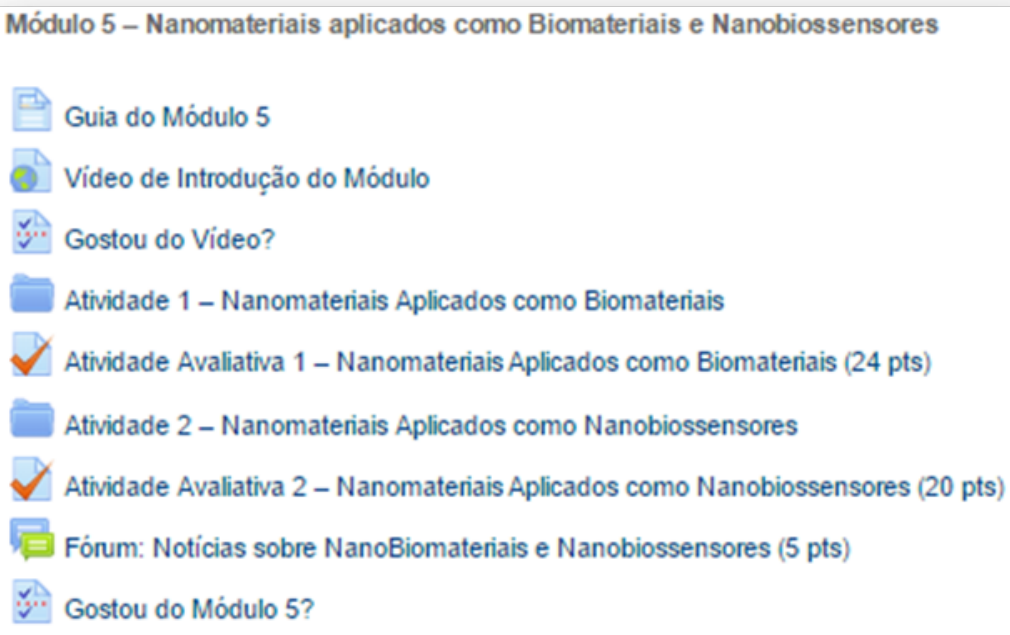

Figura 18. Interface do Módulo 5 da Ação de Ensino aplicada à Turma $A$, acompanhada de recursos e atividades pedagógicas disponibilizados, a saber: (i) guia do módulo; (ii) vídeo de introdução do módulo; (iii) fórum; (iv) leituras obrigatórias e complementares; (iv) atividade avaliativa; entre outros.

\section{Módulo 6 - Perspectivas da Utilização de Nanobiomáquinas e Nanobaterias nas}

\section{Ciências da Saúde}

Descrição: Nesse módulo, foram apresentados e discutidos os conceitos básicos sobre as nanobiomáquinas e nanobaterias, bem como discutido o atual estado da arte no tema.

Justificativa: Compreender os principais conceitos relacionados ao tema das nanobiomáquinas e nanobaterias utilizadas no âmbito das ciências da saúde, conhecer o atual estado da arte sobre o tema com ênfase no que já é realidade e o que se almeja para o futuro, bem como desenvolver questões e respostas relacionadas ao tema do módulo sobre pontos de interesse e aqueles nos quais se deseja obter mais informações.

A Figura 19 mostra o sumário do Módulo 6 - Perspectivas da Utilização de Nanobiomáquinas e Nanobaterias nas Ciências da Saúde da primeira Ação de Ensino. 


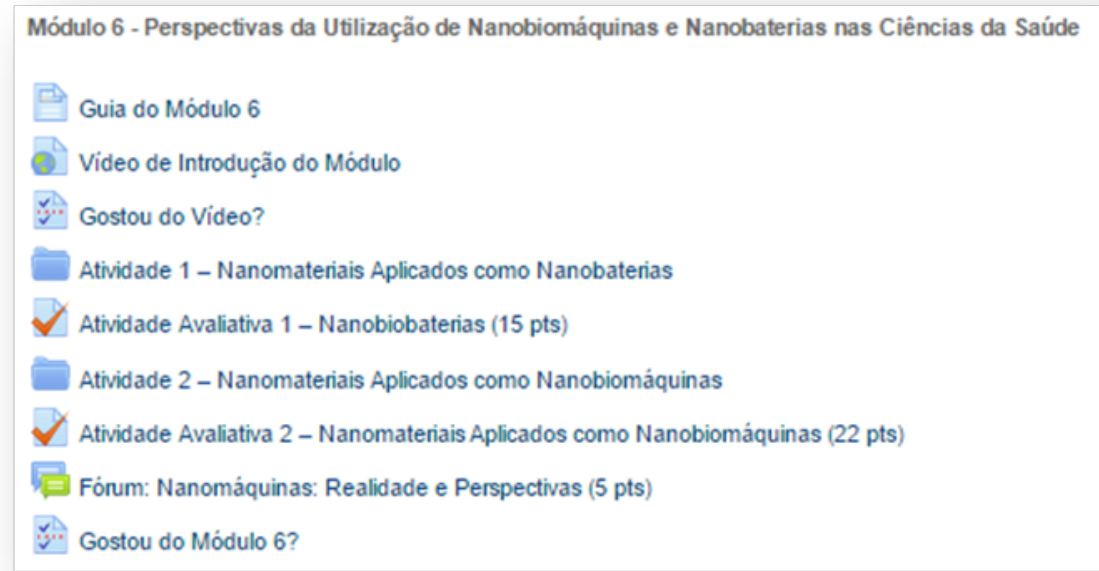

Figura 19. Interface do Módulo 6 da Ação de Ensino aplicada à Turma $A$, acompanhada de recursos e atividades pedagógicas disponibilizados, a saber: (i) guia do módulo; (ii) vídeo de introdução do módulo; (iii) fórum; (iv) leituras obrigatórias e complementares; (iv) atividade avaliativa; entre outros.

\section{Módulo 7 - Avaliação Final}

Descrição: Esse módulo foi destinado à "Avaliação Final" dos alunos do curso “Tópicos de Nanociência e Nanotecnologia Aplicados às Ciências da Saúde e Enfermagem”.

Justificativa: Responder um questionário com perguntas de "falso ou verdadeiro" sobre o tema dos módulos estudados.

A Figura 20 mostra o sumário do Módulo 7 - Avaliação Final da primeira Ação de Ensino.

\section{Módulo 7 -Avaliação final \\ Guia do Módulo 7 \\ Vídeo de Introdução do Módulo \\ Gostou do Video? \\ Atividade Avaliativa Final (72 pts) \\ Gostou do Módulo 7?}

Figura 20. Interface do Módulo 7 da Ação de Ensino aplicada à Turma A, acompanhada de recursos e atividades pedagógicas disponibilizados, a saber: (i) guia do módulo; (ii) vídeo de introdução do módulo; (iii) atividade avaliativa final; entre outros. 


\subsection{Análise do Público-alvo Atingido pelas Ações}

A Figura 21 mostra a distribuição dos alunos inscritos no curso "Tópicos de Nanociência e Nanotecnologia Aplicados às Ciências da Saúde" por procedência, nível de formação e área de atuação, enquanto a Tabela 4 lista o quantitativo percentual vinculado à distribuição. Como esperado, as colunas vinculadas à graduação se destacam das demais em ambas as procedências.

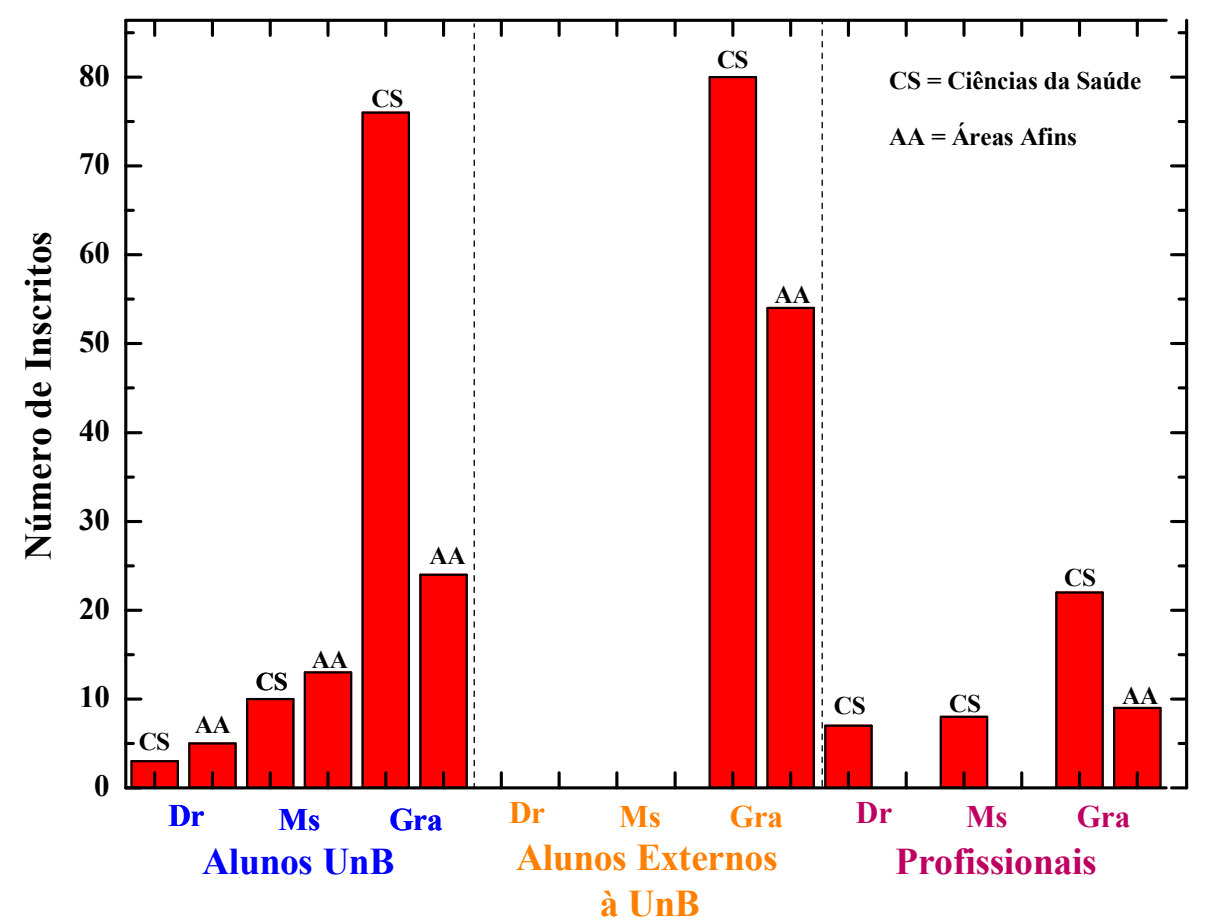

Figura 21. Distribuição dos alunos inscritos no curso por procedência, nível de formação e área de atuação. Como esperado, as colunas vinculadas à graduação se destacam das demais.

Tabela 4. Lista do quantitativo absoluto e percentual de cursistas inscritos na ação de ensino por procedência, nível de formação e área de atuação.

\begin{tabular}{|c|c|c|c|c|}
\hline Procedência & Nível de Formação & Área de Atuação & $\begin{array}{c}\mathrm{N}^{\circ} \mathrm{de} \\
\text { Cursistas } \\
\end{array}$ & $\begin{array}{c}\text { Percentual } \\
(\%) \\
\end{array}$ \\
\hline \multirow{6}{*}{ Alunos da UnB } & \multirow{2}{*}{ Doutorado } & Ciências da Saúde & 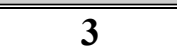 & $1,0 \%$ \\
\hline & & Áreas Afins & 5 & $1,6 \%$ \\
\hline & \multirow{2}{*}{ Mestrado } & Ciências da Saúde & 10 & $3,2 \%$ \\
\hline & & Áreas Afins & 13 & $4,2 \%$ \\
\hline & \multirow{2}{*}{ Graduação } & Ciências da Saúde & 76 & $24,4 \%$ \\
\hline & & Áreas Afins & 24 & $7,7 \%$ \\
\hline \multirow{3}{*}{$\begin{array}{c}\text { Alunos } \\
\text { Externos à } \\
\text { UnB }\end{array}$} & \multirow{2}{*}{ Doutorado } & Ciências da Saúde & (0 & $\mathbf{0}$ \\
\hline & & Áreas Afins & $\mathbf{0}$ & 0 \\
\hline & Mestrado & Ciências da Saúde & $\mathbf{0}$ & $\mathbf{0}$ \\
\hline
\end{tabular}


Capítulo 5 - Estudo Comparativo Entre as Ações de Ensino

\begin{tabular}{|c|c|c|c|c|}
\hline & & Áreas Afins & $\mathbf{0}$ & $\mathbf{0}$ \\
\hline & \multirow{2}{*}{ Graduação } & Ciências da Saúde & 80 & $25,7 \%$ \\
\hline & & Áreas Afins & 54 & $17,4 \%$ \\
\hline \multirow{6}{*}{ Profissionais } & \multirow{2}{*}{ Doutorado } & "Ciências da Saúde & 7 & $2,3 \%$ \\
\hline & & Áreas Afins & $\mathbf{0}$ & $\mathbf{0}$ \\
\hline & \multirow{2}{*}{ Mestrado } & Ciências da Saúde & 8 & $2,6 \%$ \\
\hline & & Áreas Afins & $\mathbf{0}$ & 0 \\
\hline & \multirow{2}{*}{ Graduação } & Ciências da Saúde & 22 & $7,1 \%$ \\
\hline & & Áreas Afins & 9 & $2,9 \%$ \\
\hline \multicolumn{3}{|c|}{ Total de Inscritos } & 311 & $100 \%$ \\
\hline
\end{tabular}

As iniciativas multidisciplinares de pesquisa nas áreas de $N \& N$ têm crescido muito nos últimos anos. No entanto, as ações de reflexão sobre o processo de ensino-aprendizagem na temática estão sendo pouco discutidas. Nesse escopo, a Fig. 21 e a Tabela 4 apresentam os resultados quantitativos referentes ao número de cursistas inscritos nas ações de ensino de $\mathrm{N} \& \mathrm{~N}$, distribuídos quanto à procedência institucional, nível de formação e área de atuação. $\mathrm{O}$ público-alvo com maior expressividade foi de alunos de graduação externos à UnB na área de ciências da saúde $(25,7 \%)$.

\subsection{Análise dos Parâmetros Índices de Sucesso, Insucesso e Evasão}

A Figura 22 (a) mostra os valores percentuais apurados para o Índice de Sucesso ou Aprovados (Menções SS e MS), enquanto a (b) mostra a comparação entre os valores percentuais apurados para os Índices de Sucesso ou Aprovados, Insucesso ou Não Aprovados (Menções MM, MI e II) e de Evasão (Menção SR - Desistentes sem Realizar Atividades) para as três ações de ensino na modalidade totalmente EaD aplicadas às turmas $\mathrm{A}, \mathrm{B}$ e $\mathrm{C}$. A Tabela 5 lista os valores absolutos e percentuais para os Índices citados acima, contendo referência às menções e equivalências em notas, obtidas pelos alunos/cursistas. 

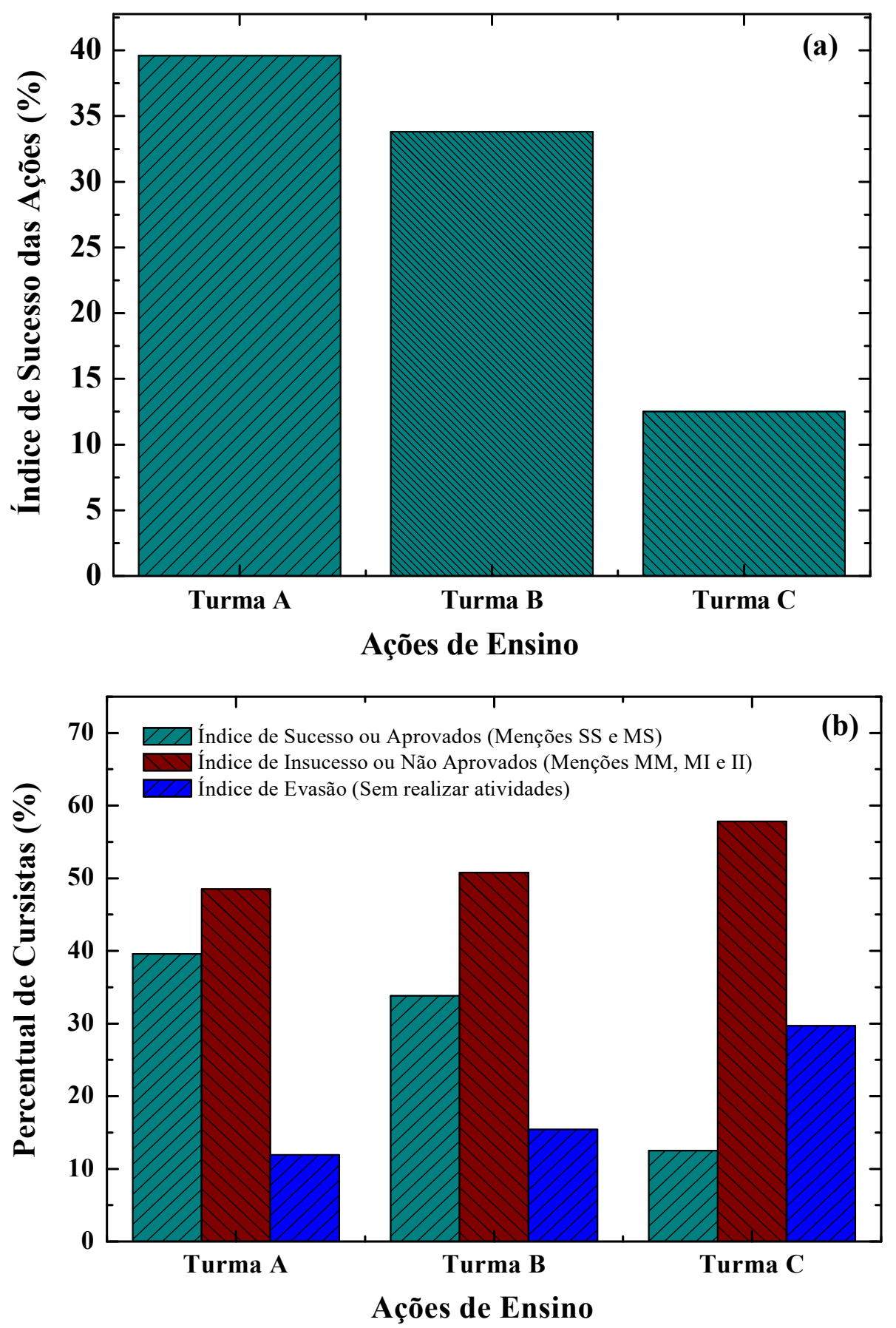

Figura 22. (a) Índice percentual de sucesso ou aprovados (menções SS e MS) e (b) comparação entre os índices de sucesso ou aprovados, insucesso ou não aprovados (menções MM, MI e II) e evasão (sem realizar atividades) para as ações de ensino aplicadas às turmas A, B e C. 
Tabela 5. Lista de valores absolutos (frequência) e percentuais associados aos índices de sucesso, insucesso e evasão das ações de ensino na modalidade totalmente $\mathrm{EaD}$, aplicadas às turmas A, B e C.

\begin{tabular}{|c|c|c|c|c|c|c|}
\hline \hline \multirow{2}{*}{$\begin{array}{c}\text { Ações de } \\
\text { Ensino }\end{array}$} & \multicolumn{3}{|c|}{$\begin{array}{c}\text { Índice de Sucesso (Menções } \\
\text { SS e MS) }\end{array}$} & \multicolumn{2}{c|}{$\begin{array}{c}\text { Índice de Insucesso } \\
\text { (Menções MM, MI e II) }\end{array}$} & $\begin{array}{c}\text { Índice de Evasão } \\
\text { (Desistentes sem Realizar } \\
\text { Atividades) }\end{array}$ \\
\cline { 2 - 7 } & $\mathbf{F}$ & $\mathbf{( \% )}$ & $\mathbf{f}$ & $\mathbf{( \% )}$ & $\mathbf{f}$ & $(\%)$ \\
\hline \hline Turma A & 40 & 39,6 & 49 & 48,5 & 12 & 11,9 \\
\hline Turma B & 22 & 33,8 & 33 & 50,8 & 10 & 15,4 \\
\hline Turma C & 8 & 12,5 & 37 & 57,8 & 19 & 29,7 \\
\hline \hline
\end{tabular}

De acordo com a Fig. 22 (a) e a Tab. 5, foi identificado que o maior valor obtido para o parâmetro índice de sucesso foi igual a 39,6\% (Turma A), enquanto o menor valor foi igual a $12,5 \%$ (Turma C). A diferença entre o maior e o menor valor é de aproximadamente 27,1\%. Destaca-se também que os valores obtidos para esse parâmetro decrescem com o tipo de ação realizada. Na Fig. 22 (b), observa-se que o maior valor obtido para o parâmetro índice de insucesso foi igual a 57,8\% (Turma C), enquanto que o menor valor foi igual a 48,5\% (Turma A). Para o parâmetro índice de evasão, destaca-se que a Turma $\mathrm{C}$ obteve o maior valor (29,7\%) para esse índice, diferentemente da Turma A que obteve o menor valor (11,9\%).

\subsection{Estratificação dos Índices de Sucesso e Insucesso}

A Figura 23 mostra a estratificação por menções do processo de aprendizagem obtido pelos alunos Aprovados e Não Aprovados nas três ações de ensino totalmente na modalidade EaD: (a) apresenta o percentual de aprovados com menções SS e MS, enquanto que a (b) exibe o percentual de não aprovados com menções MM, MI, II e SR. A Tabela 6 lista os valores absolutos e percentuais para os Índices citados acima, contendo referência ao número de aprovados e não aprovados de cada turma e suas respectivas menções. 

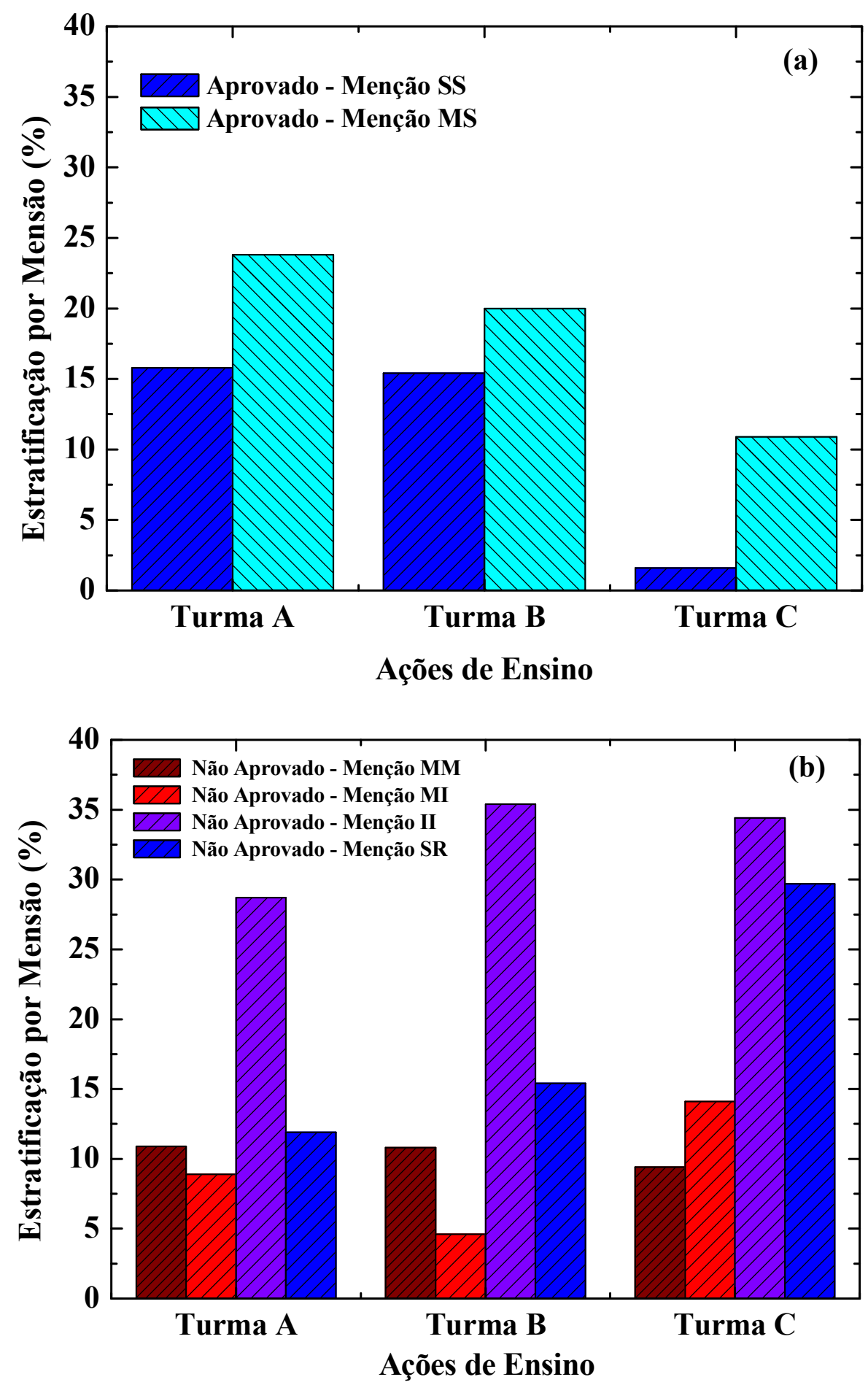

Figura 23. Estratificação por menções do processo de aprendizagem obtidas pelos alunos aprovados e não aprovados nas três ações de ensino: (a) aprovados com menções SS e MS e (b) não aprovados com menções MM, MI, II e SR. 
Tabela 6. Lista de valores absolutos e percentuais associados aos índices de aprovados e não aprovados por meio de estratificação por menções "SS e MS" e "MM, MI, II e SR", respectivamente, nas ações de ensino aplicadas às turmas $\mathrm{A}, \mathrm{B}$ e $\mathrm{C}$.

\begin{tabular}{|c|c|c|c|c|c|c|c|c|c|c|c|c|}
\hline \multirow{3}{*}{$\begin{array}{c}\text { Ações de } \\
\text { Ensino }\end{array}$} & \multicolumn{4}{|c|}{ Aprovados } & \multicolumn{8}{|c|}{ Não Aprovados } \\
\hline & \multicolumn{2}{|c|}{ Menção SS } & \multicolumn{2}{|c|}{ Menção MS } & \multicolumn{2}{|c|}{ Menção MM } & \multicolumn{2}{|c|}{ Menção MI } & \multicolumn{2}{|c|}{ Menção II } & \multicolumn{2}{|c|}{ Menção SR } \\
\hline & $\mathbf{n}^{\circ}$ & $(\%)$ & $n^{\circ}$ & $(\%)$ & $n^{\circ}$ & $(\%)$ & $\mathbf{n}^{\circ}$ & $(\%)$ & $\mathbf{n}^{\circ}$ & $(\%)$ & $n^{\circ}$ & $(\%)$ \\
\hline Turma A & 16 & 15,8 & 24 & 23,8 & 11 & 10,9 & 9 & 8,9 & 29 & 28,7 & 12 & 11,9 \\
\hline Turma B & 9 & 13,8 & 13 & 20,0 & 7 & 10,8 & 3 & 4,6 & 23 & 35,4 & 10 & 15,4 \\
\hline Turma C & 1 & 1,6 & 7 & 10,9 & 6 & 9,4 & 9 & 14,1 & 22 & 34,4 & 19 & 29,7 \\
\hline
\end{tabular}

De acordo com a Fig. 23 (a) e a Tab. 6, foi identificado que o maior valor obtido para o parâmetro índice de aprovados com menção SS foi igual a 15,8\% para a Turma A, enquanto o menor valor foi igual a $1,6 \%$ para a Turma $\mathrm{C}$. A diferença entre o maior e o menor valor é de aproximadamente $14,2 \%$. Ainda dentro do parâmetro de aprovados, o maior valor obtido com menção MS foi 23,8\% para a Turma A, enquanto o menor valor foi igual a 10,9\% para a Turma C, cuja diferença entre o maior e o menor valor aproxima de 12,9\%. Destaca-se também que os valores obtidos para esse parâmetro se decrescem com o tipo de ação realizada. Na Fig. 23 (b), observa-se que o maior valor obtido para o parâmetro índice de não aprovados com menção MM foi igual a 10,9\% para a Turma A, enquanto que o menor valor foi de 9,4\%, para a Turma C. O maior valor obtido com menção MI foi de 14,1\%, para a Turma C, e o menor valor foi 4,6\%, para a Turma B. Na menção II o maior valor obtido $(35,4 \%)$ para a Turma B e o menor valor para a Turma A $(28,7 \%)$. Por último, com menção SR, o maior valor obtido foi de $29,7 \%$ para a Turma C e o menor valor foi de $11,9 \%$ para a Turma A.

\subsection{Correlação dos Índices com a Origem dos Cursistas}

$\mathrm{Na}$ Figura 24, são apresentados os valores percentuais apurados dos índices pela origem dos cursistas, para as três ações de ensino totalmente $\mathrm{EaD}$ aplicadas às turmas $\mathrm{A}, \mathrm{B}$ e C: (a) tem-se o Índice de Sucesso ou Aprovados, (b) mostra o Índice de Insucesso ou Não Aprovados e (c) exibe o Índice de Evasão. A Tabela 7 lista os valores absolutos associados aos Índices de Sucesso, Insucesso e Evasão, por procedência, nível de formação e área de atuação, das ações de ensino. 


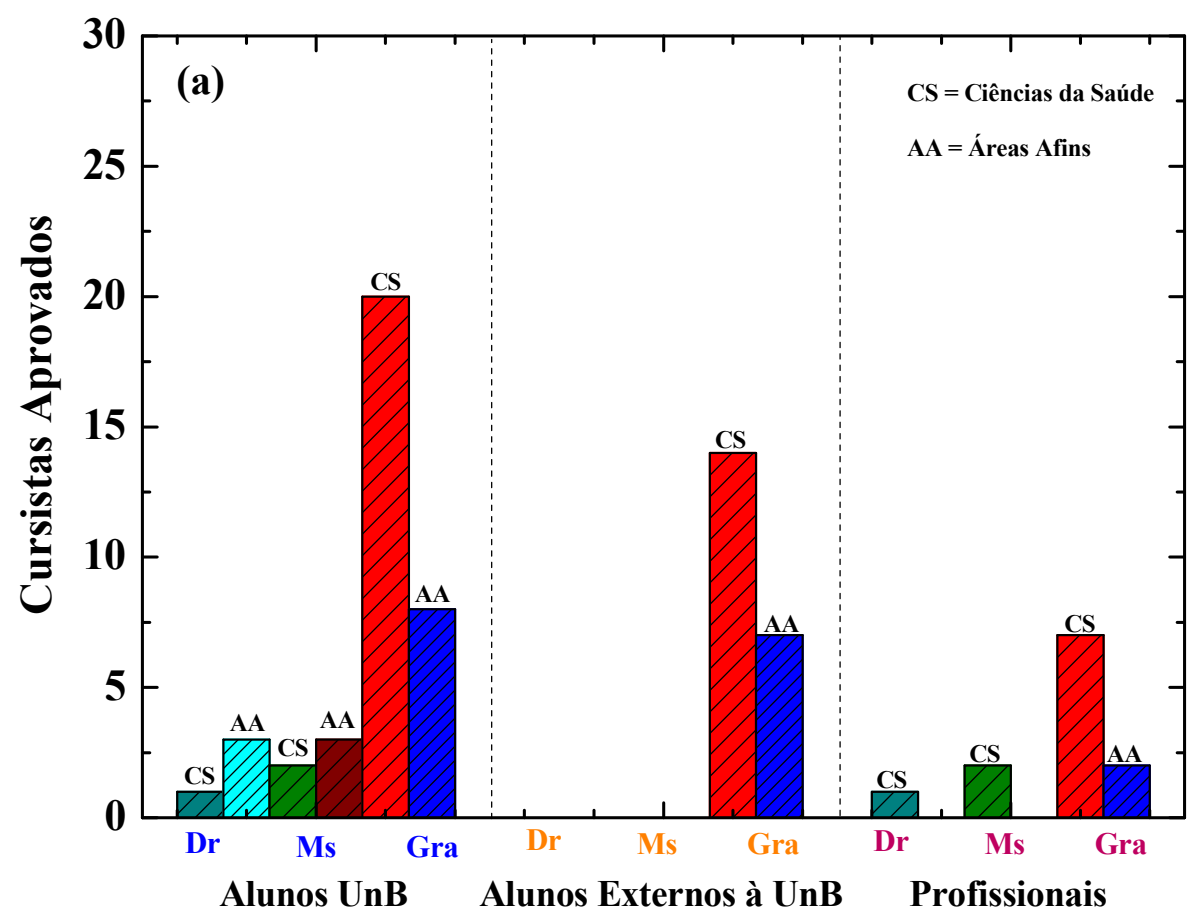

\section{Origem dos Cursistas}

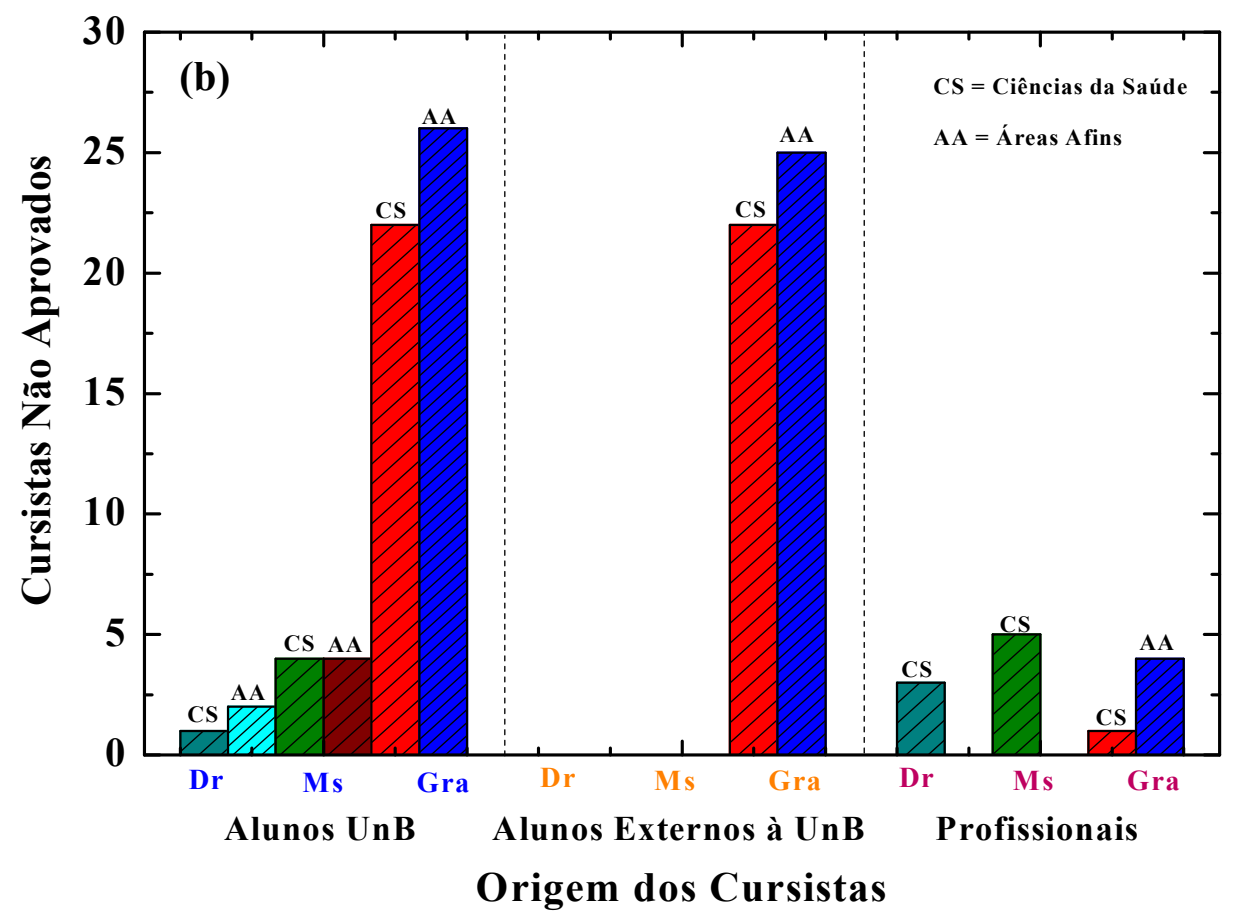




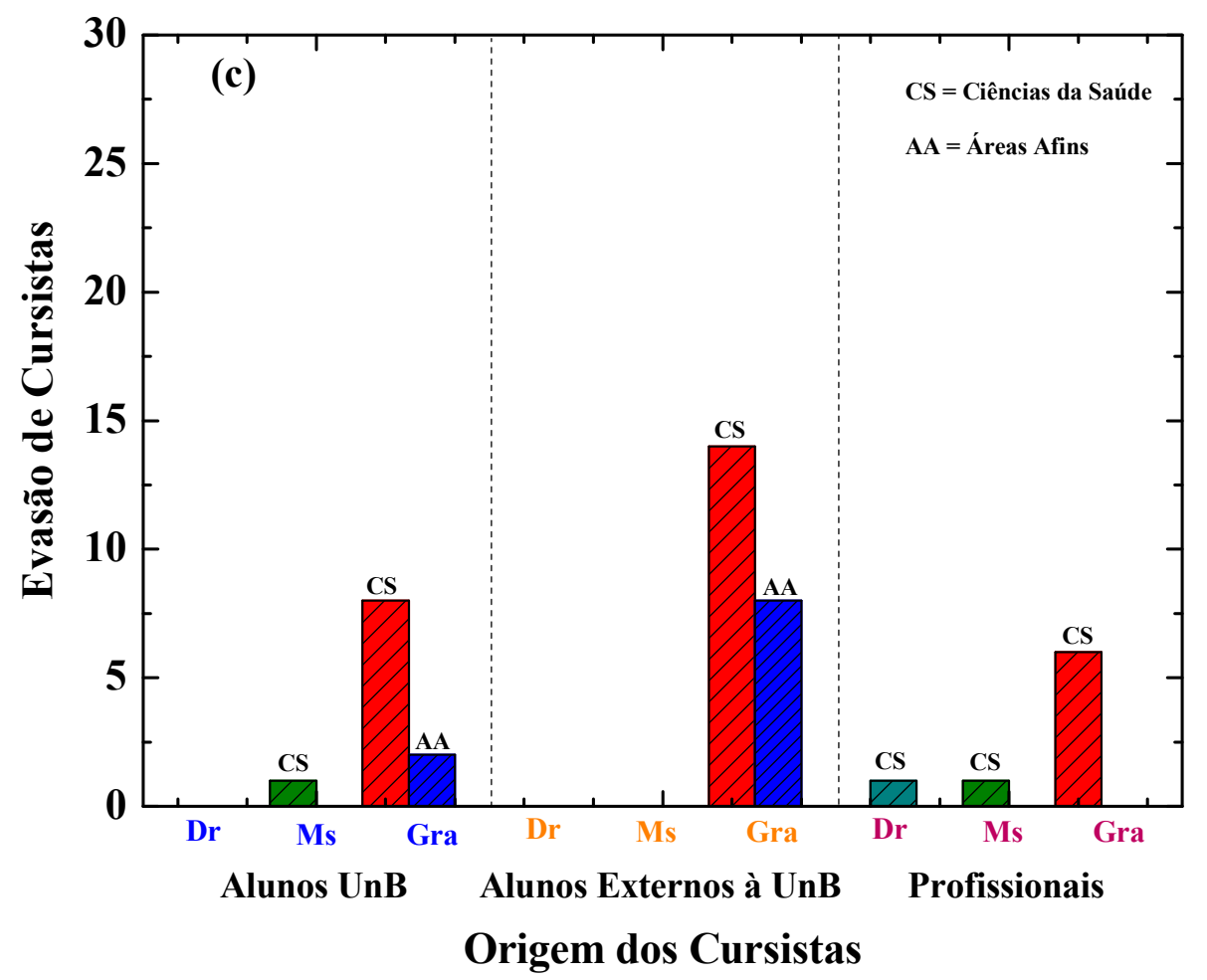

Figura 24. Apresenta os valores percentuais apurados dos índices pela origem dos cursistas, para as três ações de ensino totalmente na modalidade EaD aplicadas para as turmas A, B e C, (a) Índice de Sucesso ou Aprovados, (b) Índice de Insucesso ou Não Aprovados e (c) Índice de Evasão.

Tabela 7. Lista os valores absolutos associados aos índices de sucesso, insucesso e evasão por procedência, nível de formação e área de atuação, das três ações de ensino totalmente na modalidade EaD.

\begin{tabular}{|c|c|c|c|c|c|}
\hline Procedência & $\begin{array}{c}\text { Nível de } \\
\text { Formação }\end{array}$ & Área de Atuação & $\begin{array}{c}\text { Índice de } \\
\text { Sucesso } \\
\end{array}$ & $\begin{array}{l}\text { Índice de } \\
\text { Insucesso } \\
\end{array}$ & $\begin{array}{c}\text { Índice de } \\
\text { Evasão }\end{array}$ \\
\hline \multirow{6}{*}{ Alunos UnB } & \multirow{2}{*}{ Doutorado } & Ciências da Saúde & 1 & 1 & $\mathbf{0}$ \\
\hline & & Áreas Afins & 3 & 2 & $\mathbf{0}$ \\
\hline & \multirow{2}{*}{ Mestrado } & Ciências da Saúde & 2 & 4 & 1 \\
\hline & & Áreas Afins & 3 & 4 & $\mathbf{0}$ \\
\hline & \multirow{2}{*}{ Graduação } & Ciências da Saúde & 20 & 22 & 8 \\
\hline & & Áreas Afins & 8 & 26 & 2 \\
\hline \multirow{6}{*}{$\begin{array}{c}\text { Alunos } \\
\text { Externos à } \\
\text { UnB }\end{array}$} & \multirow{2}{*}{ Doutorado } & "Ciências da Saúde & $\overline{00}$ & 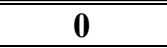 & 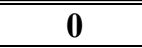 \\
\hline & & Áreas Afins & $\mathbf{0}$ & $\mathbf{0}$ & $\mathbf{0}$ \\
\hline & \multirow{2}{*}{ Mestrado } & Ciências da Saúde & $\mathbf{0}$ & $\mathbf{0}$ & $\mathbf{0}$ \\
\hline & & Áreas Afins & $\mathbf{0}$ & $\mathbf{0}$ & $\mathbf{0}$ \\
\hline & \multirow{2}{*}{ Graduação } & Ciências da Saúde & 14 & 22 & 14 \\
\hline & & Áreas Afins & 7 & 25 & 8 \\
\hline \multirow{4}{*}{ Profissionais } & \multirow{2}{*}{ Doutorado } & Ciências da Saúde & 1 & 3 & 1 \\
\hline & & Áreas Afins & $\mathbf{0}$ & $\mathbf{0}$ & $\mathbf{0}$ \\
\hline & \multirow{2}{*}{ Mestrado } & Ciências da Saúde & 2 & 5 & 1 \\
\hline & & Áreas Afins & $\mathbf{0}$ & $\mathbf{0}$ & $\mathbf{0}$ \\
\hline
\end{tabular}




\begin{tabular}{|l|c|c|c|c|c|}
\hline \multirow{2}{*}{ Graduação } & Ciências da Saúde & $\mathbf{7}$ & $\mathbf{1}$ & $\mathbf{6}$ \\
\cline { 3 - 6 } & & Áreas Afins & $\mathbf{2}$ & $\mathbf{4}$ & $\mathbf{0}$ \\
\hline \hline \multicolumn{2}{|c|}{ Total de Cursistas } & $\mathbf{7 0}$ & $\mathbf{1 1 9}$ & $\mathbf{4 1}$ \\
\hline
\end{tabular}

De acordo com a Fig. 24 (a) e a Tab. 7, identifica-se que o maior quantitativo de cursistas aprovados exibe nível de graduação na área de ciências da saúde. Esse padrão se repetiu para as três classes de procedência, a saber, alunos UnB (20), alunos externos à UnB (14) e profissionais (07). O menor valor quantitativo de cursistas aprovados expõe nível de doutorado na área de ciências da saúde, procedentes da UnB (01), e profissionais (01). Não houve aluno aprovado no curso externo à UnB. Na Fig. 24 (b), observa-se que o valor absoluto de cursistas não aprovados é o maior entre os três índices, totalizando 119 cursistas. Foi identificado um quantitativo maior de cursistas não aprovados de graduação em áreas afins nas classes de alunos da UnB (26) e externos à UnB (25). Já na classe de profissionais, o maior índice consiste de cursistas com mestrado na área de ciências da saúde (05). O menor valor para o índice de não aprovados é o de cursistas com doutorado em ciências da saúde, da UnB (01), de profissionais com o nível de graduação na área de ciências da saúde (01) e de alunos externos à UnB, no nível de graduação, atuantes em ciências da saúde (22). Enquanto, na Fig. 24 (c), os resultados do índice de evasão indicam que os alunos da UnB (08), externos à UnB (14) e profissionais (06) de graduação na área de ciências da saúde apresentam o maior índice.

\subsection{Análise dos Parâmetros "Percepção Média sobre o Curso" e "Percepção sobre os Módulos" e "Avaliação Final do Curso"}

A Figura 25 mostra a média dos resultados obtidos acerca do conceito médio das turmas e conceito médio dos módulos, aplicados às três ações de ensino sob a percepção dos cursistas: (a) tem-se o Conceito Médio das Turmas e (b) mostra o Conceito Médio por Módulo. A Tabela 8 lista o número de respostas e o conceito médio sobre cada módulo executado no curso, aplicadas nas ações de ensino (turmas A, B e C) e, por último, o conceito médio geral do curso. 

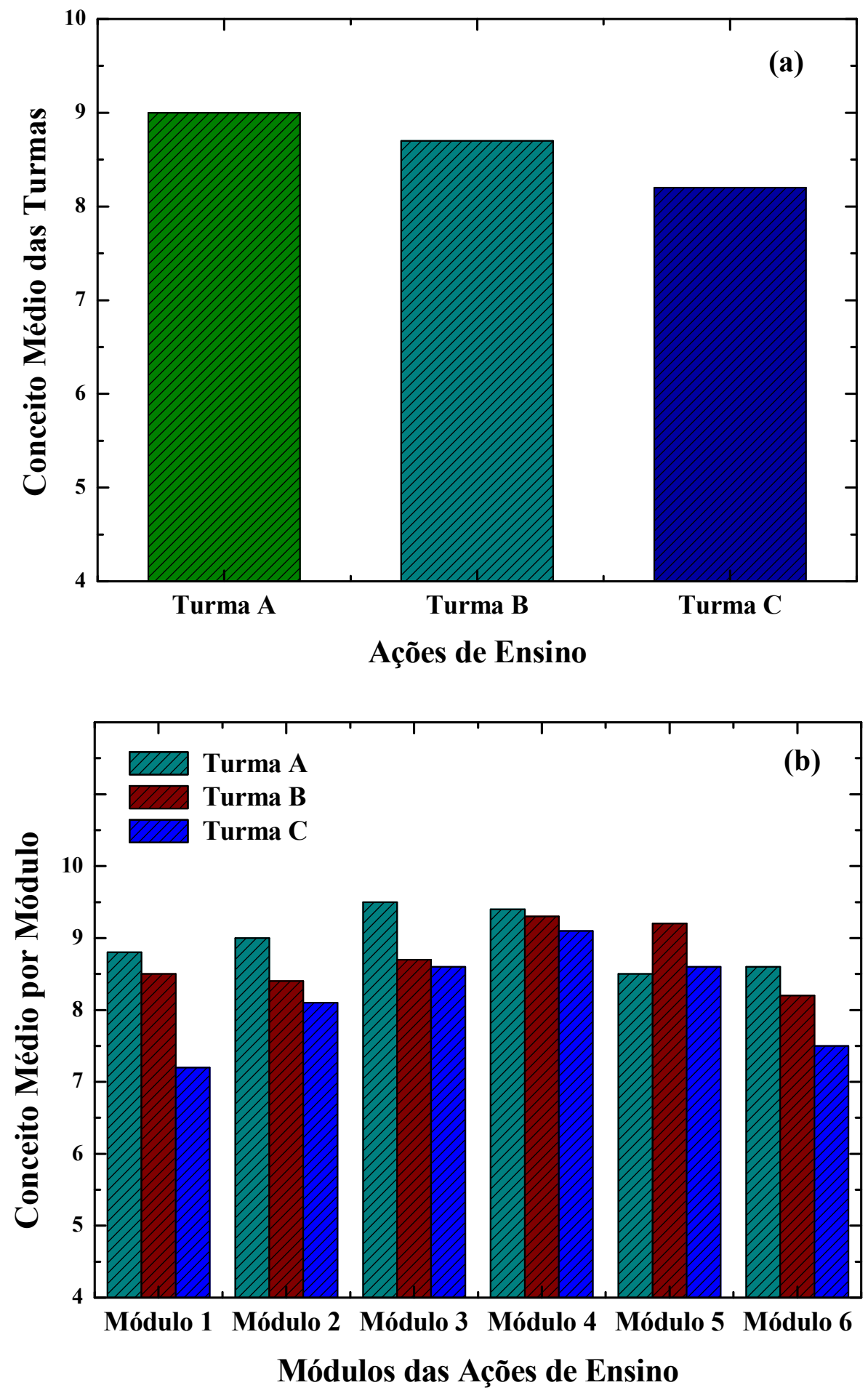

Figura 25. Apresenta a média dos resultados obtidos acerca do conceito médio das turmas e conceito médio dos módulos, aplicados nas três ações de ensino sob a percepção dos cursistas: (a) tem-se o Conceito Médio das Turmas e (b) mostra o Conceito Médio por Módulo. 
Tabela 8. Lista o número de respostas e o conceito médio sobre cada módulo executado no curso, aplicadas nas ações de ensino, turmas A, B e C, e o conceito médio geral do curso.

\begin{tabular}{|c|c|c|c|c|c|c|}
\hline \multirow[b]{2}{*}{ MÓDULOS } & \multicolumn{2}{|c|}{ Turma A } & \multicolumn{2}{|c|}{ Turma B } & \multicolumn{2}{|c|}{ Turma C } \\
\hline & $\begin{array}{c}\mathrm{N}^{\circ} \mathrm{de} \\
\text { Respostas }\end{array}$ & $\begin{array}{l}\text { Conceito } \\
\text { Médio }\end{array}$ & $\begin{array}{c}\mathrm{N}^{\circ} \mathrm{de} \\
\text { Respostas }\end{array}$ & $\begin{array}{l}\text { Conceito } \\
\text { Médio }\end{array}$ & $\begin{array}{c}\mathrm{N}^{\circ} \text { de } \\
\text { Respostas }\end{array}$ & $\begin{array}{l}\text { Conceito } \\
\text { Médio }\end{array}$ \\
\hline Módulos 1 & 35 & 8,8 & 30 & 8,5 & 15 & 7,2 \\
\hline Módulos 2 & 33 & 9,0 & 27 & 8,4 & 13 & 8,1 \\
\hline Módulos 3 & 33 & 9,5 & 22 & 8,7 & 15 & 8,6 \\
\hline Módulos 4 & 31 & 9,4 & 21 & 9,3 & 9 & 9,1 \\
\hline Módulos 5 & 33 & 8,5 & 12 & 9,2 & 9 & 8,6 \\
\hline Módulos 6 & 38 & 8,6 & 5 & 8,2 & 8 & 7,5 \\
\hline $\begin{array}{c}\text { Conceito Médio do } \\
\text { Curso }\end{array}$ & \multicolumn{2}{|c|}{9,0} & \multicolumn{2}{|c|}{8,7} & \multicolumn{2}{|c|}{8,2} \\
\hline
\end{tabular}

Observa-se, na Fig. 25 (a) e na Tab. 8, que os resultados da análise do conceito médio do curso ocorreram de forma decrescente. Cabe destacar que a primeira ação de ensino ministrada para a Turma A apresentou a melhor avaliação entre as três ações de ensino aplicadas $(9,0)$, enquanto que as turmas subsequentes, B e C, obtiveram resultados de 8,7 e 8,2, respectivamente. Em geral, significa que o curso foi bem avaliado por ambas as turmas quanto à qualidade técnica, didática e metodológica. Na Fig. 25 (b), a Turma A apresentou novamente o melhor conceito médio em praticamente todos os módulos, exceto no Módulo 5 , que trata do tema específico de "nanomateriais aplicados como biomateriais e nanobiossensores", que foi melhor avaliado pela Turma B $(9,2)$. Ressalta-se que a menor porcentagem referente ao conceito médio por módulo foi de 7,2 para o Módulo 1, da Turma C.

A Figura 26 mostra a média das notas dos cursistas na avaliação final das três ações de ensino aplicadas às turmas A, B e C: (a) tem-se a Média da Avaliação Final das turmas e (b) mostra o percentual das notas da Avaliação Final do Curso. A Tabela 9 lista os valores percentuais dos parâmetros analisados nas três ações de ensino referentes à "Média da Avaliação Final do Curso" e "Avaliação Final do Curso" utilizando notas normalizadas de zero a dez (0-10). 

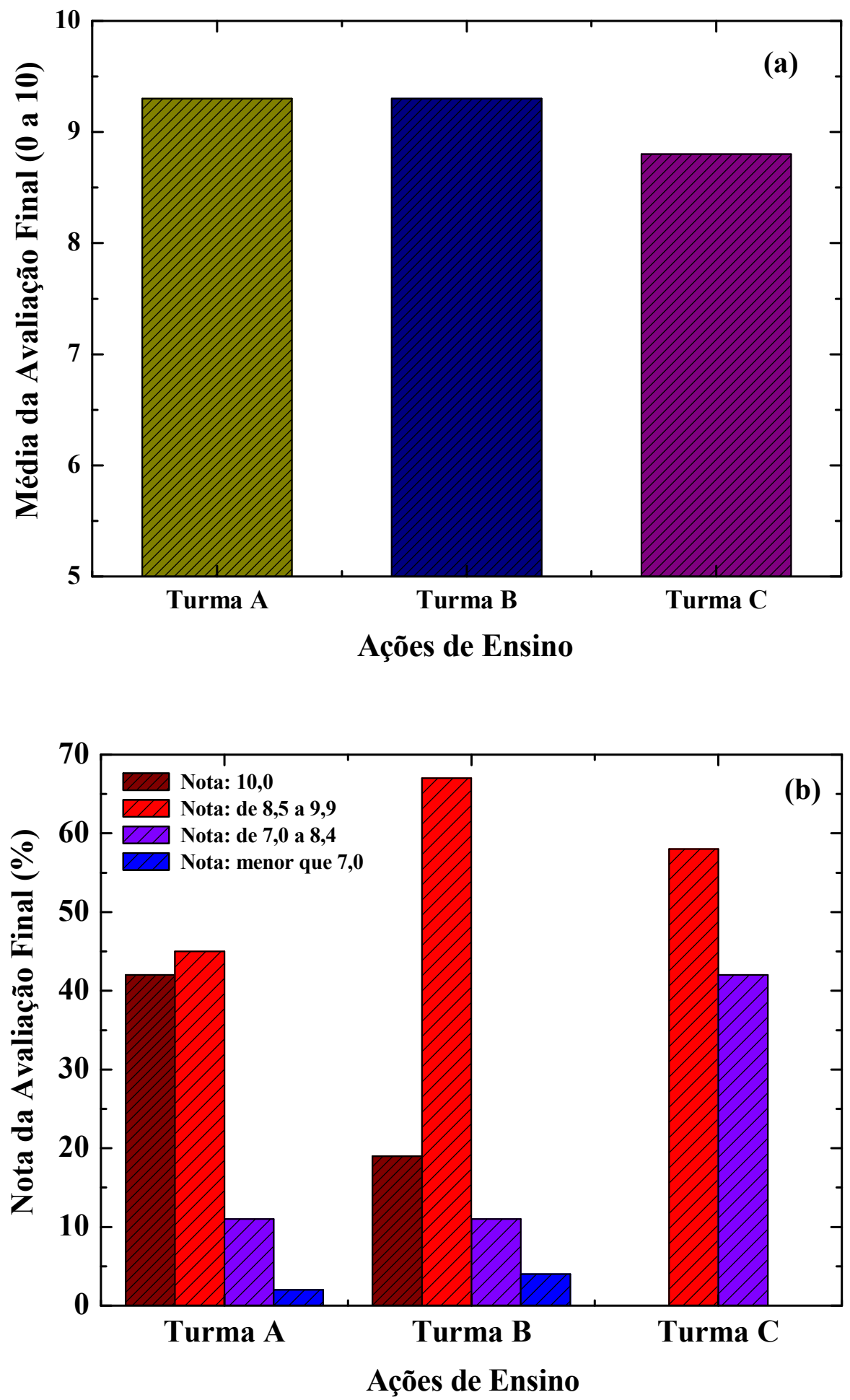

Figura 26. Representação da média das notas dos cursistas na avaliação final das três ações de ensino aplicadas às turmas A, B e C: (a) tem-se a média da avaliação final das turmas; e (b) mostra o percentual das notas da avaliação final do curso. 
Tabela 9. Lista os valores percentuais dos parâmetros analisados nas três ações de ensino aplicadas às turmas A, B e C referentes à "Média da Avaliação Final do Curso" e "Avaliação Final do Curso" utilizando notas normalizadas de zero a dez (0-10).

\begin{tabular}{|c|c|c|c|c|}
\hline \multirow{2}{*}{ Parâmetro } & & \multicolumn{3}{|c|}{ Ações de Ensino } \\
\hline & & Turma A & Turma B & Turma C \\
\hline \multicolumn{2}{|l|}{$\begin{array}{l}\text { Média da Avaliação } \\
\text { Final do Curso }\end{array}$} & 9,3 & 9,3 & 8,8 \\
\hline \multirow{2}{*}{ Avaliação Final: 10} & $\%$ & $42 \%$ & $19 \%$ & $\mathbf{0 \%}$ \\
\hline & $\mathrm{f}$ & 22 & 5 & 0 \\
\hline \multirow{2}{*}{ Avaliação Final: de 8,5 a 9,9 } & $\%$ & $45 \%$ & $67 \%$ & $58 \%$ \\
\hline & $\mathrm{f}$ & 24 & 18 & 7 \\
\hline \multirow{2}{*}{ Avaliação Final: de 7,0 a 8,4 } & $\%$ & $11 \%$ & $11 \%$ & $42 \%$ \\
\hline & $\mathrm{f}$ & 6 & 3 & 5 \\
\hline \multirow{2}{*}{ Avaliação Final: menor que 7,0} & $\%$ & $2 \%$ & $4 \%$ & $0 \%$ \\
\hline & $\mathrm{f}$ & 1 & 1 & 0 \\
\hline
\end{tabular}

Como pode ser visto na Fig. 26 (a) e na Tab. 9, os resultados obtidos no parâmetro "Média da Avaliação Final" apresentam exatamente a mesma média percentual equivalente a 9,3 para as Turmas A e B, enquanto a Turma $\mathrm{C}$ exibe 8,8. Cabe ressaltar que ambas as ações de ensino tiveram, em geral, médias desejáveis no que tange ao objetivo da atividade. De acordo com a Fig. 26 (b), a nota da "avaliação final entre 8,5 e 9,9" se sobressaiu entre as demais notas alcançadas nas ações de ensino e as médias obtidas foram de 45\% (Turma A), $67 \%$ (Turma B) e 58\% (Turma C). Observa-se que o menor percentual atingido, felizmente, foi a nota da "avaliação final menor que 7,0", avalizando, desse modo, a qualidade e eficiência na realização do curso, principalmente nos quesitos técnicos, metodológicos e do conteúdo.

\subsection{Análise do Parâmetro "Retenção do Conhecimento"}

A Figura 27 (a) mostra a média percentual da Avaliação de Retenção do Conhecimento em função das três ações de ensino aplicadas às Turmas $\mathrm{A}, \mathrm{B}$ e C, enquanto a Figura 27 (b) mostra o percentual de acertos na Avaliação de Retenção do Conhecimento em função do tempo, 20, 60 e 100 dias após o término das ações de ensino. A Tabela 10 lista os valores absolutos e percentuais na Avaliação de Retenção do Conhecimento por ação de ensino. 

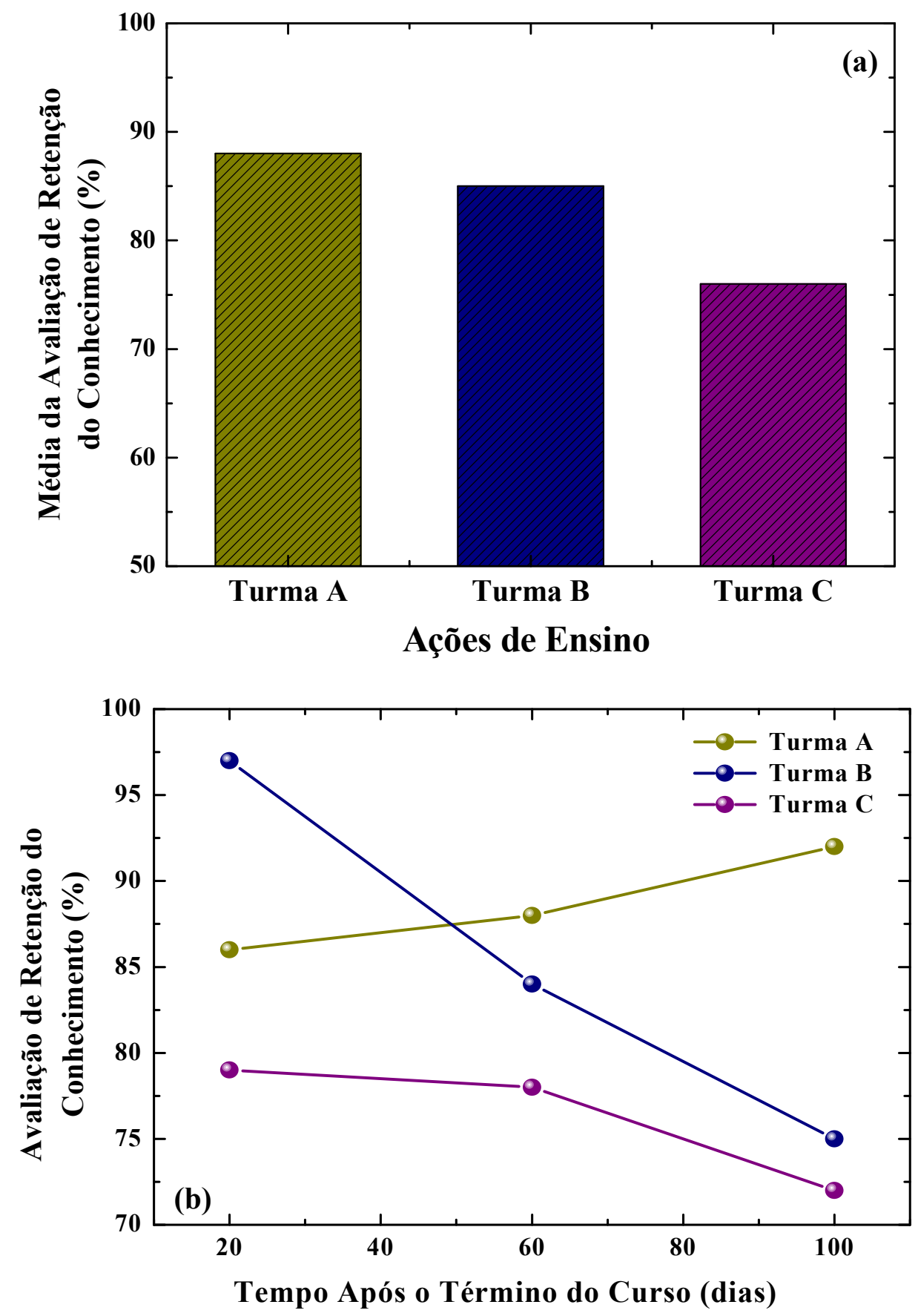

Figura 27. (a) mostra a média percentual da avaliação de retenção do conhecimento em função da ação de ensino; e (b) exibe a evolução do parâmetro da avaliação de retenção do conhecimento em função do tempo, após o término dos três cursos, com intervalos de 20, 60 e 100 dias. 
Tabela 10. Lista os valores absolutos e percentuais na Avaliação de Retenção do Conhecimento por ação de ensino, aplicadas às Turmas A, B e C.

\begin{tabular}{|c|c|c|c|c|}
\hline \multirow{2}{*}{\multicolumn{2}{|c|}{ Parâmetro }} & \multicolumn{3}{|c|}{ Ações de Ensino } \\
\hline & & Turma A & Turma B & Turma C \\
\hline \multicolumn{2}{|c|}{$\begin{array}{c}\text { Média das Avaliações } \\
\text { de Retenção do Conhecimento }\end{array}$} & $88 \%$ & $85 \%$ & $76 \%$ \\
\hline \multirow{3}{*}{$\begin{array}{l}\text { Avaliação de Retenção do } \\
\text { Conhecimento: } 20 \text { dias }\end{array}$} & $\%$ & $86 \%$ & $97 \%$ & $79 \%$ \\
\hline & Nota $(0-20)$ & 17,2 & 19,3 & 15,7 \\
\hline & Frequência (f) & 5 & 11 & 6 \\
\hline \multirow{3}{*}{$\begin{array}{l}\text { Avaliação de Retenção do } \\
\text { Conhecimento: } 60 \text { dias }\end{array}$} & $\%$ & $88 \%$ & $84 \%$ & $78 \%$ \\
\hline & Nota $(0-20)$ & 17,5 & 16,7 & 15,6 \\
\hline & Frequência (f) & 12 & 9 & 5 \\
\hline \multirow{3}{*}{$\begin{array}{l}\text { Avaliação de Retenção do } \\
\text { Conhecimento: } 100 \text { dias }\end{array}$} & $\%$ & $92 \%$ & $75 \%$ & $72 \%$ \\
\hline & Nota $(0-20)$ & 18,3 & 15 & 14,4 \\
\hline & Frequência (f) & 12 & 6 & 7 \\
\hline
\end{tabular}

Como pode ser visto na Fig. 27 (a) e na Tab. 10, os resultados obtidos no parâmetro "Média da Avaliação de Retenção do Conhecimento", por ação de ensino, exibem diferentes médias percentuais, a saber, Turma A (88\%), Turma B (85\%) e Turma C (76\%). Cabe ressaltar que as três ações de ensino alcançaram médias desejáveis para o objetivo da atividade. De acordo com a Fig. 27 (b), nota-se que o maior percentual de acertos na avaliação de retenção do conhecimento, após 20 dias do término do curso, foi de $97 \%$ para a Turma B; após 60 e 100 dias, a Turma A apresentou o maior percentual de acertos, 88\% e 92\%, respectivamente. Observa-se que os menores percentuais de acertos nos parâmetros de avaliação de retenção do conhecimento, após 20, 60 e 100 dias do término do curso, foi obtido pela ação de aprendizagem da Turma C. Cabe destacar que os percentuais de acertos foram crescentes na Turma A e decrescentes nas Turmas B e C.

Com relação à frequência de alunos que participaram da atividade de retenção do conhecimento após intervalos de 20,60 e 100 dias do término do curso, a quantidade máxima e mínima por ação de ensino, constituiu em: (i) Turma A - máxima de 12 alunos na avaliação de 60 e 100 dias e mínima de alunos na avaliação de 20 dias, sendo que a média dos alunos que participaram foi de 9,6 alunos por avaliação; (ii) Turma B - máxima de 11 alunos na avaliação de 20 dias e mínima de seis alunos na avaliação de 100 dias, a média dos alunos que participaram foi de 8,6 alunos por avaliação; e (iii) Turma $\mathrm{C}$ - máxima de sete alunos na avaliação de 100 dias e mínima de cinco alunos na avaliação de 60 dias, sendo que a média dos alunos que participaram foi de seis alunos por avaliação. A atividade de retenção do conhecimento aplicada após o término do curso não era obrigatória, ou seja, o aluno tinha o livre arbítrio para responder o questionário. 


\subsection{Retomada dos Objetivos do Trabalho}

Com base na interface entre as áreas da nanociência e nanotecnologia, ciências da saúde e enfermagem, foram idealizadas três ações de ensino na modalidade totalmente a distância com diferentes abordagens didáticas, utilizando a Plataforma Aprender da UnB. Para atingir os objetivos específicos do trabalho, realizou-se um estudo de natureza comparativa útil para analisar e indicar qual das ações foi a mais eficaz.

Nesse contexto, retomando os objetivos específicos do trabalho, os resultados indicam:

$1^{\circ}$ Objetivo Específico: “Conceber uma formação/curso na modalidade totalmente EaD na temática do trabalho que envolva três Ações de Ensino distintas, utilizando a "Plataforma Aprender" da Universidade de Brasília como Ambiente Virtual de Aprendizagem (AVA)".

Considerações: Com base nos resultados apresentados no item 5.1 - "Seleção do Tema dos Módulos", foram identificados e justificados seis temas de maior potencial e interesse para as áreas do estudo e que melhor se ajustam ao ensino na modalidade EaD. Foram formuladas e testadas, na Plataforma Aprender da UnB, três ações de ensino na modalidade totalmente EaD como abordagens didáticas fundamentadas em conteúdos escritos (Turma A), vídeos (Turma B) e aulas expositivas (Turma C).

$2^{\circ}$ Objetivo Específico: "Efetuar um estudo comparativo da eficácia das três Ações de Ensino testadas, baseadas principalmente em conteúdos escritos, vídeos e aulas expositivas, utilizando parâmetros como "Índice de sucesso, insucesso e evasão do curso", "Avaliação geral do curso", "Retenção do conhecimento", entre outros".

Considerações: Com base nas etapas experimentais e metodológicas realizadas na execução deste trabalho, descritas no Capitulo 4 - "Abordagem Metodológica", foi delineado um estudo comparativo da eficácia das três ações de ensino testadas. As ações didáticas foram fundamentalmente baseadas em conteúdos escritos (Turma A), vídeos (Turma B) e aulas expositivas (Turma C). Além das principais ações citadas, utilizaram-se também diversos recursos didáticos detalhados no mesmo capítulo citado acima; a seguir, cinco recursos comuns às três ações de ensino: (i) ferramentas tecnológicas de comunicação; (ii) espaço denominado "fórum de notícias", destinado à postagem de informações sobre o tema; (iii) espaço para atividade avaliativa do módulo, com um conjunto de 10 questões de falso e verdadeiro sobre as atividades dos módulos; (iv) item "vídeo de encerramento do curso"; (v) espaço de retenção do conhecimento, destinado para o aluno testar o conhecimento em N\&N. Já os resultados permitiram sugerir diferenças de eficácia entre elas. 
$3^{0}$ Objetivo Específico: "Dentre as três Ações de Ensino propostas, identificar a mais eficaz para o ensino da Nanociência e Nanotecnologia Aplicadas às Ciências da Saúde e Enfermagem para estudantes e profissionais da saúde, bem como sugerir elementos decisivos para a eficácia da estratégia de ensino".

Considerações: Com base nos resultados apresentados nos itens 5.3, 5.4, 5.6 e 5.7, respectivamente - "Índice de sucesso, insucesso e evasão do curso", "Estratificação dos Índices de Sucesso e Insucesso", "Percepção Média sobre o Curso" e "Percepção sobre os Módulos" e "Avaliação Final do Curso", e "Retenção do Conhecimento", a metodologia que se mostrou mais eficaz foi a baseada fundamentalmente em conteúdos escritos (Turma A). Nesse sentido, sugere-se, a seguir, os dois principais elementos decisivos para a eficácia da estratégia de ensino, sendo que o tema será abordado em detalhes no Capitulo 6: (i) maior familiaridade com essa metodologia e preservação da zona de conforto do aluno; (ii) maior possibilidade de controle da interatividade aluno/sistema, propiciando momentos de reflexão e complemento do conteúdo. 


\section{$6^{0}$ CAPÍTULO - DISCUSSÕES E REFLEXÕES ACERCA DO ESTUDO COMPARATIVO}

Com o intuito de refletir, relacionar e discutir os resultados gerados na temática e expostos no Capítulo anterior, está apresentado, neste Capítulo, um aprofundamento das considerações acerca das ações e estratégias de ensino propostas.

Análise da Ação de Ensino Mais Eficaz (Turma A): Com base nos parâmetros índice de sucesso, estratificação do índice de sucesso, percepção média sobre o curso, percepção sobre os módulos, avaliação final do curso e parâmetro retenção do conhecimento e, diferentemente do inicialmente esperado, a metodologia que se mostrou mais eficaz foi a baseada fundamentalmente em conteúdo escrito (Turma A), que tecnicamente se pautou em atividades menos interativas e mais conceituais. Nesse sentido, entende-se que os principais fatores que justificam essa observação são: (a) maior familiaridade com essa metodologia e preservação da zona de conforto do aluno; (b) maior possibilidade de controle da interatividade aluno/sistema, propiciando momentos de reflexão e complemento do conteúdo; (c) maior facilidade de retenção do conhecimento quando se utilizam metodologias fundamentadas em material escrito; (d) experiência de aprendizagem mais ativa, no qual coube ao aluno o protagonismo na formação do conhecimento e manipulação da informação; e, (e) a despeito do aumento da motivação do estudante quando se utilizam recursos mais interativos, é recomendável que tais ações estejam associadas a formas tradicionais de ensino e registro do conhecimento. Estudos foram encontrados na literatura científica (COIMBRA; SILVA, 2016; DINOV; SANCHEZ, 2008; GAO; LEHMAN, 2013), apresentando evidências preliminares que sustentam a hipótese de que ambientes ou ações de ensino que proporcionam experiências mais ativas com o aluno protagonista da aprendizagem (caso da Turma A), produzem ganhos de eficácia no ensino e retenção de conhecimento.

Análise do Público-alvo Atingido pelas Ações: Dos resultados apresentados no item 5.2, é possível tecer um conjunto de considerações sobre o tema. A saber: (i) foram realizadas ações de divulgação utilizando cartazes e, principalmente, via correio eletrônico direcionado a cursos de graduação, pós-graduação e institutos; e, em aproximadamente 30 dias, foram registrados 311 inscritos e uma lista de espera superior a 70 interessados. Tais informações evidenciam o destaque que ações na modalidade $\mathrm{EaD}$ e o tema $\mathrm{N} \& \mathrm{~N}$ têm ganhado na área de ciências da saúde e enfermagem. Relatos encaminhados pelos cursistas mostraram que o tema 
é visto como com potencial de revolucionar a temática nos tratamentos da área da saúde; (ii) as inscrições recebidas de cursistas internos à UnB foram superiores aos das demais instituições, evidenciando maior interesse pelo tema ou simplesmente maior acesso às informações do curso; (iii) comparando o nível de formação dos cursistas, os alunos de graduação representaram mais de $50 \%$ dos interessados na temática, provavelmente pelo maior número graduandos e o seu interesse nato em adquirir novos conhecimentos e ampliar a multidisciplinaridade de suas formações; e (iv) como esperado, os cursistas profissionais que já concluíram ao menos um curso de graduação - representaram pequena fração do total geral e tal classe exibe fundamentalmente formação em nível de graduação, mestrado e doutorado, buscam nesta modalidade de ensino mais conhecimentos na fronteira de suas áreas, bem como a formação continuada.

Análise dos Parâmetros Índices de Sucesso, Insucesso e Evasão: Em geral, os principais índices avaliados pelos gestores e professores de uma determinada ação de ensino na modalidade presencial ou educação a distância são os índices de sucesso, insucesso e evasão, uma vez que tais índices estão associados, dentre muitos fatores, à eficácia da aplicação e à qualidade do curso e fatores socioculturais. Analisando os resultados exibidos no item 5.3, é possível identificar três principais tendências associadas aos índices de sucesso, insucesso e evasão dos cursistas, na realização das ações de ensino:

(i) Para as ações de ensino realizadas neste estudo, destaca-se que o índice médio de sucesso obtido foi superior a $28 \%$. Com base na literatura científica, o índice de sucesso em ações na modalidade $\mathrm{EaD}$ nas mais diversas temáticas encontra-se na faixa de 10 a $25 \%$ (ABED, 2015). Nesse sentido, o índice médio de sucesso obtido está coerente com os valores reportados na literatura. Para índice geral de sucesso exibido pelas ações de ensino, sugere-se que o mesmo esteja associado: (a) à utilização planejada das TIC e sua funcionalidade, agregando mais interatividade às atividades, possivelmente aumentando a motivação dos alunos, viabilizando novas formas de acessar e construir o conhecimento; (b) à consolidação da utilização da modalidade EaD junto à comunidade acadêmica da UnB; (c) ao alinhamento do conteúdo programático proposto para as ações de ensino com os recursos e atividades pedagógicas mais adequadas, visando aumentar a relação entre aprendizagem e esforço; (d) ao nível de conhecimento prévio/escolaridade adequado para a complexidade e a especificidade da temática; e (e) à atualidade do tema e à potencialidade de revolução científica e tecnológica que a Nanociência e a Nanotecnologia podem proporcionar nas áreas de Ciências da Saúde e Enfermagem; 
(ii) Um dos principais pontos de reflexão da utilização da modalidade EaD é a evasão de estudantes. Segundo o Censo EAD Brasil 2014, o último divulgado pela Associação Brasileira de Educação a Distância (ABED, 2015), “a evasão é apontada por grande parte das instituições como um dos maiores obstáculos enfrentados nos diferentes tipos de cursos EAD”. Em geral, têm-se observado índices médios de evasão de $25 \%$ a $50 \%$ para ações totalmente a distância. Para as ações de ensino aplicadas às Turmas A, B e C, a taxa média de evasão não alcançou $20 \%$, permanecendo abaixo da faixa identificada pelo Censo EaD Brasil. A literatura indica diversos fatores associados com a taxa de evasão e insucesso em ações $\mathrm{EaD}$ (ABED, 2015), que estão presentes à realidade deste estudo e aos participantes da pesquisa, a saber: (a) maturidade acadêmica para utilização da modalidade a distância, que nem sempre está consolidada em toda a comunidade universitária; (b) a complexidade, multidisciplinaridade, especificidade e grau de abstração da temática $\mathrm{N} \& \mathrm{~N}$, uma vez que tais fatores induzem o aluno a buscar novos conhecimentos além do curso, e a especificidade da temática reduz a possibilidade de sua utilização profissional/ prática pelo aluno; (c) indisponibilidade de tempo para a realização adequada e satisfatória das atividades de estudo e avaliação; (d) dificuldade natural do curso e a falta de suporte personalizado a cada aluno; (e) falta de habilidade com tecnologias digitais utilizadas na modalidade EaD; (f) confusão e não atingimento das expectativas devido à inicialização em cursos sem o completo entendimento do tema e metodologia; ( $g$ ) falta de identificação do aluno com a temática e conteúdos abordados na ação de ensino; e (h) a gratuidade e não obrigatoriedade do curso (curso de extensão acadêmica) podem reduzir a motivação e envolvimento dos alunos com as metas e tempo a ser desprendido para a ação de ensino.

(iii) O índice de insucesso é um parâmetro complementar às taxas de sucesso e evasão e, consequentemente, os valores relatados na literatura estão entre 35 e $65 \%$, em ações de $\mathrm{EaD}$, nas mais diversas temáticas. Para as ações de ensino realizadas nos cursos, o índice médio de insucesso apresentou valor próximo a $52 \%$, quase no centro da faixa relatada na literatura científica. No caso específico desse índice, sugere-se que os principais fatores que influenciam este parâmetro sejam os mesmos que estão associados ao índice de evasão apresentado no item anterior. Acrescentam-se a esta lista os seguintes possíveis fatores: (a) organização temporal inadequada pode contribuir para a redução do rendimento e notas do cursista; e (b) dificuldade do aluno em seguir orientações ou do curso nas orientações para execução das atividades.

Cabe destacar que, ao realizar uma análise dos índices de sucesso, insucesso e evasão de cursos na modalidade EaD, é necessário considerar quais os critérios (metodologia de 
cálculo) cada autor ou gestor define para sua ação de ensino. Em geral, há uma tendência por parte dos gestores educacionais em considerar as taxas de sucesso e evasão como medidas de avaliação dos cursos a distância. Assim como no ensino regular presencial e independentemente do nível, na modalidade $\mathrm{EaD}$ os índices de sucesso, insucesso e evasão são grandes desafios para os gestores e para a sociedade. Do ponto de vista institucional, a evasão discente gera ineficiência na utilização de recursos financeiros e temporal, bem como desmotivação na equipe de ensino. No entanto, a reflexão dos prováveis motivos que levaram à evasão discente proporciona uma interessante avaliação de percurso para o aperfeiçoamento das ações de ensino. Do ponto de vista social, a evasão escolar implica a formação de uma sociedade com menor média de permanência escolar, fatores socioeconômicos e baixa qualificação média da sociedade (ALMEIDA, 2007).

Estratificação dos Î́ndices de Sucesso e Insucesso: Os índices de sucesso e insucesso de cursos na modalidade $\mathrm{EaD}$ estão associados a diversos fatores relacionados à população de alunos que se utilizam desta ação de formação, bem como a questões referentes à estrutura cognitiva do processo de ensino/aprendizagem e didática do curso. Cada módulo das ações de ensino foi avaliado por diversos instrumentos e compôs a média final do cursista, classificada segundo os critérios internos da UnB (SS, MS, MM, MI, II e SR). Estratificando o parâmetro índice de sucesso em menções SS e MS, identifica-se, em concordância com os valores absolutos do índice de sucesso, que os valores de ambas as menções decrescem com o tipo da ação de ensino (Turmas A, B e C) e são maiores para a menção MS. Considerando que a média final dos alunos em uma atividade de ensino exibe, em geral, um comportamento tipo distribuição normal ou gaussiana, era esperado que o percentual de notas MS superasse as notas SS, por estarem mais próximas da média geral das turmas. Ressalta-se também que, devido à multidisciplinaridade, complexidade e grau de abstração do tema, era esperado que o percentual de conceitos finais próximos à nota máxima (SS) fosse relativamente menor que as demais menções. Estratificando o parâmetro índice de insucesso em menções MM, MI, II, observa-se que a menção com maior valor é a II, entre 28,7 e $35,4 \%$, indicando que a maior parte dos alunos com insucesso na ação de ensino foi até próximo ao final do curso, porém com o aproveitamento muito baixo. Fatores como a complexidade do tema, necessidade de buscar conhecimentos complementares, conciliação com diversas outras atividades e baixa organização temporal do aluno foram, possivelmente, os principais fatores para o baixo aproveitamento.

Correlação dos Índices com a Origem dos Cursistas: Buscar correspondência entre os parâmetros índices de sucesso, insucesso e evasão e a origem dos cursistas por procedência 
(alunos UnB, alunos externos à UnB e profissionais), nível de formação (doutorado, mestrado e graduação) e área de atuação (ciências da saúde e áreas afins) pode sugerir fatores e indícios que atuaram decisivamente para a verificação dos valores observados. Com relação aos alunos aprovados nas três ações de ensino (total de 70), afere-se que 53\% são alunos da UnB, 30\% são alunos externos à UnB e 17\% são profissionais. Dos alunos da UnB aprovados, destaca-se que a maior parte (29\%) são graduandos na área de saúde. Tal valor pode se justificar, uma vez que a maior quantidade de alunos inscritos tinha esse perfil - alunos de graduação - e, em geral, com maior disponibilidade temporal para se dedicar a cursos complementares e mais interesse pela formação com temas da atualidade. Com relação aos alunos não aprovados (insucesso) nas três ações de ensino (total de 119), destaca-se que 50\% estão matriculados na UnB, $39 \%$ são externos à UnB e $11 \%$ são profissionais. Dos alunos internos e externos à UnB não aprovados, destaca-se que a maior parte $(80 \%)$ são graduandos. Tal valor pode se justificar, uma vez que a maior quantidade de alunos inscritos tinha esse perfil e, em geral, têm maior propensão a não administrar adequadamente o tempo e maior dificuldade com temas multidisciplinares e complexos. Proporcionalmente, o índice de insucesso dos cursistas profissionais também foi alto, indicando provavelmente o não ajuste do escopo da ação de ensino com suas expectativas profissionais e/ou necessidade de conciliação com diversas atividades profissionais. Já analisando os alunos que compuseram o índice de evasão nas três ações de ensino (total de 41), cabe enfatizar que 54\% são alunos externos à UnB, $27 \%$ são alunos da UnB e 19\% são profissionais. Dos alunos externos à UnB evadidos, registra-se que a maior parte (34\%) são de graduação, da área de Ciências da Saúde. Sugere-se que a maior quantidade de alunos evadidos tenha esse perfil devido à complexidade e especificidade do tema. Sugere-se também que, absoluta e proporcionalmente, o índice de evasão nas ações de ensino seja menor entre os alunos da UnB devido à cultura já consolidada de utilização de ações na modalidade totalmente a distância.

Análise dos Parâmetros "Percepção Média sobre o Curso" e "Percepção sobre os Módulos" e "Avaliação Final do Curso": Os parâmetros "Percepção sobre os Módulos" e "Percepção Média sobre o Curso" referem-se, respectivamente, à média das avaliações destes parâmetros realizadas pelos cursistas ao final de cada módulo e à média entre essas percepções. Tais parâmetros são dependentes fundamentalmente da qualidade técnica e metodológica do conteúdo do curso, sobreposição entre o nível mínimo necessário para boa realização do curso e o nível médio de formação do corpo discente, fornecendo subsídios de acompanhamento com o intuito de garantir a qualidade técnico-metodológica do curso. Analisando os resultados referentes à percepção média das turmas para com a qualidade 
técnica do módulo, a partir de sua percepção individualizada, Fig. 25 (a), identifica-se média máxima igual a 9,0 (9,0 pontos, em 10 possíveis) para ação de ensino ministrada à Turma $\mathrm{A}$ e a média mínima igual a 8,2 (8,2 pontos, em 10 possíveis) para a ação de ensino ministrada à Turma C. Dessa forma, o perfil de evolução dos dados observados anteriormente foi mantido, reforçando a sugestão da maior eficácia da ação de ensino baseada em conteúdo escrito. Com relação à percepção dos cursistas sobre cada módulo, destaca-se que o padrão de melhores resultados para metodologia aplicada à Turma $\mathrm{A}$ foi mantido para todos os módulos, com exceção do Módulo 5. Cabe destacar que, para os três módulos iniciais, a diferença de percepção entre as ações de ensino foi mais abrupta, possivelmente devido ao fato de serem módulos que abordam os conceitos iniciais e mais intuitivos. Já para os módulos finais $(4,5$ e 6), que trataram de temas mais abstratos, a diferença de percepção entre eles foi menos abrupta. Nesse contexto, sugere-se que a boa percepção sobre o módulo esteja associada à maior percepção de aprendizagem do tema e com a interação mais ativa com o conteúdo, sendo então maior para os módulos da Turma A. Sugere-se também que a possibilidade de maior manuseio do conteúdo por parte do aluno e a possibilidade de buscar conhecimento complementar tenham favorecido a boa percepção sobre os módulos na Turma A.

Análise do Parâmetro "Avaliação Final do Curso": $O$ processo de acompanhamento e avaliação da aprendizagem foi realizado ao longo das três ações de ensino por meio das discussões realizadas em cada atividade, nível de interação dos alunos no fórum, nível das respostas a instrumentos de avaliação dos módulos, frequência de acesso e participação no ambiente virtual de aprendizagem, entre outros. Ao término do curso, foi realizada uma Avaliação final, que consistiu no compêndio das 30 principais questões (30 questões, com níveis de dificuldade e peso diferentes) sobre os temas abordados ao longo do curso. Em concordância com os resultados observados para os parâmetros anteriores, o maior (9,3 pontos, em 10 possíveis) e menor ( 8,8 pontos, em 10 possíveis) valores médios foram observados para a Turma A e C, respectivamente, sugerindo a maior eficácia da metodologia desenvolvida na ação de ensino aplicada a Turma A. Como esperado, as maiores notas foram obtidas com maior frequência por cursistas da Turma A e decresceram em função da ação de ensino, reforçando a percepção de maior eficácia de aprendizado da Turma A.

Cabe registrar que o processo avaliativo tem sido objeto de grande discussão na comunidade acadêmica e produtiva devido à sua: (i) complexidade técnico-científica, no qual buscam-se desenvolver ferramentas e metodologias para aumentar a representatividade da informação; (ii) dimensão formativa, visando acompanhar o desenvolvimento do aluno e orientá-lo no processo de busca pelo conhecimento; e (iii) dimensão somativa, visando o 
monitoramento do caminho a ser seguido e cumprimento dos objetivos propostos. Tais dimensões são sensíveis à multidisciplinaridade, complexidade e especificidade da temática "Nanociência e Nanotecnologia aplicadas às Ciências da Saúde e Enfermagem" e foram levadas em consideração na montagem do processo avaliativo das ações de ensino comparadas (OTSUKA et al., 2011; OTSUKA et al., 2004). Nesse sentido, a avaliação final do curso de educação a distância é refletida de forma que favoreça o processo de aprendizagem do cursista, levando em consideração as especificidades desta modalidade de ensino, que cada vez mais exige do aluno protagonismo, interação, autonomia e colaboração. A utilização de atividades avaliativas no processo de ensino-aprendizagem visa aprimorar as práticas de educação a distância, potencializar os pontos positivos e reformular os pontos negativos da avaliação, identificar as dificuldades do aluno e planejar intervenções pedagógicas mais assertivas. Nesse contexto, identifica-se que os parâmetros analisados apresentaram resultados satisfatórios, refletindo informações sobre elementos necessários à implementação de uma avaliação nos espaços de aprendizagem a distância, sobretudo para assegurar um padrão de qualidade aos processos de ensino-aprendizagem na modalidade EaD (ROQUE; SILVA, 2011).

Análise do Parâmetro "Retenção do Conhecimento": O conceito de retenção do conhecimento ou retenção de informação, em função do tempo, está diretamente associado ao processo de aprendizagem e consequentemente à qualidade da ação de ensino, bem como em fatores que podem facilitar ou dificultar a retenção do conhecimento por parte dos alunos. Visando monitorar a efetividade da retenção dos conteúdos abordados no curso e estimar o nível de aprendizagem significativa dos alunos, cada cursista foi convidado a responder periodicamente, após 20, 60 e 100 dias, um questionário pela plataforma MOODLE sobre tópicos básicos e fundamentais abordados nos seis módulos finalísticos do curso. A utilização de atividade de retenção do conhecimento ao final de curso EaD pode ser uma excelente estratégia para avaliar e validar se as etapas metodológicas selecionadas foram adequadas, e consequentemente agregar valor à ação de ensino. Para potencializar o processo de ensinoaprendizagem na educação a distância, é desejável um espaço interativo, confiável, em que a reciprocidade na construção do conhecimento seja estimulada. Analisando os resultados do parâmetro "Percentual médio de retenção de conhecimento" dos cursistas, de acordo com a metodologia descrita do item 5.7 (AUSUBEL, 2000), observa-se o mesmo padrão de evolução dos parâmetros anteriores. A média máxima (88\%) para ação de ensino ministrada a Turma A e a média mínima (76\%) para a ação de ensino ministrada a Turma $\mathrm{C}$ reforçaram a sugestão da maior eficácia da ação de ensino baseada em conteúdo escrito. Como esperado, a 
tendência média é de redução da retenção do conhecimento em função do tempo (Fig. 27); porém, como desejando, tais reduções ocorreram a taxas não elevadas. Tais observações sugerem que, ao menos, os conceitos básicos da Nanociência e Nanotecnologia aplicadas às Ciências da Saúde e enfermagem foram preservados nesse intervalo de tempo, indicando a adequação da utilização de metodologias EaD para essa finalidade. Segundo Battisti (2012), o conceito de retenção do conhecimento está intrinsicamente associado ao conceito de aprendizagem significativa, que reside em duas características fundamentais do novo conhecimento: (i) não arbitrariedade; e (ii) substantivação. Nesse sentido, a aprendizagem se torna significativa à medida que os novos conceitos são agrupados às estruturas de conhecimento prévio do cursista. Sugere-se que esse processo foi mais favorecido para a ação de ensino aplicada à Turma $\mathrm{A}$, uma vez que nesta metodologia o aluno não atuou apenas como um receptor passivo, mas colaborou com a construção do seu próprio conhecimento. 


\section{CONCLUSÕES E PERSPECTIVAS FUTURAS}

A popularização e a difusão da tecnologia digital nos últimos 20 anos têm transformado significativamente a sociedade, bem como se trata de um movimento irreversível. A tecnologia tem proporcionado mudanças na vida pessoal e profissional dos indivíduos, impactando diretamente sobre a sociedade em diferentes aspectos como, por exemplo, formas de trabalho, comunicação, acesso e formas de obtenção. Nesse contexto, ações de ensino parcial ou totalmente a distância já correspondem a mais $25 \%$ das ações de ensino no Brasil. No país, o percentual de matrículas em cursos de graduação privados subiu expressivamente de menos de 1\% em 2004 para mais de 20\% no mesmo ano. Para o biênio 2016-17, espera-se que esse crescimento seja ainda mais acentuado em decorrência da redução de porte do Programa FIES e da crise econômica no Brasil, ambos causando migração natural do ensino presencial para o ensino a distância.

Devido aos seus pontos fortes, como flexibilidade temporalmente, baixo custo per capita, ausência de limitações geográficas, possibilidade de oferta de um grande número de vagas, entre outros, a educação a distância vem ampliando significativamente sua inserção na sociedade e mudando/complementando a forma de aprendizagem e acesso ao conhecimento. Temas atuais, multidisciplinares e complexos, como a Nanociência e a Nanotecnologia, começaram a ser difundidos por meio dessas ações de ensino. Baseado na literatura científica e nos resultados obtidos na execução das três turmas deste trabalho, não foram identificadas limitações expressivas que inviabilizariam a utilização de ações de aprendizado totalmente a distância para a temática N\&N aplicadas à ciência da saúde e enfermagem.

Ações de ensino na modalidade EaD na temática N\&N, aplicadas às Ciência da Saúde e enfermagem, ainda são mínimas no sistema nacional de ensino e estão concentradas fundamentalmente na forma de cursos de extensão (entre 40 e 60h), ações de atualização profissional e disciplinas de graduação e pós-graduação. Os temas abordados nas ações são, em geral: conceitos básicos sobre Nanociência e Nanotecnologia, contextualização da escala manométrica, aplicações gerais (eletrônica, têxtil, agronegócio, automobilísticas entre outros) e aplicações nas áreas de Ciências da Saúde (sistemas tipo drug-delivery, diagnósticos rápidos, sensores, fármacos, cosméticos e cosmecêuticos).

Existem relativamente poucos estudos sobre os melhores caminhos para o ensino e difusão da Nanociência e Nanotecnologia, aplicadas às ciências da saúde, utilizando ambientes virtuais de ensino. No entanto, tanto as aplicações da Nanotecnologia, quanto a 
forma inovadora de ensiná-la e difundi-la na formação de recursos humanos, tem potencial para proporcionar significativos avanços para a sociedade. Nesse sentido, os temas de maior relevância identificados foram: (i) Conceitos Básicos Sobre N\&N; (ii) Aplicações Consolidadas da Nanotecnologia; (iii) Materiais para Sistemas Tipo Drug Delivery; (iv) N\&N Aplicadas Contra o Câncer; (v) Biomateriais e Nanobiossensores; e (vi) Nanobiomáquinas e Nanobaterias.

Dentre os principais resultados obtidos no trabalho, destacam-se: (i) o público-alvo com maior expressividade foi de alunos de graduação externos a UnB na área de ciências da saúde (25,7\%); (ii) o parâmetro "Índice de Sucesso ou Aprovados" foi melhor avaliado para Turma A (39,6\%), enquanto a Turma C exibiu o menor valor (12,5\%) e, consequentemente, a Turma A apresentou o menor valor de "Insucesso ou Não Aprovados", e para o índice de "Evasão" a Turma C obteve o maior valor (29,7\%); (iii) para o parâmetro de "Sucesso", a menção com maior frequência de ocorrência foi a MS para Turma A $(23,8 \%)$, sendo que a maior diferença ocorreu com a Turma C; (iv) para a correlação dos Índices de "Sucesso, Insucesso e Evasão" quanto à origem dos cursistas, os alunos de graduação da UnB na área de ciências da saúde foram os que tiveram melhor aproveitamento; (v) com relação ao conceito médio do curso, registra-se que a Turma A apresentou melhor avaliação entre as ações de ensino performadas $(9,0)$; e, (vi) para o parâmetro "Média da Avaliação de Retenção do Conhecimento" por ação de ensino, este exibiu valores percentuais altos, porém decrescentes, sendo iguais a $88 \%$ para a Turma A, $85 \%$ para a Turma B e $76 \%$ para a Turma C.

Associado à análise sobre o grau de eficácia das três ações de ensino da N\&N, aplicadas às ciências da saúde e enfermagem na modalidade $\mathrm{EaD}$, pode-se enfatizar que a ação de ensino aplicada à Turma $\mathrm{A}$, baseada principalmente em conteúdos escritos, exibiu melhor avaliação. Tal fato está associado a diversos fatores, dos quais podem-se citar: (i) maior familiaridade com a metodologia e maior grau de retenção da informação quando utiliza-se ferramentas cognitivas associadas a leitura; e (ii) maior facilidade de ênfase aos pontos mais importantes de cada tema.

\section{Perspectivas para Trabalhos Futuros}

(i) Aprofundar as análises dos resultados obtidos com a realização das ações de ensino, levando em consideração outros parâmetros como, por exemplo, sociais e econômicos, correlação com outras atividades acadêmicas, entre outros; 
(ii) Realizar nos estudos para testar a eficácia e efetividade das ações de ensino, utilizando diferentes proporções temporais (EaD/Presencial), comparando ações totalmente e parcialmente a distância e totalmente presencial;

(iii) Analisar os resultados quantitativos obtidos do ponto de vista estatístico e do espaço amostral, utilizado, com o intuito de realizar estrapolações e generalizações de tendências e conclusões alcançadas com o trabalho;

(iv) Testar e comparar a eficácia e efetividade dessas ações de ensino para grupos amostrais provenientes de áreas distintos (exatas, humanas, biológicas e saúde), objetivando avaliar como diferentes backgrounds podem influenciar no processo de aprendizagem;

(v) Desenvolver atividades de transferência de conhecimento no tema por meios de ações, como a Disciplina que será ofertada via NESPROM-CEAM-UnB e pela empresa Mais E-duc e projetos de difusão científica (FAP-DF e CAPES), com a finalidade de testar as ações em diferentes objetivos; e

(vi) Promover e estimular a difusão do conhecimento e reflexões geradas na temática $\mathrm{EaD}$, destinada ao ensino de $\mathrm{N} \& \mathrm{~N}$ aplicadas às ciências da saúde à sociedade em geral (incluindo professionais da saúde) por meio de publicações, seminários, fóruns e cursos. 


\section{REFERÊNCIAS}

ABDI, Agência Brasileira de Desenvolvimento Industrial. Cartilha sobre nanotecnologia. Brasília, DF, 2010a. Disponível em:

$<$ http://www.abdi.com.br/Estudo/Cartilha\%20nanotecnologia.pdf $>$. Acesso em: 22 jun. 2016.

ABDI, Agência Brasileira de Desenvolvimento Industrial. Estudo prospectivo nanotecnologia. Brasília, DF, p. 392, 2010b. (Série Cadernos da Indústria ABDI XX). Disponível em:

$<$ http://www.abdi.com.br/Estudo/Estudo\%20Prospectivo\%20de\%20Nanotecnologia.pdf $>$. Acesso em: 22 jun 2016.

ABDI, Agência Brasileira de Desenvolvimento Industrial. Panorama de nanotecnologia. Brasília, DF, p. 180, 2010c. (Série Cadernos da Indústria ABDI XIX). Disponível em: $<$ http://www.abdi.com.br/Estudo/Panorama\%20de\%20Nanotecnologia.pdf $>$. Acesso em: 22 jun. 2016.

ABED. Censo EaD Brasil 2014: relatório analítico da aprendizagem a distância no Brasil. Curitiba: Ibpex, 2015. Disponível em: <www.abed.org.br>. Acesso em: 01 mai. 2016.

ADAMS, F.C.; BARBANTE, C. Nanoscience, nanotechnology and spectrometry. Spectrochimica Acta Part B, v. 86, p. 3-13, 2013. Disponível em: $<$ http://dx.doi.org/10.1016/j.sab.2013.04.008>. Acesso em: 10 jan. 2016.

ALFONSO, A. B. Situação atual da divulgação e do treinamento em nanociência e nanotecnologia no Brasil. Mundo Nano - Red NANODYF-CYTED, v. 4, n. 2, 2011. Disponível em: <www.mundonano.unam.mx>. Acesso em: 02 abr. 2016.

ALMEIDA, O. C. de S. de. Evasão em cursos a distância: validação de instrumento, fatores influenciadores e cronologia da desistência. 2007. 177f. Dissertação (Mestre em Gestão Social e do Trabalho) - Universidade de Brasília, Brasília, 2007.

ALVES, L. Educação a Distância: conceitos e história no Brasil e no mundo. Associação Brasileira de Educação a Distância, v. 10, 2011. Disponível em:

$<$ http://www.abed.org.br/revistacientifica/Revista_PDF_Doc/2011/Artigo_07.pdf $>$. Acesso em: 22 ago. 2015.

ALVES, V. L. de S.; BOHOMOL, E.; CUNHA, I. C. K. O. Educação de pós-graduação em enfermagem à distância: avaliação sob a perspectiva dos discentes. Acta Paulista de Enfermagem, v. 28, nº 2, p. 139-145, 2015. Disponível em:

$<$ http://www.scielo.br/pdf/ape/v28n2/1982-0194-ape-28-02-0139.pdf>. Acesso em: 01 ago. 2016.

ANDERSON, G.; TREDWAY, C.; CALICE, C. A longitudinal Study of Nursing Students' Perceptions of Online Course Quality. Journal of Interactive Learning Research, v. 26, n. 1, p. 5-21, 2015. Chesapeake, VA: Association for the Advancement of Computing in Education (AACE). 
ANVISA, AGÊNCIA NACIONAL DE VIGILÂNCIA SANITÁRIA. Diagnóstico

Institucional de Nanotecnologia. Brasília, DF, 2014. Disponível em:

$<$ http://portal.anvisa.gov.br/wps/wcm/connect/fb117d80436c3cacb1b5b72a042b41f5/Diagn\%

C3\%B3stico+Institucional+de+Nanotecnologia+-+CIN+2014+-

+ Dicol.pdf?MOD=AJPERES $>$. Acesso em: 20 jun. 2015.

AUSUBEL, D. P. Aquisição e retenção de conhecimentos: uma perspectiva cognitiva. Plátano Edições Técnicas, Lisboa. Paralelo Editora: 1 ed. 2000.

BARBOSA, A. F. (Coord). Pesquisa sobre o uso das tecnologias da informação e comunicação nos domicílios brasileiros (livro eletrônico): TIC domicílios 2015. São Paulo: Comitê Gestor da Internet no Brasil, 2015a.

BARBOSA, A. F. (Coord). Pesquisa sobre o uso das tecnologias da informação e comunicação nas escolas brasileiras (livro eletrônico): TIC educação 2014. São Paulo: Comitê Gestor da Internet no Brasil, 2015b. Disponível em:

$<$ http://cetic.br/media/docs/publicacoes/2/TIC_Educacao_2014_livro_eletronico.pdf $>$. Acesso em: 17 ago. 2016.

BARBOSA, A. F. (Coord). Pesquisa sobre o uso das tecnologias de informação e comunicação nos estabelecimentos de saúde brasileiros (livro eletrônico): TIC Saúde 2014. São Paulo: Comitê Gestor da Internet no Brasil, 2015c. Disponível em:

$<$ http://www.cetic.br/media/docs/publicacoes/2/tic_saude_2014_livro_eletronico.pdf $>$. Acesso em: 17 ago. 2016.

BATTISTI, P. Retenção do Conhecimento na EaD: “O Estudo de Caso do Programa de Capacitação em Rede - Competências para o Ciclo de Desenvolvimento de Inovações Projeto e-NOVA”. 2012. 131f. Dissertação (Mestrado em Engenharia e Gestão do Conhecimento) - Universidade Federal de Santa Catarina, UFSC, Florianópolis, 2012.

BAYOMI, M. A. et al. In vivo evaluation of arteether liposomes. Int. J. Pharm., Amsterdam, v. 175, p. 1-7, 1998. Disponível em: <http://dx.doi.org/10.1016/S03785173(98)00182-3>. Acesso em: 12 nov. 2015.

BELLUCCI, F. S. Caracterização dielétrica de partículas nanométricas e nanoestruturadas de óxido de niobato da família tetragonal tungstênio bronze com estequiometria KSr $2 \mathbf{N b}_{5} \mathbf{O}_{15}$. 2008. 158f. Dissertação (Mestrado em Ciência e Tecnologia de Materiais) - Faculdade de Ciências e Tecnologia, Universidade Estadual Paulista, Presidente Prudente, 2008.

BERKOWITZ, A. C.; GODDARD, D. M. Novel drug delivery systems: future directions. J. Neurosc. Nurs. v. 41, n. 2, p. 115-20, 2009. Disponível em:

$<$ https://www.ncbi.nlm.nih.gov/pubmed/19361127>. Acesso em: 20 jan. 2016.

BRASIL. Decreto 5.622, de 19 de dezembro de 2005. Regulamenta o artigo 80 da Lei ${ }^{\circ}$ 9.394, de 20 de dezembro de 1996, que estabelece as diretrizes e bases da educação nacional. Diário Oficial (da República Federativa do Brasil), Brasília, 2005. Disponível em: $<$ http://www.planalto.gov.br/ccivil_03/_ato2004-2006/2005/decreto/d5622.htm>. Acesso em: 15 abr. 2016. 
BRASIL. Decreto 5.773, de 9 de maio de 2006. Dispõe sobre o exercício das funções de regulação, supervisão e avaliação de instituições de educação superior e cursos superiores de graduação e sequenciais no sistema federal de ensino. Diário Oficial (da República Federativa do Brasil), Brasília, DF, 10 mai. 2006. Disponível em: $<$ http://www2.mec.gov.br/sapiens/portarias/dec5773.htm>. Acesso em: 25 ago. 2016.

BRASIL. Decreto 6.303, de 12 de dezembro de 2007. Altera dispositivos dos Decretos nos 5.622, de 19 de dezembro de 2005, que estabelece as diretrizes e bases da educação nacional, e 5.773, de 9 de maio de 2006, que dispõe sobre o exercício das funções de regula- ção, supervisão e avaliação de instituições de educação superior e cursos superiores de graduação e sequenciais no sistema federal de ensino. Diário Oficial (da República Federativa do Brasil), Brasília, DF, 13 dez. 2007. Disponível em: $<$ http://www.planalto.gov.br/ccivil_03/_Ato20072010/2007/decreto/D6303.htm>. Acesso em: 25 ago. 2016.

BRASIL. Ministério da Ciência, Tecnologia e Inovação. Secretaria de Desenvolvimento Tecnológico e Inovação. A nanotecnologia como plataforma tecnológica para a inovação. Brasília, 2012-2013. 86p.

BRASIL. Portaria $n^{\circ} 10$, de 02 de julho de 2009. Fixa critérios para dispensa de avaliação in loco e dá outras providências. Diário Oficial (da República Federativa do Brasil), Brasília, DF, 03 jul. 2009. Disponível em:

$<$ http://portal.mec.gov.br/dmdocuments/portaria10_seed.pdf $>$. Acesso em: 25 ago. 2016.

CHAN, Z. C. Y. Students' and Experts' Perspectives on Three Learning and Teaching Activities. Nurse Educ Pract, v. 14, n. 5. p. 449-454, 2014. Disponível em: $<$ https://www.ncbi.nlm.nih.gov/pubmed/24679519>. Acesso em: 24 jan. 2016.

COIMBRA, V. C.; SILVA, L. D. T. A. da. Uma reflexão da formação docente frente aos desafios da atualidade no âmbito da EaD. v. 5, n. 1, 2016. Disponível em:

$<$ http://www.periodicos.letras.ufmg.br/index.php/anais_linguagem_tecnologia/article/view/10 593/9421>. Acesso em: 10 ago. 2016.

Communication from the commission: to the European parliament, the council, the European economic and social committee and the committee of the regions on the regions. ' $A$

European Strategy for Key Enabling Technologies - A Bridge to Growth and Jobs'. COM, 2009.

CRESWELL, J. W. Projeto de pesquisa: métodos qualitativo, quantitativo e misto. Artmed, 2010.

CUNHA, J. (Coord). Acordo entre Estácio e Kroton vai movimentar educação a distância. Folha de São Paulo. 12 jul. 2016. Disponível em:

$<$ http://www1.folha.uol.com.br/mercado/2016/07/1790728-acordo-entre-estacio-e-kroton-vaimovimentar-educacao-a-distancia.shtml>. Acesso em: 27 ago. 2016.

CURTIS, A.; WILKINSON, C. Nantotechniques and approaches in biotechnology. Trends Biotechnol., v. 19, n. 3, p. 97-101, 2001. Disponível em: $<$ https://www.ncbi.nlm.nih.gov/pubmed/11179802>. Acesso em: 16 set. 2015. 
DIMER, F. A. et al. Impactos da nanotecnologia na saúde: produção de medicamentos. Quím. Nova [online]. v. 36, n. 10, p. 1520-1526, 2013. Disponível em:

$<$ http://dx.doi.org/10.1590/S0100-40422013001000007>. Acesso em: 30 jul. 2015.

DINOV, N. C.; SANCHEZ, J. Central limit theorem: new SOCR applet and demonstration activity. Journal of Statistics Education. v. 16, n. 2, 2008. Disponível em: <www2.amstat.org/publications/jse/v16n2/dinov.html>. Acesso em: 10 ago. 2016. Education, v. 37, n. 1, p. 1-3, mai. 2016. Disponível em: $<$ http://dx.doi.org/10.1080/01587919.2016.1157010>. Acesso em: 02 jun. 2016.

ELLWANGER, A. L. et al. O ensino de nanociências por meio de objetos de aprendizagem. CINTED-UFRGS. Novas tecnologias na educação. v. 10, n. 1, 2012. Disponível em: $<$ http://seer.ufrgs.br/renote/article/download/30884/19237>. Acesso em: 10 abr. 2016.

FALLEIROS, J. P. B.; BRANDL, A. L.; FONSECA, A. R. A. da. Aplicações da nanotecnologia no diagnóstico e tratamento de câncer. Nucleus, v.8, n.1, p. 1-20, 2011. ISSN-e 1982-2278. Disponível em: <http://www.technology.org/2013/05/28/research-offerspromising-new-approach-to-treatment-of-lung-cancer/>. Acesso em: 13 abr. 2015.

FECYT. Fundación Española para la ciência y la tecnologia. Nanociencia y Nanotecnología. Entre la ciencia ficción del presente y la tecnología del futuro. Gobierno de España. Ministerio de Ciencia y Innovación. 2009. Disponível em: $<$ http://www.fecyt.es $>$. Acesso em: 05 mai. 2016.

FEYNMAN, R. P. Plenty of Room at the Bottom. American Physical Society annual meeting, CalTech, 1959.

FIGUEIRAS, A. R. R.; COIMBRA, A. B.; VEIGA, F. J. B. Nanotecnologia na saúde: aplicações e perspectivas. Boletim Informativo Geum., v. 5, n. 2, p. 14-26, 2014. ISSN $2237-$ 7387. Disponível em: <http://revistas.ufpi.br/index.php/geum/article/view/1729/1705>. Acesso em: 26 fev. 2016.

GAO, T.; LEHMAN, J. D. The effects of different levels of interaction on the achievement and motivational perceptions of college students in a web-based learning environment. Journal of Interactive Learning Research, v. 14, n. 4, p. 367-386, 2013.

HOLANDA, V. R. et al. Ensino e Aprendizagem em Ambiente Virtual: Atitude de Acadêmicos de Enfermagem. Revista Mineira de Enfermagem, v. 19, n. 1, p. 141-147, 2015. Disponível em: <http://www.reme.org.br/exportar-pdf/992/v19n1a12.pdf $>$. Acesso em: 01 fev. 2016.

Instituto Inovação. Nanotecnologia. Knowledge Center. 2005. Disponível em: $<$ http://institutoinovacao.com.br/>. Acesso em: 21 jun. 2016.

JORDAN, K. MOOC Completion Rates. Disponível em: <http://www.katyjordan.com/>. Acesso em: 21 ago. 2016. 
KAKUSHI, L. E.; ÉVORA, Y. D. M. Social networking in nursing education: integrative literature review. Rev. Latino-Am. Enfermagem. v. 24, 2016. Disponível em: $<$ http://dx.doi. org/10.1590/1518-8345.1055.2709>. Acesso em: 13 ago. 2016.

KATO, Y.; ITO, D.; KITANI, Y. Blue-colored gold nanoparticles for immunological measurement, process for production of same, and measurement method using same. PCT/JP2011/075519, 2013.

KENNEDY, E.; LAURILLARD, D.; HORAN, B.; CHARLTON, P. Making meaningful decisions about time, workload and pedagogy in the digital age: the Course Resource Appraisal Model. Distance Education, v. 36, n 2, pag. 177-195, jun. 2015. Disponível em: $<$ http://dx.doi.org/10.1080/01587919.2015.1055920>. Acesso em: 04 jun. 2016. doi: 10.1080/01587919.2015.1055920.

LACERDA, G. L. Educação a distância na formação profissional continuada de professores da educação básica: analisando contratos e destratos didáticos a partir de um estudo de caso. Educar em Revista (Impresso), p. 275-290, 2014.

LAKATOS, E. M.; MARCONI, M. de A. Fundamentos de metodologia científica. 6. ed. 5. reimp. São Paulo: Atlas, 2007.

MARCIAL, E.C. (Org.). Megatendências mundiais 2030: o que entidades e personalidades internacionais pensam sobre o futuro do mundo? : Contribuição para um debate de longo prazo para o Brasil. Brasília: Ipea, 2015. p. 175. Disponível em:

$<$ http://www.ipea.gov.br/portal/index.php?option=com_content\&view=article\&id=26450>. Acesso em: 14 mar. 2016.

MARCONE, G. P. de S. Nanotecnologia e nanociência: aspectos gerais, aplicações e perspectivas no contexto do brasil. Perspectivas da Ciência e Tecnologia, v.7, n. 2, 2015. Disponível em:

$<$ http://revistascientificas.ifrj.edu.br:8080/revista/index.php/revistapct/article/view/588/377>. Acesso em: 10 abr. 2016.

MCNEW, R. E. et al. Distance education programs: the technical support to be successful. Stud Health Technol Inform. 2016; 225: p. 987-8. PubMed PMID: 27332445. Disponível em: $<$ http://www.ncbi.nlm.nih.gov/pubmed/27332445>. Acesso em: 29 jul. 2016.

MULVANEY, P. Nanoscience vs nanotechnology-defining the field. ACS Nano, v. 9, n. 3, p. 2215-2217, 2015. Disponível em: <http://pubs.acs.org/doi/abs/10.1021/acsnano.5b01418>. Acesso em: 12 mai. 2016.

NAIDU, S. The case for open educational practice. Distance Education, v. 37, n. 1, p. 1-3, mai. 2016. Disponível em:

$<$ http://dx.doi.org/10.1080/01587919.2016.1157010>. Acesso em: 02 jun. 2016.

NOVO, M. S. Nanociência, nanotecnologia: uma visão desde seu nascimento até apresentação das temáticas à sociedade. 2003. 94f. Tese (Doutorado em Educação e Ciências) - Programa de Pós-Graduação em Ciências: Química da Vida e da Saúde, FURG, 2013. 
OLIVEIRA, A. E. de; SILVA, E. da. Educação a distância e sua contribuição na inclusão social. v. 5, n. 10, 2015. ISSN: 2236-4099.

OLIVEIRA, A.; STADLER, P. de C. Videoaulas: uma forma de contextualizar a teoria na prática. Curitiba, mai. 2014.

OLIVEIRA, D. S. de. O uso do vídeo em EaD: desafios no processo de ensino aprendizagem. Rev. Cesuca Virtual: conhecimento sem fronteiras, v.1, n. 1, jul. 2013.

OLIVEIRA, R. F. de. et al. Water-gated phthalocyanine transistors: Operation and transduction of the peptide-enzyme interaction. Organic Electronics. v. 31, p. 217-226, 2016. Disponível em: <http://dx.doi.org/10.1016/j.orgel.2016.01.041>. Acesso em: 04 jun. 2016.

OTANI, M. A. P et al. A educação a distância na formação de profissionais da saúde: revisão integrativa da literatura. Investigação Qualitativa em Saúde. Atas CIAIQ, v. 2. 2016. Disponível em: < http://proceedings.ciaiq.org/index.php/ciaiq2016/article/view/757>. Acesso em: 28 jul. 2016.

OTSUKA, J. L. et al. Avaliação online: o modelo de suporte tecnológico do projeto teleduc. 2004.

OTSUKA, J. L. et al. Educação a Distância: formação do estudante virtual. São Carlos: UAB-UFSCar, 2011. Disponível em: < http://hdl.handle.net/123456789/660>. Acesso em: 07 out. 2015.

OTSUKA, J. L. et al. Educação a Distância: formação do estudante virtual. São Carlos: 2011.

PIMENTEL, L. F. et al. Nanotecnologia farmacêutica aplicada ao tratamento da malária. Ver. Bras. Cienc. Farm. [online]. v. 43, n. 4, p. 503-514, 2007. Disponível em: $<$ http://dx.doi.org/10.1590/S1516-93322007000400003>. Acesso em: 12 ago. 2015.

PINTO, A. A. M. et al. Métodos de ensino na graduação em enfermagem: uma revisão integrativa da literatura. Investigação Qualitativa em Educação. Atas CIAIQ: v. 1. 2016. Disponível em: <http://proceedings.ciaiq.org/index.php/ciaiq2016/article/view/693/681>. Acesso em: 22 ago. 2016.

POSSARI, L. H. V.; NEDER, M. L. C. Material didático para a EaD: processo de produção. Cuiabá: EdUFMT, 2009.

PUC-RJ - Engenharia em Nanotecnologia. Mandala da Nanotecnologia. Rio de Janeiro, 2011. Disponível em: $<$ http://nanotech.ica.ele.puc-rio.br/img/mandala.gif $>$. Acesso em: 05 mai. 2015.

ROQUE, G. O. B.; SILVA, L. M. da. Metodologia para avaliação e acompanhamento de cursos a distância: em busca da qualidade. 2011 
RUSH, P. Isolation and Connection: the experience of distance education. International Journal of E-Learning \& Distance Education. v. 30, n. 2, 2015. Disponível em:

$<$ http://www.ijede.ca/index.php/jde/article/view/936/1597>. Acesso em: 15 ago. 2016.

SANCHEZ, F. (Coord). Anuário Brasileiro Estatístico de Educação Aberta e a Distância. AbraEAD. 4 ed. São Paulo: Instituto Monitor, 2008. Disponível em:

$<$ http://www.abraead.com.br/anuario/anuario_2008.pdf>. Acesso em: 02 abr. 2016.

SANTOS, A. P. dos; ROSA, S. V. L. Uma didática para o ensino de Nanotecnologia. Quaestio, Sorocaba, SP, v. 18, n. 1, p. 293-308, mai. 2016. Disponível em:

$<$ http://periodicos.uniso.br/ojs/index.php?journal $=$ quaestio\&page $=$ article\&op $=$ view\&path $\% 5$ $\mathrm{B} \% 5 \mathrm{D}=2579 \&$ path\%5B\%5D=2177>. Acesso em: 29 jun. 2016.

SANTOS, A. P. R. et al. Aplicação da nanotecnologia no fotoenvelhecimento. Atas de Ciências da Saúde), São Paulo, v. 3, n. 2, p. 32-43, abr. 2016. ISSN 2448-3753. Disponível em: <http://revistaseletronicas.fmu.br/index.php/ACIS/article/view/1081>. Acesso em: 29 jun. 2016.

SHRIVASTAVA, S.; DASH, D. Applying nanotechnology to human health: revolution in biomedical sciences. Journal of Nanotechnology, v. 2009, Article ID 184702, p. 14, 2009. Disponível em: <http://dx.doi.org/10.1155/2009/184702>. Acesso em: 22 out. 2015.

SILVA, F. R. da; CAMPOS, V. C. O ensino a distância ao longo das gerações EaD. Rev. Digital da Secretaria de Estado da Educação da Paraíba. Dez - jul, p. 127-135, 2016. Disponível em:

$<$ http://www.sec.pb.gov.br/revista/index.php/compartilhandosaberes/article/download/69/73>. Acesso em: 07 jul. 2016.

SILVA, S. L. A.; VIANA, M. M.; MOHALLEM, N. D. S. Afinal, o que é Nanociência e Nanotecnologia ; uma abordagem para o ensino médio. Química Nova na Escola. v. 31, n. 3, ago. 2009.

SOUZA, C. S.; IGLESIAS, A. G.; FILHO, A. P. Estratégias Inovadoras para métodos de Ensino Tradicionais - Aspectos Adicionais. Medicina (Ribeirão Preto), v. 47, n. 3, p. 284292, 2014. Disponível em: <http://revista.fmrp.usp.br/2014/vol47n3/6_Estrategiasinovadoras-para-metodos-de-ensino-tradicionais-aspectos-gerais.pdf $>$. Acesso em: 30 mai. 2016.

SPECIA, R. Z. et al. (Coords) Mundo nano. Revista Interdisciplinaria en Nanociencias y nanotecnología. UNAM, v. 9, n. 16, p. 1-212, 2016. Disponível em:

$<$ http://www.mundonano.unam.mx >. Acesso em: 21 ago. 2016.

TANIGUCHI, N. On the Basic Concept of 'Nano-Technology'. Proc. ICPE; Tokyo, Part II, Japan Society of Precision Engineering, 1974.

UNIVERSIDADE DE BRASÍLIA. Plataforma Aprender. 2004. Disponível em: $<\mathrm{http}$ ://aprender.unb.br/>. Acesso em: 11 jan. 2016. 


\section{ANEXOS}

ANEXO A - Modelo do Folder de Divulgação das Ações de Ensino
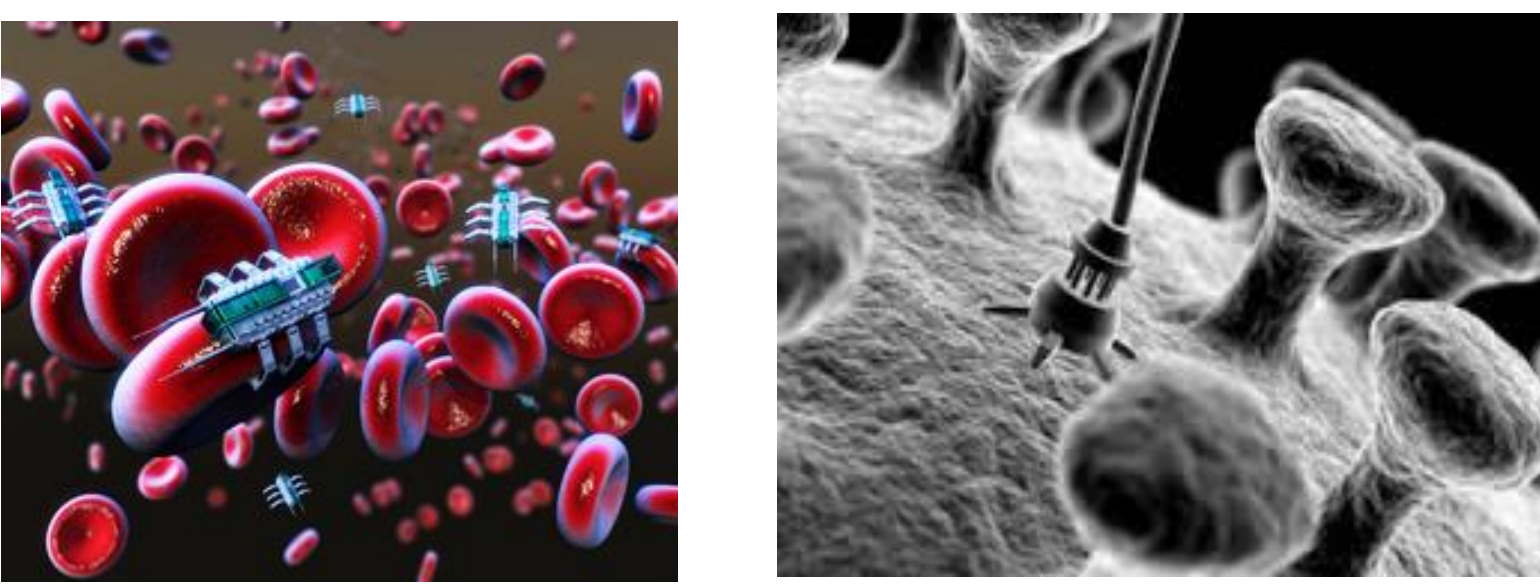

Vocês já ouviram falar sobre Nanociência e Nanotecnologia?

"Venham conhecer os conceitos e aplicações básicas da Nanociência e

Nanotecnologia e sua potencial revolução nas Ciências da Saúde"

\section{Curso Totalmente EaD: "Tópicos de Nanociência e Nanotecnologia Aplicados às Ciências da Saúde”}

Público Alvo: Aberto a toda a comunidade (alunos de graduação e pós-graduação da UnB e de outras instituições, vinculados às áreas afins do conhecimento).

Inscrições: 01/03/2015 a 10/04/2015

Período do Curso (por ação de ensino):

Turma A - 10/04/2015 a 30/06/2015

Turma B - 01/06/2015 a 20/08/2015

Turma C - 01/08/2015 a 20/10/2015

Carga Horária: $42 \mathrm{~h}$

Investimento: Gratuito e com certificação pela UnB

Professor Coordenador: Prof. Dr. Elioenai Dornelles Alves (UnB)

Inscrições pelo e-mail: nanotecnologia.nesprom@gmail.com

Realização: Núcleo de Estudos em Educação e Promoção da Saúde - NESPROM Universidade de Brasillia - UnB 
ANEXO B - Documento de Aprovação pelo Comitê de Ética

Título da Pesquisa: Estudo e Desenvolvimento de Metodologia EaD destinada ao Ensino da Nanociência e Nanotecnologia, Aplicadas às Ciências da Saúde e Enfermagem.

Pesquisador Responsável: Jackeline Neres dos Santos

Área Temática:

Versão: 3

CAAE: 41860815.0 .0000 .0030

Submetido em: 08/07/2015

Instituição Proponente: Programa de Pós-Graduação em Enfermagem - Mestrado Universidade de Brasilia

Situação da Versão do Projeto: Aprovado

Localização atual da Versão do Projeto: Pesquisador Responsável

Patrocinador

Principal:

FUND COORD DE APERFEICOAMENTO DE PESSOAL DE NIVEL SUP 


\section{FACULDADE DE CIÊNCIAS DA SAÚDE DA UNIVERSIDADE DE BRASÍLIA - CEP/FS-UNB}

\section{PARECER CONSUBSTANCIADO DO CEP}

\section{DADOS DO PROJETO DE PESQUISA}

Título da Pesquisa: Estudo e Desenvolvimento de Metodologia EaD destinada ao Ensino da Nanociência e Nanotecnologia Aplicadas às Ciências da Saúde e Enfermagem.

Pesquisador: Jackeline Neres dos Santos

Área Temática:

Versão: 3

CAAE: 41860815.0 .0000 .0030

Instituição Proponente: Programa de Pós Graduação em Enfermagem - Mestrado - Universidade de

Patrocinador Principal: FUND COORD DE APERFEICOAMENTO DE PESSOAL DE NIVEL SUP

\section{DADOS DO PARECER}

Número do Parecer: 1.190 .796

\section{Apresentação do Projeto:}

"Introdução: Nanociência e Nanotecnologia são novas áreas multidisciplinares que concentram esforços para compreender e utilizar as propriedades nanométrica da matéria (1×10-9m) sendo que tais áreas têm aportado consideráveis avanços científicos, tecnológicos e de inovação para as Ciências da Saúde e Enfermagem. No entanto, metodologias de ensino, a difusão e a formação de profissionais nestas áreas ainda precisam de maiores ações de desenvolvimento. Objetivos: propor, desenvolver, testar e otimizar metodologias EaD de ensino de Nanociência e Nanotecnologia aplicadas às Ciências da Saúde e Enfermagem visando o desenvolvimento de uma Ação de Aprendizagem altamente eficiente para a difusão e promoção do tema. Metodologia: Será realizado um estudo multidisciplinar do estado da arte no tema, seguido da elaboração e aplicação de três versões da Ação de Aprendizagem (standard, conceitos básicos e aplicações tecnológicas). Após a análise dos resultados preliminares destas três versões, será proposto uma nova versão otimizada do curso composta pelos melhores resultados das três versões anteriores visando uma maior eficiência na transmissão do conhecimento. Parâmetros como estratégias de ensino/aprendizagem e retenção do conhecimento serão propostos e testados. Resultados Esperados: Espera-se que os resultados ampliem a interação entre as áreas do conhecimento envolvidas no projeto incrementando o nível de difusão do tema, bem como contribua com novas metodologias, informações sistemáticas e conclusivas para a área de $\mathrm{EaD}$ em enfermagem. Almeja-se também proporcionar uma formação mais ampla, sólida, multidisciplinar e completa dos alunos de ciências da saúde e enfermagem,

Endereço: Faculdade de Ciências da Saúde - Campus Darcy Ribeiro

Bairro: Asa Norte

UF: DF

Município: BRASILIA

CEP: $70.910-900$

Telefone: (61)3107-1947

E-mail: cepfsunb@gmail.com 


\section{FACULDADE DE CIÊNCIAS DA SAÚDE DA UNIVERSIDADE DE BRASÍLIA - CEP/FS-UNB}

Continuação do Parecer: 1.190 .796

além de gerar um produto final (ação de aprendizagem) caracterizado como produto tecnológico inovador."

\section{Objetivo da Pesquisa:}

"Objetivo Primário:

Propor, desenvolver, testar, otimizar e retestar metodologias EaD de ensino de Nanociência e Nanotecnologia aplicadas às Ciências da Saúde e Enfermagem visando o desenvolvimento de uma Ação de Aprendizagem altamente eficiente para a difusão e promoção do tema proposto.

Objetivo Secundário:

- Promover um estudo multidisciplinar sobre o tema "Nanociência e Nanotecnologia aplicadas às áreas das Ciências da Saúde e Enfermagem" e suas interfaces, bem como, com base na literatura científica, propor uma versão standard inicial de uma Ação de Aprendizagem composta por até 10 módulos de alta qualidade técnico-científica idealizada inicialmente para o ambiente virtual; • Propor e testar duas novas metodologias EaD para o ensino do tema do projeto, sendo a primeira baseada no conjunto de conceitos e princípios básicos da área e a segunda baseada no conjunto de aplicações de cada subtema. Desta forma, será possível comparar e determinar o desempenho dos alunos em cada módulo para as três versões (standard, conceitos básicos e aplicações) da Ação de Aprendizagem; - Baseado nos resultados estatísticos e qualitativos das três versões da Ação de Aprendizagem aplicados anteriormente, compor e testar uma quarta versão otimizada da Ação de Aprendizagem composta pelos até 10 melhores módulos escolhidos pelos cursistas. Desta forma, espera-se que esta versão otimizada do curso proporcione condições de ensino/aprendizagem mais eficientes e significativas para os alunos; • Para a primeira e a quarta versão da Ação de Aprendizagem, realizar uma comparação dos parâmetros "Índice de sucesso do curso", "Tempo médio de realização do curso", "Avaliação geral do curso", entre outros, visando estimar e quantificar o ganho de eficiência na realização do curso e determinar a influência de outros parâmetros críticos de sucesso; • Promover a Difusão, Divulgação e Popularização técnico-científica de temas multidisciplinares na interface das áreas de Nanociência, Nanotecnologia, Ciência da Saúde e Enfermagem, bem como consolidar o tema junto aos de enfermagem e proporcionar a formação de recursos humanos altamenteatualizados."

\section{Avaliação dos Riscos e Benefícios:}

Segundo o pesquisador:

"Riscos:

Os riscos decorrentes da participação do cursista na pesquisa estarão associados com à complexidade e multidisciplinaridade do tema, o que demanda do cursista estudos paralelos em temas fora de sua área de formação, tornando a conclusão do curso um grande desafio. Uma vez que o curso de extensão é 100\% na modalidade EaD há o risco associado a não administração adequada do tempo, o que pode implicar na

Endereço: Faculdade de Ciências da Saúde - Campus Darcy Ribeiro

Bairro: Asa Norte

UF: DF Município: BRASILIA

CEP: $70.910-900$

Telefone: (61)3107-1947

E-mail: cepfsunb@gmail.com 


\section{FACULDADE DE CIÊNCIAS DA SAÚDE DA UNIVERSIDADE DE BRASÍLIA - CEP/FS-UNB}

Continuação do Parecer: 1.190 .796

concentração e possível não conclusão de atividades em tempo hábil ao longo do curso. Para minimizar os riscos serão disponibilizados leituras complementares de temas correlatos, tutoriais e tutorias e mensagens de reforço de datas e monitoramento de frequência de acesso dos alunos.

Benefícios:

Com a realização deste Projeto de Mestrado espera-se alcançar resultados técnico-científicos, de formação de Rh, de inovação tecnológica e difusão e popularização do tema que contribuam para o desenvolvimento das áreas de ciências da saúde e enfermagem.5.1. Do Ponto de Vista Técnico-Científico:Do ponto de vista técnico-científico, espera-se que os resultados: (i) Ampliem significativamente interação entre as áreas de Nanociência, Nanotecnologia, Ciências da Saúde e enfermagem, (ii) Aportem novas contribuições técnicocientíficas para a interface das áreas acima citadas, (iii) Incrementem o nível de difusão de ambas as áreas e de sua interface e (iv) Contribuam com novas metodologias, informações sistemáticas e conclusivas para a área de EaD.5.2. Do Ponto da Inovação Tecnológica:Do ponto de vista da inovação tecnológica, esperase que os resultados obtidos com o projeto: (i) Produzam um curso e um conjunto de novos materiais didáticos inovadores capazes de ampliar o espectro de conhecimento dos cursistas e os estimule a manter a formação continuada e (ii) Gere um produto final que possa ser caracterizado com um produto tecnológico passível de ser protegido intelectualmente por meio de um pedido de depósito de patente.5.3. Do Ponto da Formação de Recursos Humanos:Do ponto de vista da formação de Rh, espera-se que os resultados obtidos com a realização do projeto: (i) Culminem na formação mais ampla, sólida, multidisciplinar e completa dos alunos de ciências da saúde e enfermagem, (ii) Sejam o referencial teórico que origine uma disciplina optativa para cursos da graduação e pós-graduação em ciências da saúde e enfermagem e (iii) Forneça uma formação mais completa e ampla no quesito alta tecnologia aplicada ao tema.Espera-se ainda que sejam formados direta ou indiretamente novos recursos humanos, tais como, alunos de iniciação científica e alunos de nível técnico gerando impacto positivo para as áreas. Neste projeto serão estimuladas as colaborações entre instituições de ensino, além dos demais segmentos da sociedade, ressaltando a valorização dos produtos resultantes dessas interações.5.4. Do Ponto de Vista da Difusão e Popularização do Tema:Do ponto de vista da Difusão e Popularização, espera-se que Ações de Aprendizagem: (i) contribuam para os cursistas incrementando a qualidade da formação; (ii) difundam e popularizem a Ciência em específico no tema "Nanociência e Nanotecnologia aplicadas à área das Ciências da Saúde e enfermagem"; (iii) ampliem o espectro de conhecimentos, incrementem a qualidade técnico-científica dos alunos de pós-graduação nesta temática."

\section{Comentários e Considerações sobre a Pesquisa:}

Trata-se de projeto de mestrado do Programa de Pós-Graduação em Enfermagem, orientado pelo prof. Dr. Elioenai Dornelles Alves.

Endereço: Faculdade de Ciências da Saúde - Campus Darcy Ribeiro

Bairro: Asa Norte

UF: DF Município: BRASILIA

CEP: $70.910-900$

Telefone: (61)3107-1947

E-mail: cepfsunb@gmail.com 


\section{FACULDADE DE CIÊNCIAS DA SAÚDE DA UNIVERSIDADE DE BRASÍLIA - CEP/FS-UNB}

Continuação do Parecer: 1.190 .796

A metodologia foi dividida em 7 etapas:

"1 Etapa - Estudo Multidisciplinar do Estado da Arte e Realização dos Créditos: Será realizado um estudo multidisciplinar do Estado da Arte sobre o desenvolvimento e aplicação de metodologias de Ensino à Distância $(\mathrm{EaD})$ para as áreas das Ciências da Saúde, Enfermagem, Nanociência e Nanotecnologia, consideradas áreas não tradicionais para o ensino a distância. Nesta etapa, o amplo conhecimento e tradição do Grupo de Pesquisa no tema serão determinantes para a seleção das metodologias mais promissoras.- Realização dos créditos obrigatórios e optativos, base de formação fundamental para o discente, visando atender as normas do Programa de Pós-Graduação em Enfermagem da UnB PPGEnf/UnB.

$2^{\circ}$ Etapa - Elaboração e Aplicação da $1^{\underline{a}}$ Versão da Ação de Aprendizagem: Nesta etapa, baseado no Estado da Arte visto na Etapa 1, será realizada a elaboração da 1르 Versão da Ação de Aprendizagem de Nanociência e Nanotecnologia aplicadas às Ciências da Saúde e Enfermagem a ser realizado no ambiente virtual e com o enfoque tradicionalmente aplicado aos cursos de Física, Química e Engenharia (versão standard). A ação será didaticamente planejada para ser realizada em 42 horas, para alunos de PósGraduação em Ciências da Saúde, Enfermagens e áreas afins da UnB e contemplará até 10 módulos sendo, por exemplo, 08 módulos abordando temas específicos e 02 módulos contemplando avaliação de monitoramento e avaliação final. Os cursistas serão convidados a contribuírem com suas percepções objetivas sobre cada um dos módulos da ação de aprendizagem. Desta forma, cada módulo receberá uma "nota" ou "percepção quantitativa" de cada cursista.

$3^{\circ}$ Etapa - Proposição e Aplicação de Novas Estratégias de Ensino/Aprendizagem: Nesta etapa, duas novas versões da Ação de Aprendizagem serão elaboradas baseadas fundamentalmente: (i) nos conceitos básicos de cada módulo; e (ii) nas aplicações principais de cada tema. Estas duas novas versões do curso serão aplicadas para a mesma amostra de alunos. Após a aplicação dos cursos, será realizada uma análise preliminar dos resultados sobre cada um dos módulos do curso. Desta forma, será possível comparar os resultados obtidos módulo a módulo nestas duas novas versões do curso com os resultados da versão standard.

$4^{\circ}$ Etapa - Preparação e Aplicação da Versão Otimizada da Ação de Aprendizagem: Após a aplicação das três versões da Ação de Aprendizagem (standard, conceitos básicos e aplicações) e de cada módulo ter sido avaliada pelos cursistas, os módulos mais bem avaliados vão compor a quarta versão ou versão otimizada da Ação de Avaliação visando privilegiar e aprimorar o processo ensino-aprendizagem dos cursistas.

$5^{\circ}$ Etapa - Comparação e Análise dos Resultados: Além das avaliações processuais de percurso realizadas ao longo da execução do projeto, entre a primeira e a quarta versão da Ação de Aprendizagem, será realizada uma comparação dos parâmetros "Índice de sucesso do curso", "Tempo médio de realização do

Endereço: Faculdade de Ciências da Saúde - Campus Darcy Ribeiro

Bairro: Asa Norte

UF: DF Município: BRASILIA

CEP: $70.910-900$

Telefone: (61)3107-1947

E-mail: cepfsunb@gmail.com 


\section{FACULDADE DE CIÊNCIAS DA SAÚDE DA UNIVERSIDADE DE BRASÍLIA - CEP/FS-UNB}

Continuação do Parecer: 1.190.796

curso", "Avaliação geral do curso", entre outros, visando estimar e quantificar o ganho de eficiência na realização do curso e determinar a influência de outros parâmetros críticos de sucesso;

$6^{\circ}$ Etapa - Monitorar a Retenção de Conhecimento: Nesta etapa do projeto serão realizadas ações periódicas de monitoramento da retenção dos conceitos fundamentais abordados ao longo do curso. $7^{\circ}$ Etapa - Publicação das Principais Contribuições Para a Área: Durante a realização do Projeto, espera-se que sejam produzidos trabalhos de congresso, artigos científicos, capítulos de livro e propriedade intelectual."

Há previsão de participação de 150 estudantes de Pós-Graduação em Ciências da Saúde, Enfermagens e áreas afins da UnB, mas não menção à maneira como serão recrutados."

\section{Considerações sobre os Termos de apresentação obrigatória:}

Documentos apresentados em atendimento às pendências apontadas no parecer No. 1.138.210:

"PB_INFORMAÇÕES_BÁSICAS_DO_PROJETO_462582.pdf", postado em 08/07/2015;

Carta em resposta às pendências apontadas pelo CEP no parecer No. 1.138.210 - "CartaRespPendencias CEPFS 08julho2015.doc", postado em 08/07/2015;

Projeto detalhado - "Projeto de Mestrado Corrigido - Versão CEP03.docx", postado em 08/07/2015.

\section{Recomendações:}

Não se aplica.

\section{Conclusões ou Pendências e Lista de Inadequações:}

Análise das respostas às pendências apontadas no parecer No. 1.138.210:

1. Detalhar melhor na metodologia quem serão os estudantes que participarão da pesquisa, quais os critérios de inclusão e exclusão, e como serão convidados a participar da pesquisa (recrutamento). RESPOSTA: Foi detalhado no item 4 "materiais e métodos" do projeto de mestrado detalhado (em anexo), abaixo do item " $7^{\circ}$ Etapa - Publicação das Principais Contribuições Para a Área" a partir do parágrafo terceiro até o final do oitavo parágrafo, quem serão os estudantes que participarão da pesquisa, quais os critérios de inclusão e exclusão, e como serão convidados a participar da pesquisa (recrutamento). $\mathrm{Na}$ página da Plataforma Brasil número 4 "Detalhamento do Projeto", foi incluído os critérios de inclusão e de exclusão, os riscos e benefícios da pesquisa.

ANÁLISE: No projeto detalhado, "Projeto de Mestrado Corrigido - Versão CEP.docx", postado em 15/06/2015, página 5 de 12, item "4. MATERIAL E MÉTODOS", subitem "2 Etapa - Elaboração e Aplicação da 1ํㅡㄹ Versão da Ação de Aprendizagem", lê-se: "A ação será didaticamente planejada para ser realizada em 42 horas, para alunos de Pós-Graduação em Ciências da Saúde, Enfermagens e áreas afins da UnB...". Ainda na nota de roda-pé, na mesma página, lê-se: "Serão priorizados os alunos de Pós-Graduação da

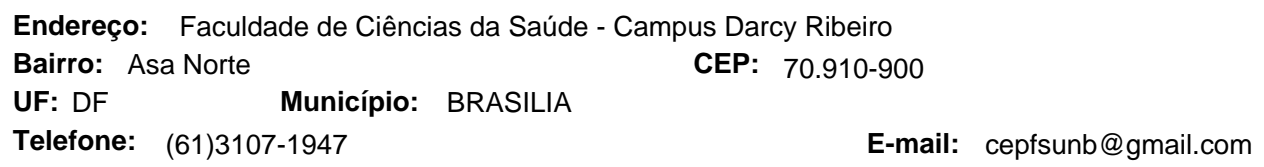




\section{FACULDADE DE CIÊNCIAS DA SAÚDE DA UNIVERSIDADE DE BRASÍLIA - CEP/FS-UNB}

Continuação do Parecer: 1.190 .796

UnB. Caso não haja alunos suficientes para a manutenção das análises estatísticas, poderão ser incluídos alunos de Pós-Graduação pertencentes a outras instituições com nível acadêmico similar ao da UnB e alunos da UnB em fase de conclusão da graduação, ambos na mesma temática.".

Na página 6 de 12, item "4. MATERIAL E MÉTODOS", último parágrafo, e página 7 de 12, primeiro parágrafo, lê-se: "Com vistas a selecionar uma amostra de cursistas estatisticamente significativa para o estudo, utilizaremos como critérios de inclusão para uma das quatro versões do curso de extensão alunos de graduação e pós-graduação da UnB da área de ciências da saúde e enfermagem. No entanto, caso haja interessados de áreas afins do conhecimento ou instituições de ensino similares as solicitações serão analisadas caso a caso, podendo ser deferidas. Os alunos inscritos serão distribuídos homogeneamente em número e formação nas quatro versões do curso, assim cada aluno participará de apenas uma versão do curso. Como principais critérios de exclusão: não serão aceites alunos inscritos fora do prazo, alunos não contemplados como critérios de inclusão e alunos inscritos que iniciem suas atividades no curso após o término do primeiro módulo.".

No projeto da Plataforma Brasil, "PB_INFORMAÇÕES_BÁSICAS_DO_PROJETO_462582.pdf", postado em 15/06/2015, página 3 de 5, item "Metodologia Proposta", lê-se: "ação será didaticamente planejada para ser realizada em 42 horas, para alunos de Pós-Graduação em Ciências da Saúde, Enfermagens e áreas afins da UnB...". PENDÊNCIA ATENDIDA

2. Toda pesquisa apresenta riscos, ainda que mínimos, como o desconforto por ser submetido quatro vezes a um curso EaD. Assim o risco de desconforto, desmotivação, desinteresse, acarretando na desistência do participante deverá ser contemplado, sem que isso incorra em punição ao participante (por exemplo, direito ao certificado). Contemplar os mesmos riscos no projeto e no TCLE. Também contemplar benefícios diretos com a participação na pesquisa, por exemplo a aquisição de conhecimentos na área.

RESPOSTA: Contemplou-se os riscos no projeto e no TCLE (em anexo). Também se contemplou os benefícios diretos com a participação na pesquisa.

ANÁLISE: No documento "Termo de Consentimento Livre e Esclarecido - Versão CEP.docx", postado em 15/06/2015, na página 1 de 2, quinto parágrafo, lê-se: "Os riscos decorrentes de sua participação na pesquisa estão associados com à complexidade e multidisciplinaridade do tema, o que demanda do cursista estudos paralelos em temas fora de sua área de formação, tornando a conclusão do curso um grande desafio. Uma vez que o curso de extensão é $100 \%$ na modalidade EaD há o risco associado a não administração adequada do tempo, o que pode implicar na concentração e possível não conclusão de atividades em tempo hábil ao longo do curso. Para minimizar os riscos serão disponibilizados leituras complementares de temas correlatos, tutoriais e tutorias e mensagens de reforço de datas e monitoramento de frequência de acesso dos alunos. Se você aceitar participar, estará contribuindo para o avanço das áreas

Endereço: Faculdade de Ciências da Saúde - Campus Darcy Ribeiro

Bairro: Asa Norte

UF: DF Município: BRASILIA

CEP: $70.910-900$

Telefone: (61)3107-1947

E-mail: cepfsunb@gmail.com 


\section{FACULDADE DE CIÊNCIAS DA SAÚDE DA UNIVERSIDADE DE BRASÍLIA - CEP/FS-UNB}

Continuação do Parecer: 1.190 .796

de ciência e tecnologia de materiais, ciências da saúde, enfermagem, e metodologias de ensino a distância (EaD).".

No projeto detalhado, "Projeto de Mestrado Corrigido - Versão CEP.docx", postado em 15/06/2015, página 7 de 12, item "4. MATERIAL E MÉTODOS", terceiro parágrafo, encontra-se o mesmo trecho. Os itens "Riscos" e "Benefícios", ddo projeto da Plataforma Brasil, "PB_INFORMAÇÕES_BÁSICAS_DO_PROJETO_462582.pdf", postado em 15/06/2015, páginas 3 e 4 de 5, foram adequados. PENDÊNCIA ATENDIDA

3. Apresentar os instrumentos de avaliação que os participantes deverão preencher ou responder e também descrever a maneira com que a retenção do conhecimento será monitorada.

RESPOSTA: Foi elaborado os instrumentos de avaliação (em anexo) que os participantes deverão preencher e responder e também foi descrito a maneira com que a retenção do conhecimento será monitorada.

ANÁLISE: No projeto detalhado, "Projeto de Mestrado Corrigido - Versão CEP.docx", postado em 15/06/2015, página 7 de 12, item "4. MATERIAL E MÉTODOS", lê-se: "A retenção do conhecimento será monitorada por meio de questionários aplicados aos alunos que concluíram satisfatoriamente o curso com questões básicas sobre os módulos nos períodos de 30, 60,120 e 180 dias após a conclusão do curso para serem respondidos voluntariamente. Cada módulo contará com dois questionários técnicos sem informações de cunho pessoal no mesmo formato ao apresentado no Anexo A.". PENDÊNCIA ATENDIDA

4. Em se tratando de pesquisa com seres humanos, este CEP entende que a dispensa do TCLE não se aplica. Ainda que a metodologia seja desenvolvida inteiramente a distância, e que nenhum contato presencial com os participantes da pesquisa esteja previsto, a aplicação do TCLE e obtenção da concordância pode ser virtual, via sistema Moodle, ou por e-mail. Assim, o TCLE deverá ser elaborado, de forma a atender os itens IV.3 da Resolução CNS 466/2012, e apresentado a este CEP.

RESPOSTA: Foi elaborado e anexado o Termo de Consentimento Livre e Esclarecido - TCLE, de forma a atender os itens IV.3 da Resolução CNS 466/2012.

Na página 5 da Plataforma Brasil foi desmarcado o item de dispensa do TCLE.

ANÁLISE: "Termo de Consentimento Livre e Esclarecido - Versão CEP.docx", postado em 15/06/2015, foi apresentado e encontra-se em conformidade com o item IV.3 da Res. CNS 466/2012. Solicita-se, no entanto, que na página 6 de 12 do projeto de pesquisa detalhado, "Projeto de Mestrado Corrigido - Versão CEP.docx", postado em 15/06/2015, o trecho "Neste caso, por se tratar de aplicação de cursos de extensão sobre a temática já mencionada sem que sejam requeridas informações de caráter pessoal dos alunos, vislumbra-se a não necessidade de obtenção do Termo de Consentimento Livre e Esclarecido (TCLE)

Endereço: Faculdade de Ciências da Saúde - Campus Darcy Ribeiro

Bairro: Asa Norte

UF: DF Município: BRASILIA

CEP: $70.910-900$

Telefone: (61)3107-1947

E-mail: cepfsunb@gmail.com 


\section{FACULDADE DE CIÊNCIAS DA SAÚDE DA UNIVERSIDADE DE BRASÍLIA - CEP/FS-UNB}

Continuação do Parecer: 1.190 .796

lançando mão da Res. CNS 466/12-IV.8 - "Nos casos em que seja inviável a obtenção do Termo de Consentimento Livre e Esclarecido ou que esta obtenção signifique riscos substanciais à privacidade e confidencialidade dos dados do participante ou aos vínculos de confiança entre o pesquisador e pesquisado, a dispensa do TCLE deve ser justificadamente solicitada pelo pesquisador responsável ao Sistema CEP/CONEP"." seja retirado. PENDÊNCIA PARCIALMENTE ATENDIDA

RESPOSTA: Primeira e única pendência: Conforme solicitado, foi retirado da página 6 de 12 do projeto pesquisa detalhado, "Projeto de Mestrado Corrigido - Versão CEP03.docx", o trecho "Neste caso, por se tratar de aplicação de cursos de extensão sobre a temática já mencionada sem que sejam requeridas informações de caráter pessoal dos alunos, vislumbra-se a não necessidade de obtenção do Termo de Consentimento Livre e Esclarecido (TCLE) lançando mão da Res. CNS 466/12-IV.8 - "Nos casos em que seja inviável a obtenção do Termo de Consentimento Livre e Esclarecido ou que esta obtenção signifique riscos substanciais à privacidade e confidencialidade dos dados do participante ou aos vínculos de confiança entre o pesquisador e pesquisado, a dispensa do TCLE deve ser justificadamente solicitada pelo pesquisador responsável ao Sistema CEP/CONEP”."

Observação:

Não serão incluídos participantes de pesquisa menores de 18 anos.

ANÁLISE: PENDÊNCIA ATENDIDA

Protocolo de pesquisa em conformidade com a Resolução CNS 466/2012 e Complementares.

\section{Considerações Finais a critério do CEP:}

Em acordo com a Resolução CNS 466/12, ítens X.1.- 3.b. e XI.2.d, os pesquisadores responsáveis deverão apresentar relatórios parcial semestral e final do projeto de pesquisa, contados a partir da data de aprovação do protocolo de pesquisa.

\section{Este parecer foi elaborado baseado nos documentos abaixo relacionados:}

\begin{tabular}{|l|l|c|c|c|}
\hline \multicolumn{1}{|c|}{ Tipo Documento } & \multicolumn{1}{|c|}{ Arquivo } & Postagem & Autor & Situação \\
\hline Outros & CartaencaminhamentoCEPFS.pdf & $12 / 02 / 2015$ & & Aceito \\
& & $20: 39: 40$ & & \\
\hline Outros & Termo de reponsabilidade.pdf & $12 / 02 / 2015$ & & Aceito \\
& & $20: 40: 00$ & & Aceito \\
\hline Outros & Currículo do Sistema de Currículos & $12 / 02 / 2015$ & & \\
& Lattes (Jackeline Neres dos Santos).pdf & $20: 45: 21$ & & Aceito \\
\hline Outros & Currículo do Sistema de Currículos & $12 / 02 / 2015$ & & \\
& Lattes (Elioenai Dornelles Alves).pdf & $20: 46: 13$ & & \\
\hline
\end{tabular}

Endereço: Faculdade de Ciências da Saúde - Campus Darcy Ribeiro

Bairro: Asa Norte

UF: DF

Município: BRASILIA

CEP: $70.910-900$

Telefone: (61)3107-1947

E-mail: cepfsunb@gmail.com 


\section{FACULDADE DE CIÊNCIAS DA SAÚDE DA UNIVERSIDADE DE BRASÍLIA - CEP/FS-UNB}

Continuação do Parecer: 1.190 .796

\begin{tabular}{|c|c|c|c|}
\hline Folha de Rosto & Folha de rosto CEP.pdf & $\begin{array}{c}13 / 02 / 2015 \\
17: 25: 12\end{array}$ & Aceito \\
\hline Outros & Planilha de Orçamento.pdf & $\begin{array}{c}13 / 02 / 2015 \\
20: 35: 15\end{array}$ & Aceito \\
\hline $\begin{array}{l}\text { Projeto Detalhado / } \\
\text { Brochura } \\
\text { Investigador }\end{array}$ & $\begin{array}{l}\text { Projeto de Mestrado Enf } 2014 \text { - Versão } \\
\text { CEP.docx }\end{array}$ & $\begin{array}{l}13 / 02 / 2015 \\
20: 35: 55\end{array}$ & Aceito \\
\hline $\begin{array}{l}\text { Informações Básicas } \\
\text { do Projeto }\end{array}$ & $\begin{array}{l}\text { PB_INFORMAÇÕES_BÁSICAS_DO_P } \\
\text { ROJETO 462582.pdf }\end{array}$ & $\begin{array}{c}13 / 02 / 2015 \\
20: 38: 22 \\
\end{array}$ & Aceito \\
\hline $\begin{array}{l}\text { Projeto Detalhado / } \\
\text { Brochura } \\
\text { Investigador } \\
\end{array}$ & $\begin{array}{l}\text { Projeto de Mestrado Corrigido - Versão } \\
\text { CEP.docx }\end{array}$ & $\begin{array}{l}15 / 06 / 2015 \\
14: 42: 34\end{array}$ & Aceito \\
\hline Outros & $\begin{array}{l}\text { CartaRespPendencias CEPFS } \\
\text { 10junho2015.doc }\end{array}$ & $\begin{array}{l}15 / 06 / 2015 \\
16: 53: 32\end{array}$ & Aceito \\
\hline $\begin{array}{l}\text { Informações Básicas } \\
\text { do Projeto }\end{array}$ & $\begin{array}{l}\text { PB_INFORMAÇÕES_BÁSICAS_DO_P } \\
\text { ROJETO 462582.pdf }\end{array}$ & $\begin{array}{c}15 / 06 / 2015 \\
16: 54: 25 \\
\end{array}$ & Aceito \\
\hline $\begin{array}{l}\text { TCLE / Termos de } \\
\text { Assentimento / } \\
\text { Justificativa de } \\
\text { Ausência }\end{array}$ & \begin{tabular}{|l} 
Termo de Consentimento Livre e \\
Esclarecido - Versão CEP.docx
\end{tabular} & $\begin{array}{l}15 / 06 / 2015 \\
14: 15: 01\end{array}$ & Aceito \\
\hline Outros & $\begin{array}{l}\text { ANEXO A - Instrumentos de } \\
\text { Avaliação.docx }\end{array}$ & $\begin{array}{l}15 / 06 / 2015 \\
15: 38: 49\end{array}$ & Aceito \\
\hline $\begin{array}{l}\text { Projeto Detalhado / } \\
\text { Brochura } \\
\text { Investigador }\end{array}$ & $\begin{array}{l}\text { Projeto de Mestrado Corrigido - Versão } \\
\text { CEP03.docx }\end{array}$ & $\begin{array}{c}08 / 07 / 2015 \\
12: 03: 20\end{array}$ & Aceito \\
\hline Outros & $\begin{array}{l}\text { CartaRespPendencias CEPFS } \\
\text { 08julho2015.doc }\end{array}$ & $\begin{array}{c}08 / 07 / 2015 \\
12: 06: 49 \\
\end{array}$ & Aceito \\
\hline $\begin{array}{l}\text { Informações Básicas } \\
\text { do Projeto }\end{array}$ & \begin{tabular}{|l} 
PB_INFORMAÇÕES_BÁSICAS_DO_P \\
ROJETO 462582.pdf
\end{tabular} & $\begin{array}{c}\text { 08/07/2015 } \\
12: 09: 01 \\
\end{array}$ & Aceito \\
\hline
\end{tabular}

\section{Situação do Parecer:}

Aprovado

Necessita Apreciação da CONEP:

Não

BRASILIA, 24 de Agosto de 2015

\section{Assinado por: \\ Marie Togashi \\ (Coordenador)}

Endereço: Faculdade de Ciências da Saúde - Campus Darcy Ribeiro

Bairro: Asa Norte

UF: DF

Município: BRASILIA

CEP: $70.910-900$

Telefone: (61)3107-1947

E-mail: cepfsunb@gmail.com 


\section{ANEXO C - Termo de Consentimento Livre e Esclarecido (TCLE)}

\section{Termo de Consentimento Livre e Esclarecido - TCLE}

Convidamos o(a) senhor(a) a participar do projeto de pesquisa "Estudo e Desenvolvimento de Metodologia de Ensino a Distância (EaD) destinada ao Ensino da Nanociência e Nanotecnologia, Aplicados às Ciências da Saúde e Enfermagem", sob a responsabilidade da pesquisadora Jackeline Neres Bellucci. O projeto busca resultados que ampliem a interação entre as áreas do conhecimento envolvidas no projeto incrementando o nível de difusão do tema, bem como contribua com novas metodologias, informações sistemáticas e conclusivas para a área $\mathrm{EaD}$ em Ciências da Saúde e Enfermagem.

O objetivo desta pesquisa é propor, desenvolver e testar metodologias de Educação a Distância de ensino de Nanociência e Nanotecnologia Aplicadas às Ciências da Saúde e Enfermagem, visando o desenvolvimento de uma Ação de Ensino mais efetiva para a difusão e promoção do tema proposto.

$\mathrm{O}$ (a) senhor(a) receberá todos os esclarecimentos necessários antes e no decorrer da pesquisa, e the asseguramos que seu nome não aparecerá sendo mantido o mais rigoroso sigilo pela omissão total de quaisquer informações que permitam identificá-lo(a).

A sua participação se dará por meio do curso de extensão na modalidade EaD intitulado "Tópicos de Nanociência e Nanotecnologia Aplicados às Ciências da Saúde", composto por sete módulos, sendo que cada módulo conterá ações de aprendizado e atividades avaliativas na forma de questionários técnicos, sobre o tema do módulo, sem perguntas de cunho pessoal, via Moodle (espaço UnB - Aprender), onde o curso está ancorado. O curso de extensão terá 42 horas de duração, sendo totalmente na modalidade $\mathrm{EaD}$.

Os riscos decorrentes de sua participação na pesquisa estão associados à complexidade e multidisciplinaridade do tema, o que demanda do cursista estudos paralelos em temas fora de sua área de formação, tornando a conclusão do curso um grande desafio. Uma vez que o curso de extensão é totalmente na modalidade $\mathrm{EaD}$, há o risco associado à não administração adequada do tempo, o que pode comprometer a concentração e a conclusão de atividades em tempo hábil ao longo do curso. Para minimizar os riscos, serão disponibilizadas leituras complementares de temas correlatos, tutoriais e tutorias e mensagens de reforço de datas e monitoramento de frequência de acesso dos alunos. Se o(a) senhor(a) aceitar participar, estará 
contribuindo para o avanço das áreas de ciência e tecnologia de materiais, ciências da saúde, enfermagem, e metodologias de educação a distância.

$\mathrm{O}$ (a) senhor(a) pode se recusar a responder (ou participar de qualquer procedimento) qualquer questão que lhe traga constrangimento, podendo desistir de participar da pesquisa em qualquer momento, sem nenhum prejuízo para o(a) senhor(a). Sua participação é voluntária, isto é, não há pagamento por sua colaboração.

Todas as despesas que o(a) senhor(a) tiver relacionadas diretamente ao projeto de pesquisa (passagem para o local da pesquisa, alimentação no local da pesquisa ou exames para realização da pesquisa) serão cobertas pelo pesquisador responsável.

Caso haja algum dano direto ou indireto, decorrente de sua participação na pesquisa, o(a) senhor(a) poderá ser indenizado, obedecendo-se as disposições legais vigentes no Brasil.

Os resultados globais da pesquisa, ou seja, sem as especificidades dos alunos, serão divulgados no Banco de Teses e Dissertações da UnB e CAPES, podendo ser publicados posteriormente. Os dados e materiais utilizados na pesquisa ficarão sob a guarda do pesquisador por um período de no mínimo cinco anos, após isso serão destruídos ou mantidos na instituição.

Se o(a) senhor(a) tiver qualquer dúvida em relação à pesquisa, por favor, telefone para: Jackeline Neres Bellucci, na Universidade de Brasilia nos telefones (61) 3547-3778 ou 98646-3778, no horário de atendimento de 10:00h às 12:00h e de 14:00h às 18:00h.

Este projeto foi Aprovado pelo Comitê de Ética em Pesquisa da Faculdade de Ciências da Saúde (CEP/FS), da Universidade de Brasîlia. O CEP é composto por profissionais de diferentes áreas, cuja função é defender os interesses dos participantes da pesquisa em sua integridade e dignidade e contribuir no desenvolvimento da pesquisa dentro de padrões éticos.

As dúvidas com relação à assinatura do TCLE ou aos direitos do participante da pesquisa podem ser obtidos por meio do telefone: (61) 3107-1947 ou do email cepfs@ unb.brou cepfsunb@gmail.com, horário de atendimento de 10:00h às 12:00h e de 13:30h às 15:30h, de segunda a sexta-feira. 